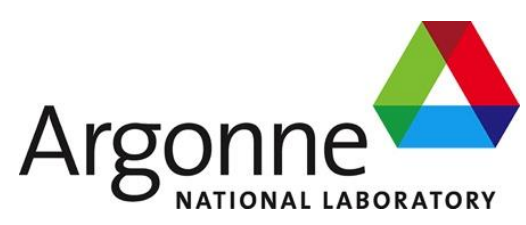

ANL-ART-103

\title{
Progress Report on Computational Analyses of Water-Based NSTF
}

Nuclear Engineering Division 


\begin{abstract}
About Argonne National Laboratory
Argonne is a U.S. Department of Energy laboratory managed by UChicago Argonne, LLC under contract DE-AC02-06CH11357. The Laboratory's main facility is outside Chicago, at 9700 South Cass Avenue, Argonne, Illinois 60439. For information about Argonne and its pioneering science and technology programs, see www.anl.gov.
\end{abstract}

\title{
DOCUMENT AVAILABILITY
}

Online Access: U.S. Department of Energy (DOE) reports produced after 1991 and a growing number of pre-1991 documents are available free via DOE's SciTech Connect (http://www.osti.gov/scitech/)

\author{
National Technical Information Service (NTIS): \\ U.S. Department of Commerce \\ National Technical Information Service \\ 5301 Shawnee Rd \\ Alexandra, VA 22312 \\ www.ntis.gov \\ Phone: (800) 553-NTIS (6847) or (703) 605-6000 \\ Fax: (703) 605-6900 \\ Email: orders@ntis.gov
}

Reports not in digital format may be purchased by the public from the

Reports not in digital format are available to DOE and DOE contractors from the

Office of Scientific and Technical Information (OSTI):

U.S. Department of Energy

Office of Scientific and Technical Information

P.O. Box 62

Oak Ridge, TN 37831-0062

www.osti.gov

Phone: (865) 576-8401

Fax: (865) 576-5728

\begin{abstract}
Disclaimer
This report was prepared as an account of work sponsored by an agency of the United States Government. Neither the United States Government nor any agency thereof, nor UChicago Argonne, LLC, nor any of their employees or officers, makes any warranty, express or implied, or assumes any legal liability or responsibility for the accuracy, completeness, or usefulness of any information, apparatus, product, or process disclosed, or represents that its use would not infringe privately owned rights. Reference herein to any specific commercial product, process, or service by trade name, trademark, manufacturer, or otherwise, does not necessarily constitute or imply its endorsement, recommendation, or favoring by the United States Government or any agency thereof. The views and opinions of document authors expressed herein do not necessarily state or reflect those of the United States Government or any agency thereof, Argonne National Laboratory, or UChicago Argonne, LLC
\end{abstract}




\section{Progress Report on Computational Analyses of Water-Based NSTF}

prepared by

Q. Lv, A. Kraus, R. Hu, M. Bucknor, D. Lisowski, D. Nunez

Nuclear Engineering Division, Argonne National Laboratory

August 2017 



\section{EXECUTIVE SUMMARY}

The Natural convection Shutdown heat removal Test Facility (NSTF) at Argonne National Laboratory (Argonne) was built to study the performance of passive safety systems for advanced nuclear reactors. It is a large-scale thermal hydraulics test facility designed to carry out highly instrumented experiments to validate the performance of Reactor Cavity Cooling System (RCCS) concepts for reactor decay heat removal that rely on natural convection cooling with either air- or water-based systems. With the successful conclusion of the airbased testing program in FY16, the transition to a water-based RCCS concept is underway. The overall assembly of the water-based NSTF will reflect a $1 / 2$ axial scale and $12.5^{\circ}$ sector slice of the primary design features of a full scale AREVA concept.

This report documents the FY17 progress and achievements made in the computational analyses of the water-based NSTF. Both system-level and high fidelity Computational Fluid Dynamics (CFD) analyses were performed to gain a complete understanding of the complex flow and heat transfer phenomena in natural convection systems. The progress on the waterbased NSTF design, instrumentation, and test planning are summarized in a companion report (ANL-ART-98).

The primary objective of the NSTF analyses is to assess the limitations in typical approaches for modeling this type of natural circulation RCCS concepts, and validate the analysis methods and computer codes which may be used in licensing. Additionally, the NSTF analyses aid in the RCCS design optimization, and supporting experiment activities, i.e. helping assure that the experimental procedures, setup, and measurements follow best practices and produce high quality, traceable data.

The primary focus of the system-level modeling was to analyze the integral system performance of the facility using RELAP5. As the NSTF is converted from air-based to water-based, more complex system behaviors are expected due to two-phase flow and heat transfer. The system analysis efforts have been focused on developing a reference model for the water-based NSTF design, verifying the scaling laws, performing pre-test simulations, and performing parametric sensitivity studies.

A reference RELAP5 model has been developed based on a water-tank modeling study, which investigated different nodalization schemes to simulate the thermal mixing inside the water tank, and the connection between the inlet nozzle and the water tank. Due to limitations in RELAP5, for example, it is not capable of modeling the three-dimensional phenomenon inside the water tank, an artificial thermal mixing region had to be modeled to simulate the three-dimensional effect. The height of the thermal mixing region that affects the initiation of flashing will need to be benchmarked against the experimental data once available. In addition, because RELAP5 is not able to track the water level inside a volume directly, the connection of the tank inlet nozzle to the tank had to be connected to the bottom of the thermal mixing region. This is important because the way the connection is modeled will affect the system flow rate. Utilizing the reference RELAP5 model, a parametric study of the effects of varying operational conditions and system configurations on the overall system performance was performed. The results of the parametric study provide insights into the system behaviors and guidance on system operations before conducting any experiments. 
Lastly, a check of the scaling law was performed on the water-based NSTF to examine any scaling distortions. A conceptual half-scale RCCS test facility was first developed based on available information from the AREVA design report as well as some reasonable assumptions. A RELAP5 model was subsequently developed for the conceptual RCCS design. The baseline two phase test was simulated for the conceptual RCCS test facility and the Argonne water-based NSTF, and the results were compared. It was found that the distortions in both single-phase and two-phase flows are less than $13 \%$.

CFD analysis has been focused on important component-level phenomena using STAR$\mathrm{CCM}+$ to supplement the system analysis of integral system behavior. A notable area of interest was the cavity region. This area is of particular interest for CFD analysis due to the multi-dimensional flow and complex heat transfer (thermal radiation heat transfer and natural convection), which are not simulated directly by RELAP5. CFD simulations allow for the estimation of the boundary heat flux distribution along the riser tubes, which is needed in the RELAP5 simulations. The CFD results can also provide additional data to help establish what level of modeling detail is necessary in RELAP5. It was found that the flow profiles in the cavity region are simpler for the water-based concept than for the air-cooled concept. The local heat flux noticeably increases axially, and is higher in the fins than in the riser tubes. These results were utilized in RELAP5 simulations as boundary conditions, to provide better temperature predictions in the system level analyses. It was also determined that temperatures were higher in the fins than the riser tubes, but within design limits for thermal stresses. Higher temperature predictions were identified in the edge fins, in part due to additional thermal radiation from the side cavity walls. 


\section{Table of Contents}

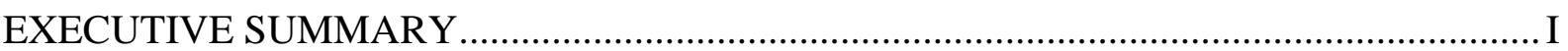

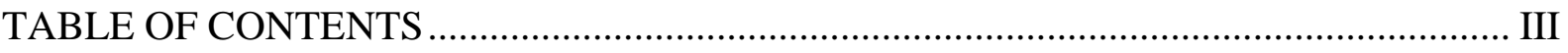

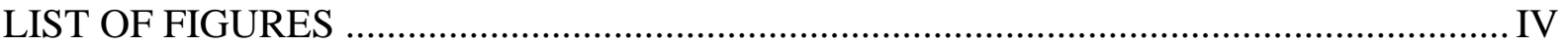

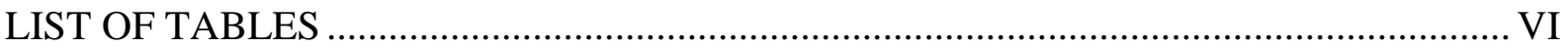

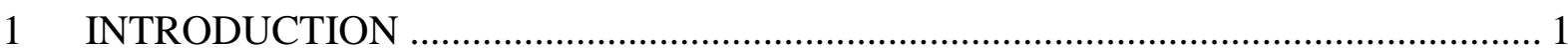

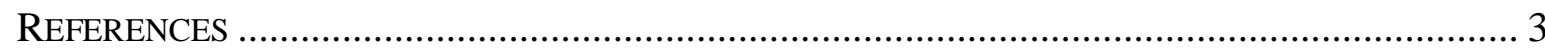

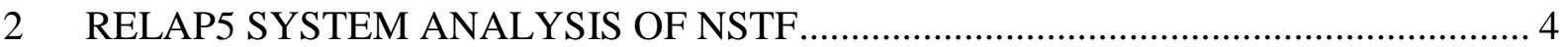

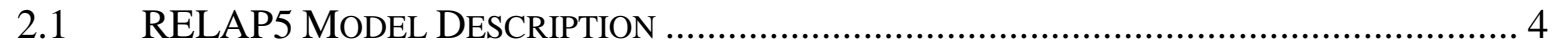

2.2 BASE CASE SIMULATION RESULTS.................................................................. 5

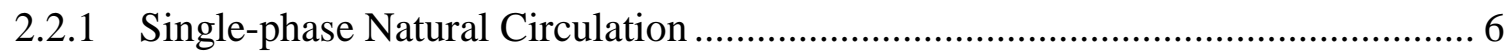

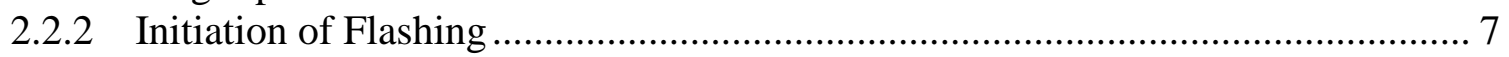

2.2.3 Breaking of Closed Circulation........................................................................ 7

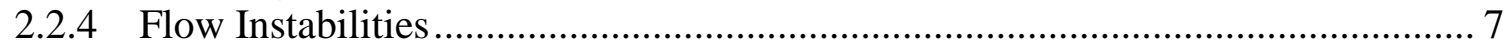

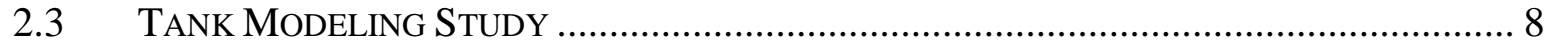

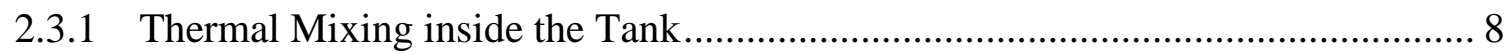

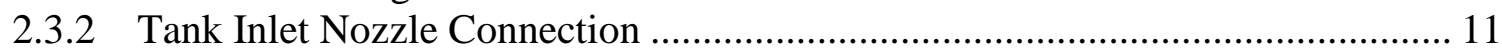

2.4 PARAMETRIC STUdY OF VARYING TEST CASES …….............................................. 13

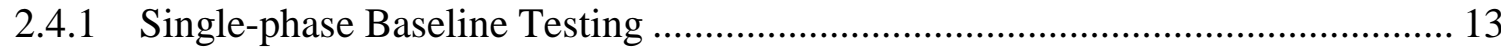

2.4.2 Two-phase Baseline Testing …………………............................................ 17

2.4.3 Integral Power Testing (Repeat Baseline with Varying Powers)......................... 17

2.4.4 Storage Tank Inventory (Repeat Baseline with Varying Initial Inventories) ...... 18

2.4.5 System Pressure (Repeat Baseline with Varying Pressures)................................ 23

2.4.6 Accident Scenario Testing ................................................................................ 24

2.4.7 Geometric Variations (Repeat Baseline with Varying Geometry) ...................... 25

2.4.8 Test Section Material Selection ........................................................................ 33

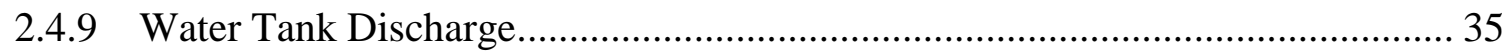

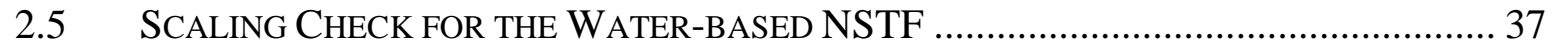

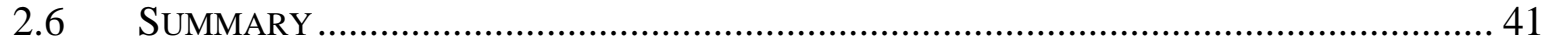

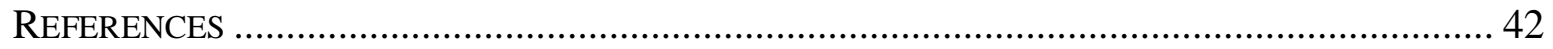

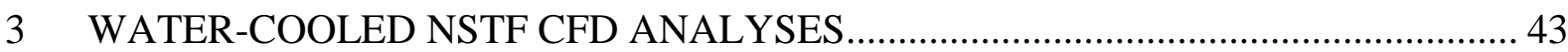

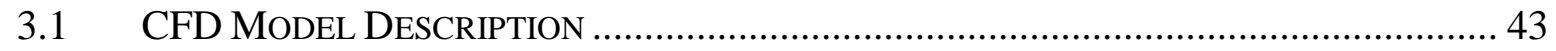

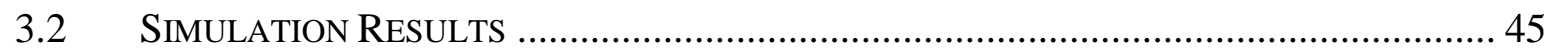

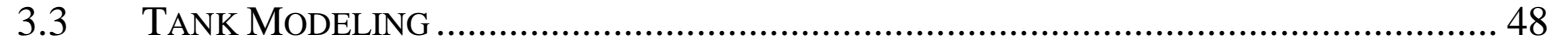

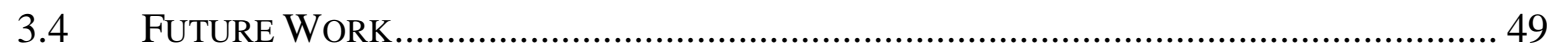

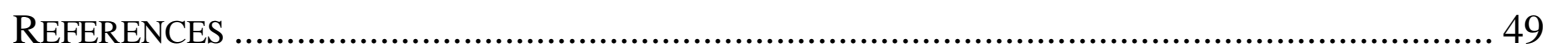

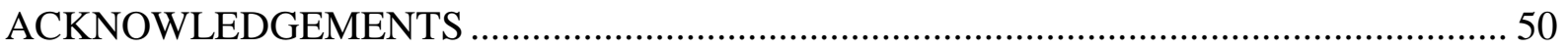




\section{LIST OF FIGURES}

Figure 1-1: Solid model rendering of water NSTF assembly as housed in Bldg. 308 at

Argonne.

Figure 1-2: Cross section of single panel (one of four), comprising two riser tubes, joined at

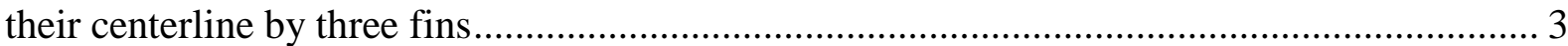

Figure 2-1: Nodalization diagram of the RELAP5 model for the water-based NSTF ............. 5

Figure 2-2: Total system mass flow rate in the baseline two-phase test case ......................... 6

Figure 2-3: Density wave oscillations spanning 4,000 seconds. Flow rate oscillations are

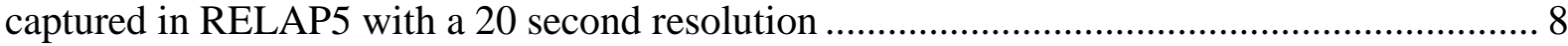

Figure 2-4: Tank model to simulate local natural recirculation and thermal mixing............... 9 Figure 2-5: Delayed initiation of flashing predicted by Model 1 compared to reference model

Figure 2-6: Unrealistic local recirculation flow inside water tank predicted by Model 1 ....... 11

Figure 2-7: Model 2 for the NSTF water tank ........................................................... 12

Figure 2-8: Comparison of system total mass flow between the reference model and Model 2

Figure 2-9: Simulation of tank cooling in RELAP5 ...................................................... 14

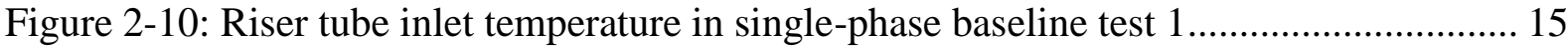

Figure 2-11: Riser tube inlet and outlet temperatures in single-phase baseline test 2 ........... 16

Figure 2-12: System total mass flow rates in the two single-phase baseline tests ................. 17

Figure 2-13: System total mass flow rates at varying power levels .................................... 18

Figure 2-14: Total system mass flow rates with varying initial water tank inventories .......... 19

Figure 2-15: System total mass flow rate with tank inventory loss of $1 \mathrm{~kg} / \mathrm{min}$.................. 20

Figure 2-16: System total mass flow rate with full tank depletion ................................... 21

Figure 2-17: Steam void fraction in the bottom half of the water tank (P950) ..................... 22

Figure 2-18: Outer surface temperature at the center of the riser tube heated section (P671). 23

Figure 2-19: System total mass flow rates at varying system pressures .............................. 24

Figure 2-20: System total mass flow rate in the accident scenario test .............................. 25

Figure 2-21: System total mass flow rates with varying water tank inlet ports .................... 26

Figure 2-22: Comparison of the single-phase natural circulation flows between the lower and

upper inlet nozzles........................................................................................ 27

Figure 2-23: System total mass flow rates with varying riser tube blockages....................... 28

Figure 2-24: System total mass flow rates with varying riser tube assembly inlet throttling.. 29

Figure 2-25: Modified RELAP5 model including a u-shaped dip in the upper chimney ........ 30

Figure 2-26: System total mass flow rate with u-shaped dip in the upper chimney ............... 31

Figure 2-27: Single-phase flow with u-shaped dip in the upper chimney ........................... 32

Figure 2-28: Two-phase flow with u-shaped dip in the upper chimney .............................. 33

Figure 2-29: System total mass flow rates with different test section materials.................... 34

Figure 2-30: Outer surface temperature at the center of the riser tube heated section............ 35

Figure 2-31: System total mass flow rates with varying water tank discharge resistance ....... 36

Figure 2-32: System pressure with varying water tank discharge resistance........................ 37

Figure 2-33: Schematic of the conceptual 1/2 scale RCCS test facility .............................. 39

Figure 2-34: Total system mass flow rates of the baseline two-phase test for the conceptual

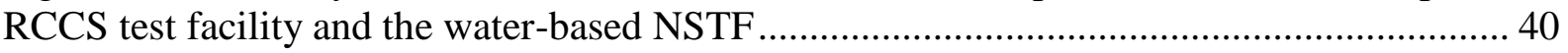

Figure 2-35: Distortions in single-phase natural circulation flow ................................... 41 
Figure 3-1: CFD domain geometry; Zoomed view on right shows tubes (green), fins (gray), and insulation (brown) 43

Figure 3-2: Views of the mesh at the axial midplane for the base case (top L), fine case (top $\mathrm{R})$, and zoomed base case (bottom) 45 Figure 3-3: Velocity magnitude at the axial midplane for the base case (L) and fine case (R) 46 Figure 3-4: Velocity magnitude at the lateral midplane for the base case (L) and fine case (R)

Figure 3-5: Boundary heat flux distribution on the hot side of the tubes ............................. 47

Figure 3-6: Temperature distribution along the top of the solid structure ............................... 47

Figure 3-7: Temperature distribution along the axial midplane ................................................ 48

Figure 3-8: Temperature distribution of the tubes and fins (zoomed view R)........................ 48 


\section{LIST OF TABLES}

Table 2-1: Scaling ratio for NSTF compared to AREVA conceptual RCCS design .............. 38

Table 2-2: Dimensions of the conceptual 1/2 RCCS test facility ........................................ 39

Table 2-3: Distortions in the single-phase and two-phase flow rates ................................. 41

Table 3-1: Thermal properties for solid materials in the CFD model .................................... 44 


\section{Introduction}

The Natural convection Shutdown heat removal Test Facility (NSTF) at Argonne National Laboratory (Argonne) was built to study the performance of passive safety systems for advanced nuclear reactors. It is a large-scale thermal hydraulics test facility designed to carry out highly instrumented experiments to validate the performance of Reactor Cavity Cooling System (RCCS) concepts for reactor decay heat removal that rely on natural convection cooling with either air- or water-based systems. The first experimental portion was focused on air-based cooling, using a $1 \frac{1}{2}$ scale design concept by General Atomics for their 350 MWt MHTGR.

With successful conclusion of this air-based testing program [1-1][1-2][1-3] in FY16, the transition to a water-based cooling concept is underway with the experimental design based on an AREVA developed RCCS concept. The overall assembly of the water NSTF will reflect a $1 / 2$ axial scale and $12.5^{\circ}$ sector slice of the full scale AREVA concept. Full details of the features can be found in the previous report [1-4], while a solid model rendering of the facility is shown in Figure 1-1. A heat flux is applied to one cavity wall by an array of electric radiant heaters, which leads to the development of a natural convection loop to cool the system. In a standard test, cold water is drawn from the water tank into the "downcomer" pipe and inlet header. Flow is then split between eight riser ducts for the length of the heated cavity. These ducts all converge at an outlet header, where flow mixes and then enters the water tank through the piping system. Note that the heat transfer panels consist of eight riser tubes and nine fin plates, fabricated into banks of two riser tubes and three fins, joined to form a single section, as shown in Figure 1-2.

This report documents the FY17 progress and achievements made in the computational analyses of the water-based NSTF. Both system-level and high fidelity Computational Fluid Dynamics (CFD) analyses were performed to gain a complete understanding of the complex flow and heat transfer phenomena in natural convection systems. The progress on the waterbased NSTF design, instrumentation, and test planning are summarized in a companion report [1-5].

The primary objective of the NSTF analyses is to assess the limitations in typical approaches for modeling this type of natural circulation RCCS concepts, and validate the analysis methods and computer codes which may be used in licensing. Additionally, the NSTF analyses aid in design optimization, and supporting experiment activities, i.e. helping to assure that the experimental procedures, setup, and measurements are performed correctly. Any issues identified can then be assessed and corrected in future tests. Throughout the course of computational modeling and code benchmarks of air-based NSTF tests, it was demonstrated that the computational effort significantly strengthened the experimental program. This mutually beneficial relationship between the analysis and experimental efforts has become integral to the overall program objective of examining the heat removal performance of the RCCS concept, and will continue in the water-based NSTF study.

The primary focus of the system-level modeling efforts was to analyze the integral system performance of the facility. As the NSTF switches from air- to water-based, more complex system behaviors are expected due to the two-phase flow and heat transfer involved. The system analysis efforts in FY17 focused on developing a reference model for the water-based NSTF design, verifying the scaling laws, performing pre-test simulations, and performing parametric sensitivity studies. Additionally, the results of the analyses help to assess the capabilities of 
existing mature codes (such as RELAP5) when they are used to simulate natural circulation systems involving single-phase water flow and transition to two-phase flow with atmospheric boiling. This work is detailed in Chapter 2.

In FY17, the CFD analyses focused on important component-level phenomena to supplement the system-level analysis of integral system behavior. A notable area of interest was the cavity region. This area is of particular interest for CFD analysis due to the multi-dimensional flow and complex heat transfer (thermal radiation heat transfer and natural convection), which are not simulated directly by RELAP5. CFD simulations allow for the estimation of the boundary heat flux distribution along the riser tubes, which can be utilized in RELAP5 to provide better temperature predictions. The results can also provide additional data to help establish the level of modeling detail necessary in the RELAP5 analyses. Also, the tube/fin temperatures can be more accurately calculated in CFD, particularly near the edges. A preliminary investigation into the flow behavior in the water storage tank was also undertaken. This work is detailed in Chapter 3.

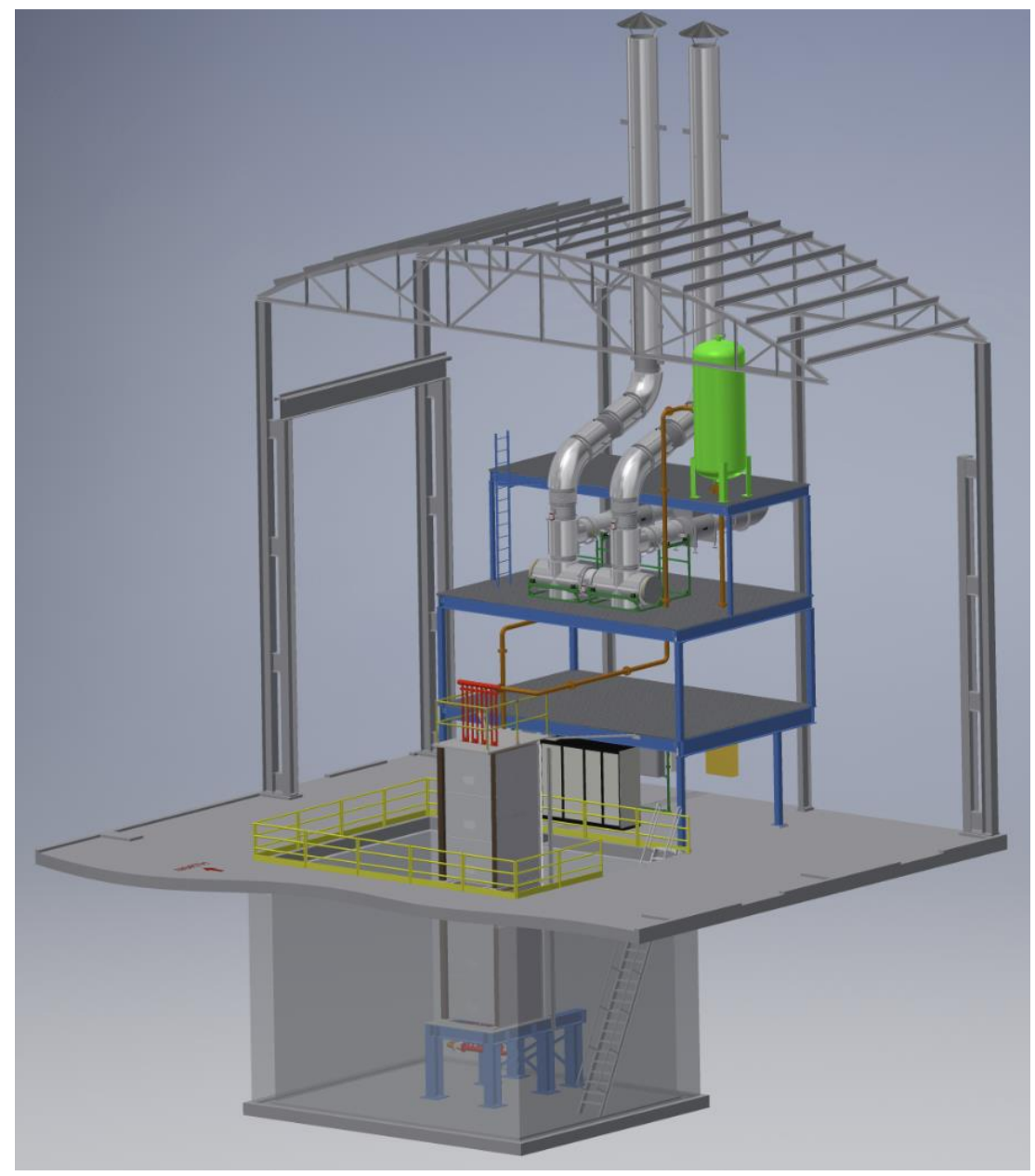

Figure 1-1: Solid model rendering of water NSTF assembly as housed in Bldg. 308 at Argonne 


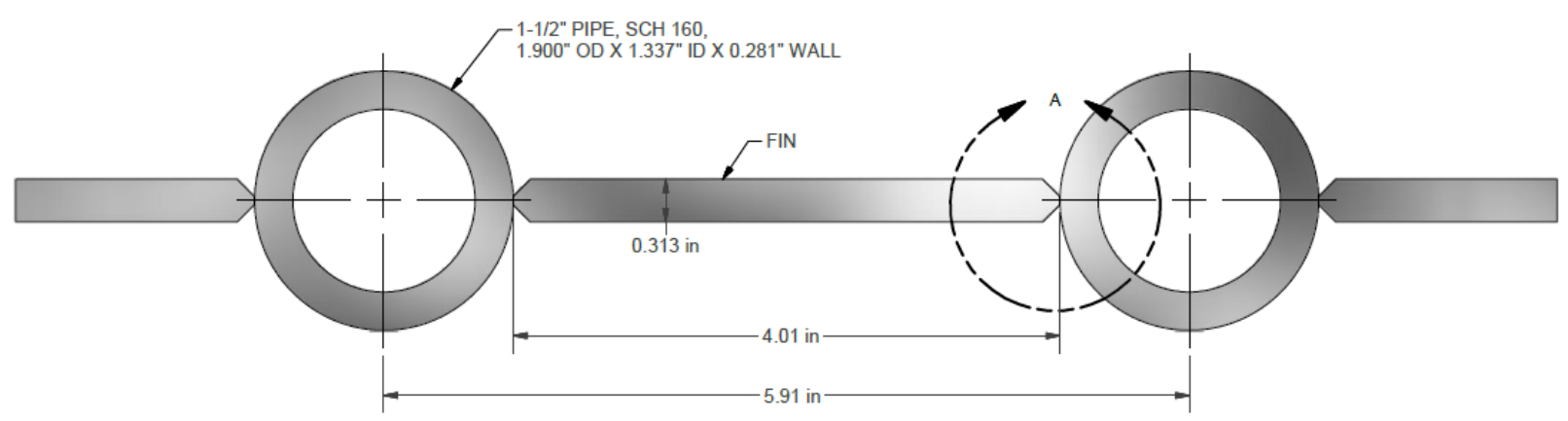

Figure 1-2: Cross section of single panel (one of four), comprising two riser tubes, joined at their centerline by three fins

\section{References}

[1-1] D. Lisowski, M. Farmer, et al., "Design Report for the 1/2 Scale Air-Cooled RCCS Tests in the Natural convection Shutdown Heat Removal Test Facility (NSTF)," ANL-SMR-8, Argonne National Laboratory, June 2014.

[1-2] R. Hu, A. Kraus, M. Bucknor, Q. Lv, and D. Lisowski, "Final Project Report on Computational Modeling and Analysis of Air-Based NSTF," ANL-ART-46, Argonne National Laboratory, June 2016.

[1-3] D. Lisowski, C. Gerardi, D. Kilsdonk, et al., "Final Project Report on RCCS Testing with the Air-based NSTF," ANL-ART-47, Argonne National Laboratory, August 2016.

[1-4] D. Lisowski, C. Gerardi, D. Kilsdonk, et al., Argonne National Laboratory, unpublished information, September 2016.

[1-5] D. Lisowski, C. Gerardi, R. Hu, et al., "Water NSTF Design, Instrumentation, and Test Planning," ANL-ART-98, August 2017. 


\section{RELAP5 System Analysis of NSTF}

Previous analysis work of the air-based NSTF shows promising capability of RELAP5 in predicting the transient system behaviors for applications to the Reactor Cavity Cooling System (RCCS) concept [2-1]. As the NSTF switches from air to water, more complex system behaviors can be expected due to the two-phase flow and heat transfer involved. Therefore, the analysis work is continued to examine the code's capability when applied to a natural circulation system involving two-phase flow and heat transfer. In addition, the analysis work of the water-based NSTF with RELAP5 also aids in the improvement of the test facility design, as well as instrumentation.

\subsection{RELAP5 Model Description}

Shown in Figure 2-1 is the reference RELAP5 model for the water-based NSTF, downselected from a tank modeling study that will be discussed in the subsequent section. The water tank is modeled as four volumes, namely, P980, P971, B969, and P950, which represent the air/steam region, non-thermal-mixing water region, thermal-mixing water region, and bottom half of the water tank, respectively. Following the water tank are a series of connecting pipes, including P890 - P840. The inlet and outlet headers of the riser tube assembly in the water-based NSTF are fabricated from a set of tees, which are modeled as branches in the present model, namely, B790 - B720 and B590 - B520. A total of eight riser are modeled, each consisting of an upstream non-heated region (P691 - P698), a heated region (P671 - P678), and a downstream non-heated region (P651 - P658). The riser tube assembly is connected back to the water tank through pipes of P490 - P450. All the pipings are made from 4.0" Sch 40 pipes, with an ID of 4.067". The physical layout of the water-based NSTF as well as the detailed dimensions can be found from [2-2]. All the piping/tank walls are modeled as heat structures, with convective boundary condition for the inner surface and adiabatic boundary condition for the outer surface. Once experimental data becomes available, the adiabatic boundary condition will be removed and replaced with heat structures to reflect actual parasitic heat losses. 


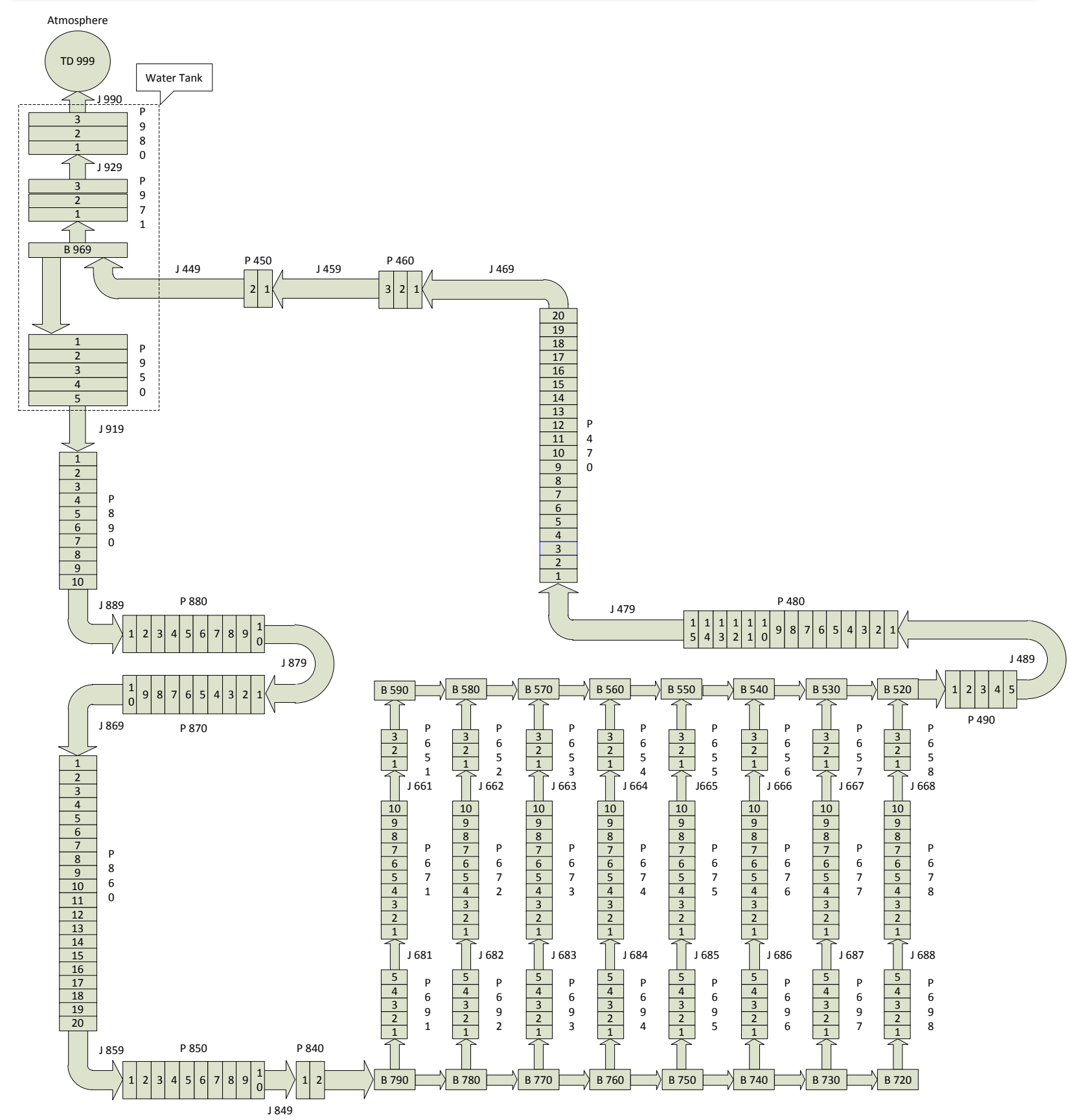

Figure 2-1: Nodalization diagram of the RELAP5 model for the water-based NSTF

\subsection{Base Case Simulation Results}

The simulation results of a baseline two-phase test case [2-2] will be first discussed to illustrate the key physical phenomena during the transient. In this baseline case, a total power of $51.6 \mathrm{~kW}$ was applied to the outer surface of the riser tube assembly, assuming a uniform heat flux. The transient was simulated with RELAP5 Mod 3.3, which is believed to perform better than RELAP5 3D for low pressure boiling simulations. A duration of 1.4E5 seconds (38.9 hours) was simulated. For the first 5,000 seconds of the simulation, there was no power applied to enable 
the system equilibrate at the user-specified initial conditions. The total mass flow rate in the system (total flow at junction J849 which is the elbow before the riser tube inlet header) during the transient is shown in Figure 2-2. Various characteristics are observed in the total mass flow rate, which correspond to different physical phenomena during the transient.

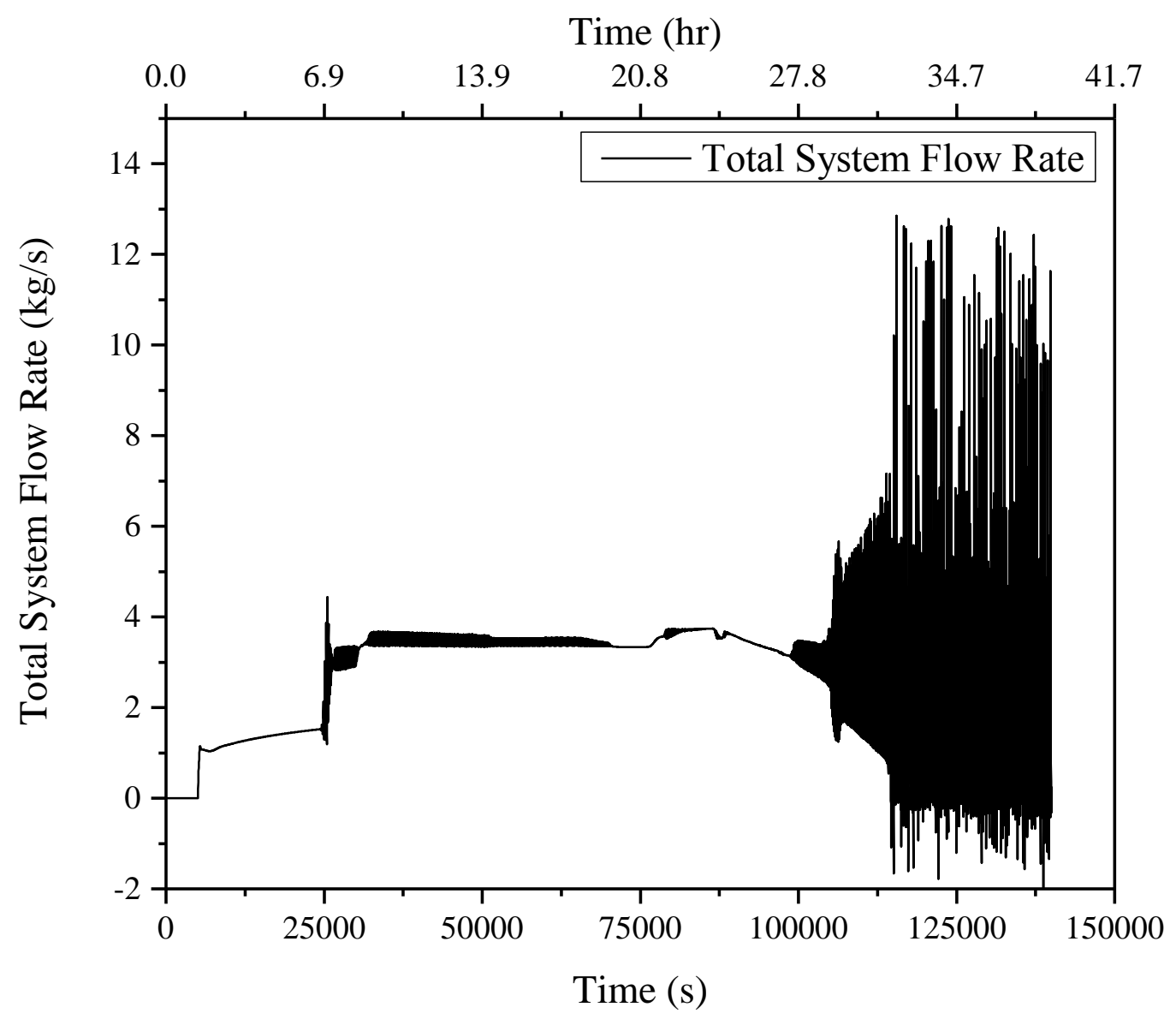

Figure 2-2: Total system mass flow rate in the baseline two-phase test case

\subsubsection{Single-phase Natural Circulation}

The first stage of the transient corresponds to single-phase natural circulation which spans from 5,000 to 24,500 seconds (6.8 hours), as shown in Figure 2-2. During the first 5,000 seconds, because there is no power applied, the total flow stays at the initial value of zero. At 5,000 seconds, with the power on, fluids inside the riser tubes are heated up, causing an immediate increase in the fluid temperatures. Because the riser tubes are vertically orientated, the increase in the fluid temperatures in the riser tubes also leads to an immediate development of buoyancy, and accordingly system flow at 5,000 seconds. Also seen is an overshoot in the system flow, which happens when the total system pressure drop catches up with the buoyancy. During the single-phase natural circulation, the system flow gradually increases due to the increasing buoyancy. 


\subsubsection{Initiation of Flashing}

As the system heats up, flashing first initiates at the horizontal returning pipe to water tank (P450 and P460) at 24,500 seconds (6.8 hours). The flashing frontal then quickly propagates to the vertical upper chimney pipe (P470) and causes an abrupt increase in the system buoyancy. Because of this, the system flow also experiences a significant increase, as seen from Figure 2-2. As the flashing frontal continues to propagate downward in pipe P470, the system buoyancy continues to increase, causing a gradual increase in the system flow. At 32,000 seconds (8.9 hours), the flashing frontal stabilizes at the $6^{\text {th }}$ node of P470 (downward), which is approximately $1.69 \mathrm{~m}$ below the tank inlet nozzle. A quasi-steady state is therefore reached, as seen from Figure $2-2$.

\subsubsection{Breaking of Closed Circulation}

As flashing induced boiling continues, the liquid level in the water tank drops. At $~ 87,500$ seconds (24.3 hours), P971 and B969 are depleted and the water level drops to the elevation of the water tank inlet nozzle, breaking the closed circulation formed in the system. As the water level continues to drop, the hydrostatic head of the cold leg decreases, as well as the buoyancy, causing a decrease in the system flow, as seen from Figure 2-2.

\subsubsection{Flow Instabilities}

Two types of flow instabilities are involved in the present case, namely, density wave oscillations and geysering. Density wave oscillations are due to multiple regenerative feedbacks between the flow rate, vapor generation rate, and pressure drop. Geysering is a periodic process of superheat and violent evaporation with possible expulsion and fluid returning. In the present case, density wave oscillations mainly occur at two stages. Density wave oscillations first occur when flashing initiates and last until the end of the two-phase quasi-steady state $(\sim 70,600$ seconds). After the system flow starts to decrease and water level in the water tank drops to a threshold point ( 98,600 seconds), density wave oscillations occur again. As the water level continues to drop, at $\sim 114,600$ seconds ( 31.8 hours), the system flow no longer sustains due to the decrease in the cold leg hydrostatic head, and the flow instability mechanism transitions from density wave oscillations to geysering, during which the system flow experiences abrupt stagnation, and due to periodic flow excursions, oscillates as seen from Figure 2-2.

Per literature [2-3][2-4], for density wave oscillations, the period is roughly $1.5-2$ times of the fluid transportation time in the pipe. For illustration purpose, a time frame from 34,000 to 38,000 seconds of the transient is selected for analysis, as shown in Figure 2-3. Over this time frame, the average oscillation period is found to be approximately 126.9 seconds. In this RELAP5 simulation, the output frequency is 1 data/20 seconds, meaning that averagely 6 data points are recorded over each period. Considering the fluid velocity from the inlet header of the riser tube assembly to the outlet of the upper chimney pipe (P470), the transportation time is approximately 57.1 seconds. The oscillation period is roughly 2.2 times of the fluid transportation time, slightly larger than the range found from literature. 


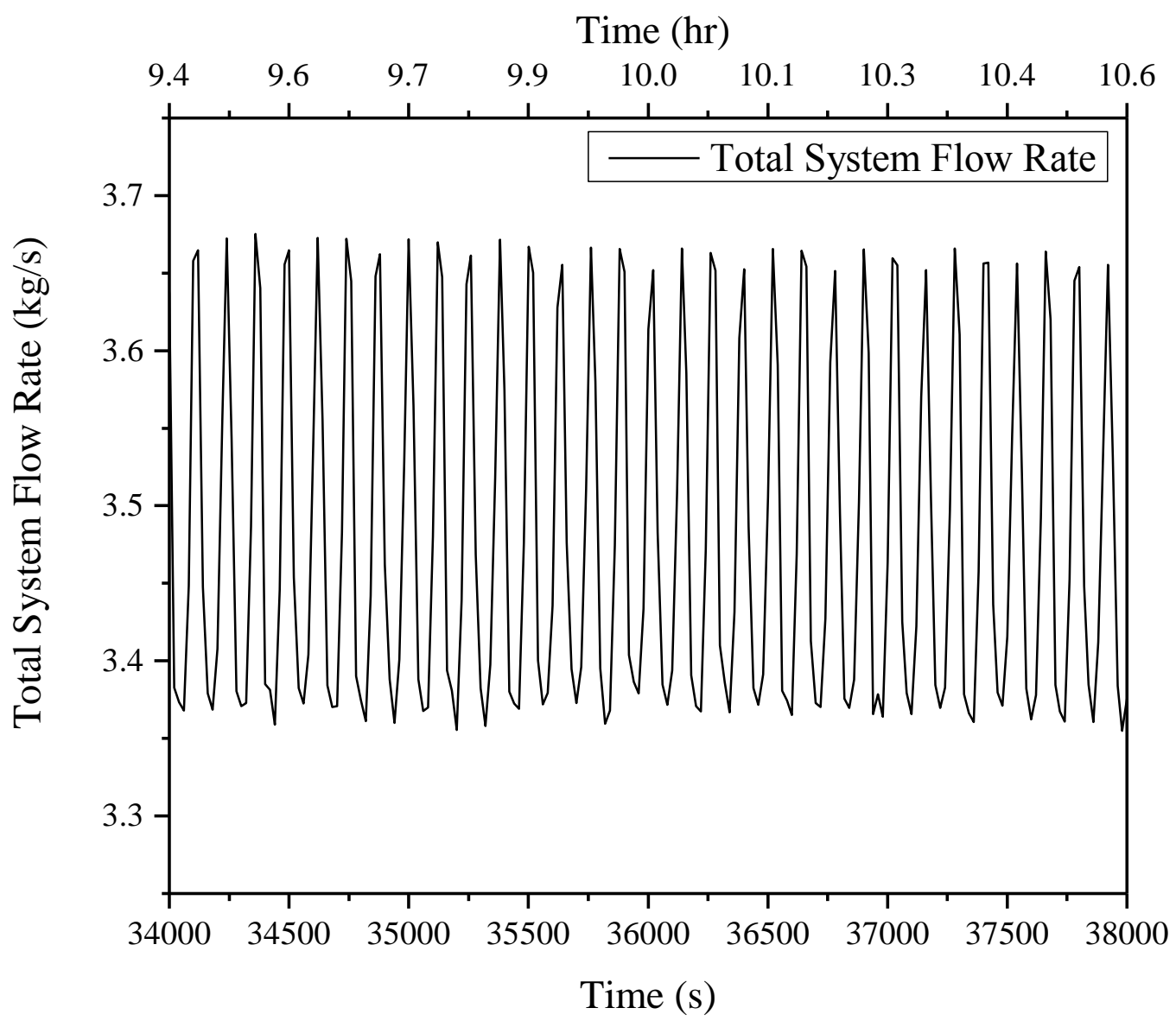

Figure 2-3: Density wave oscillations spanning 4,000 seconds. Flow rate oscillations are captured in RELAP5 with a 20 second resolution

\subsection{Tank Modeling Study}

The reference RELAP5 model discussed in the previous section was selected from a parametric tank modeling study. It was found that the tank modeling is important in determining the system transient behaviors, especially the initiation of flashing, and decrease of system flow. The tank modeling was mainly focused on two aspects, namely, thermal mixing inside the tank, and tank inlet nozzle connection.

\subsubsection{Thermal Mixing inside the Tank}

During the single-phase natural circulation, when the heated water returns to the water tank, due to the buoyancy, local natural recirculation and thermal mixing will occur inside the water tank. Thermal mixing inside the water tank will affect the energy balance of the water being circulated inside the loop, and thus the initiation of flashing. To simulate the local natural recirculation and thermal mixing inside the water tank, a tank model (Model 1) as shown in Figure 2-4 was developed. In this tank model, two branches B970 and B969 were adopted, each representing half of the cylindrical volume. The two branches are connected in parallel, along with B971 and P950, to form a local closed circulation loop. 


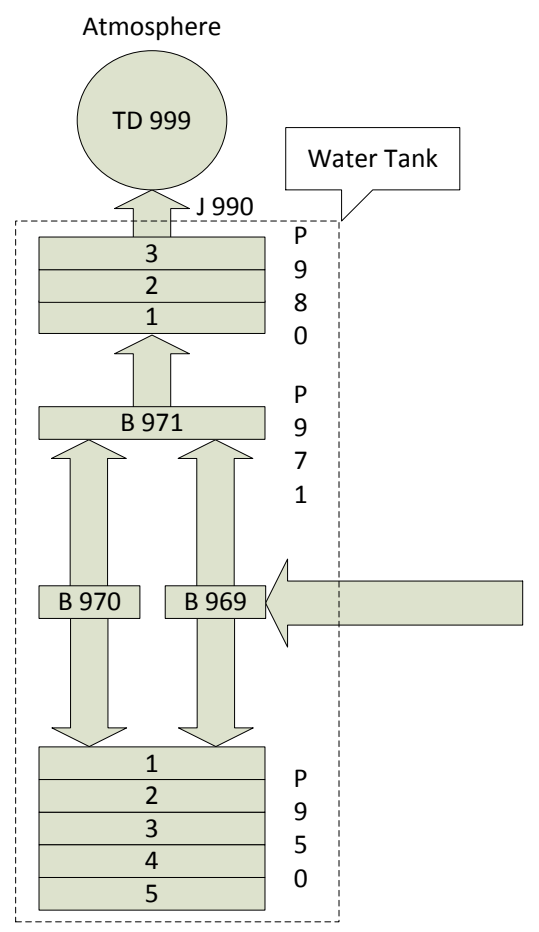

Figure 2-4: Tank model to simulate local natural recirculation and thermal mixing

Compared to the reference model shown in Figure 2-1, Model 1 forces all the water inside the tank to participate in thermal mixing and thus will predict a delayed initiation of flashing, as shown in Figure 2-5. In a real case, there will be complicated three-dimensional phenomena in the water tank, the net effect of which might result in a partially thermal-mixed water tank. Model 1 does not encompass the flexibility of modeling the varying extent of thermal mixing in the water tank, while the reference model, by adjusting the height of the thermal mixing region B969, can simulate all the way from a completely non-thermal-mixed tank to a completely thermal-mixed tank. With experimental data available later, the reference model can be benchmarked to determine the proper height for the thermal mixing region. 


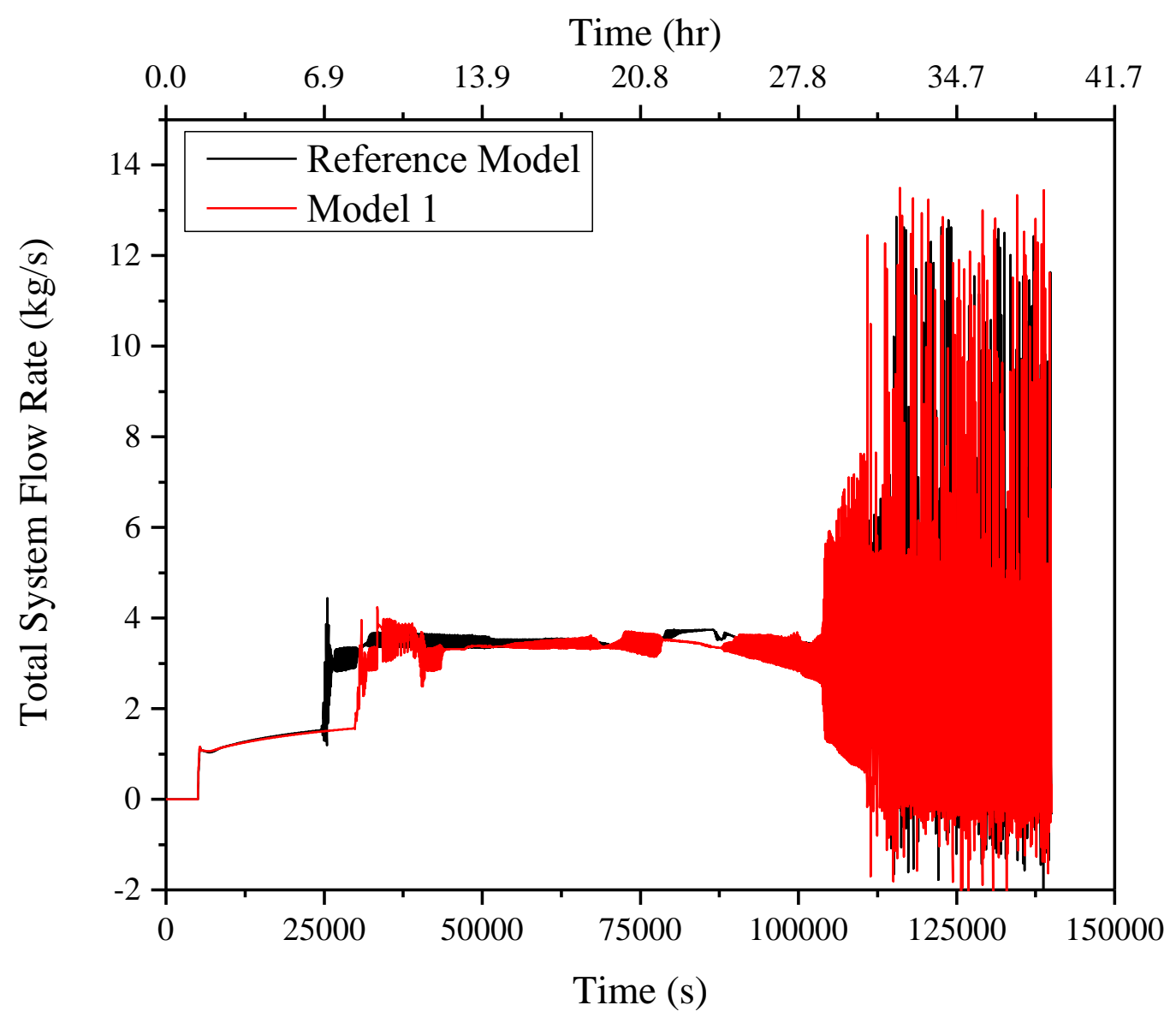

Figure 2-5: Delayed initiation of flashing predicted by Model 1 compared to reference model

There has been another defect identified for Model 1. It was found that, Model 1 predicts unrealistic local recirculation flow inside the water tank, as seen in Figure 2-6. The predicted local recirculation flow is two orders of magnitude larger than the system flow, which is not realistic considering the larger inertia of the water insider the tank. The predicted unrealistic local recirculation flow even imposes some effect on the system flow, as can been seen from Figure 2-5. Variations of Model 1 were also investigated by adding flow resistance (expansion and contraction form losses) to the junctions in B969 and B970, but still predicting unrealistic local recirculation flows. Therefore, Model 1 was not selected. 


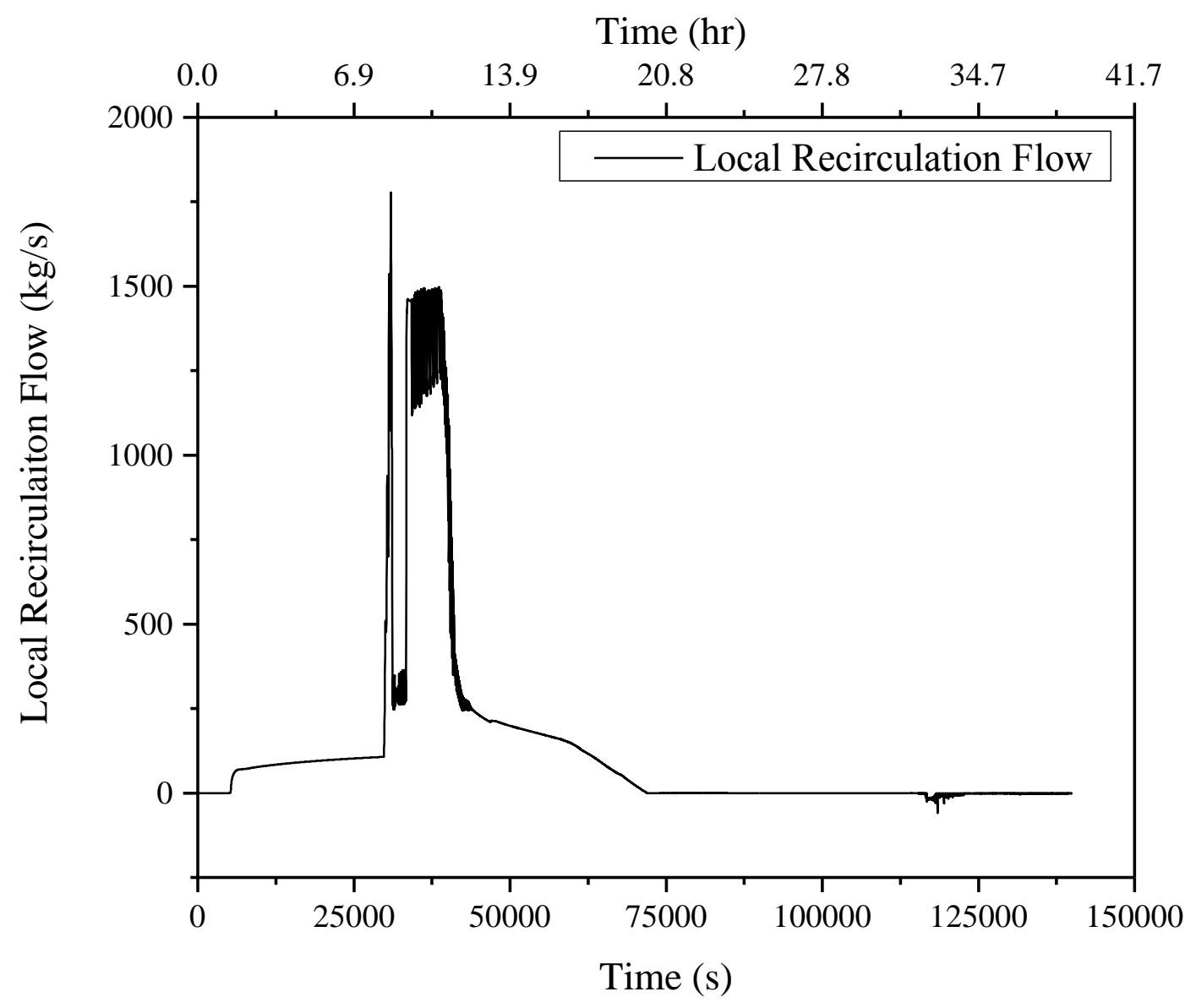

Figure 2-6: Unrealistic local recirculation flow inside water tank predicted by Model 1

\subsubsection{Tank Inlet Nozzle Connection}

In the NSTF water tank design, the inlet nozzle is connected to the side of the tank. In RELAP5, crossflow inlet option is available, which was selected to model the water tank inlet nozzle configuration. Considering the defects of Model 1 discussed earlier, a second RELAP5 model for the water-based NSTF (Model 2) was developed by merging B970 into B969 while using the crossflow inlet configuration, as shown in Figure 2-7. The predicted system total mass flow rate for the baseline two-phase test case [2-2] with Model 2 is illustrated in Figure 2-8, along with the result predicted by the reference model. In Model 2, the top half of B969 would participate in thermal mixing during the single-phase natural circulation. The height of the thermal mixing region in Model 2 (half of the height of B969) is $0.265 \mathrm{~m}$, larger than that of the thermal mixing region in the reference model $(0.205 \mathrm{~m})$, therefore causing a slightly delayed initiation of flashing. The two-phase quasi-steady-state flows predicted by the two models are identical. However, there is indeed a significant difference between the two models, which lies in when the system flow starts to decrease. As can be seen from Figure 2-8, Model 2 predicts an earlier decrease in the system total flow than the reference model. Theoretically, since the phenomenon of system flow decrease is associated with break of the closed loop circulation, it ought not to occur until the water level inside the water tank descends to the elevation of the inlet 
nozzle. It was found that, the reference model, with the inlet nozzle connected to the bottom of B969, predicts the phenomenon as expected, while Model 2 predicts it earlier. A closer examination on the system behavior revealed that, the system flow decrease occurs when the tank water level drops to B969 in Model 2. Because RELAP5 is not capable of tracking the water level inside a branch, once the water level drops to B969, RELAP5 treats the entire volume as a uniform mixture of water and steam with decreasing average density. For the crossflow inlet boundary condition, RELAP5 assumes the connection is made to the midpoint of the side of the volume. Thus, once the water level drops to B969, although the bottom half of B969 that is part of the circulation loop is still filled with water, because of the reasons mentioned above, the cold leg hydrostatic head starts to decrease, and accordingly the system flow. Theoretically, this issue can be resolved by using an infinitesimal B969, which however will result in too small time steps due to the Courant limit and also the loss of the flexibility of controlling the thermal mixing region height. To cope with this issue, the reference model was developed by moving the tank inlet connection to the bottom of B969 and also changing the heights of B969 and P950 accordingly.

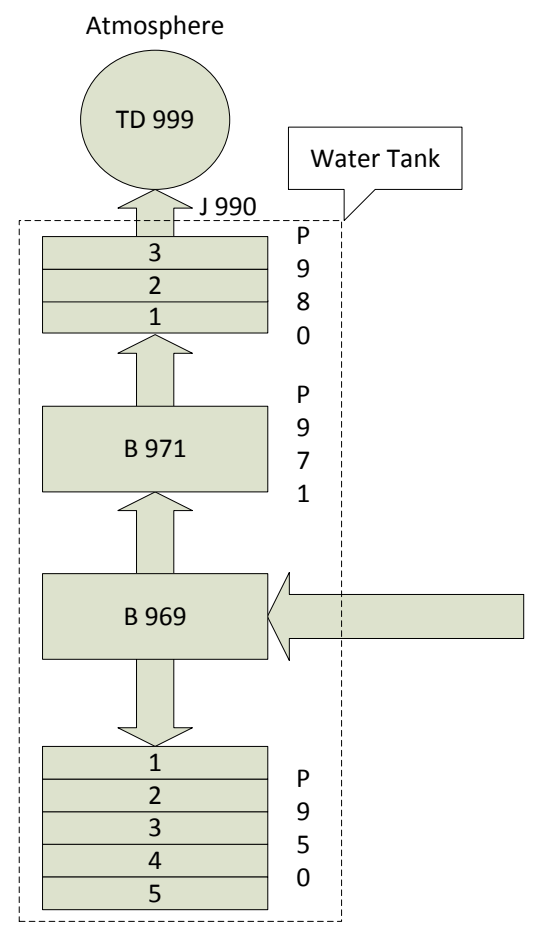

Figure 2-7: Model 2 for the NSTF water tank 


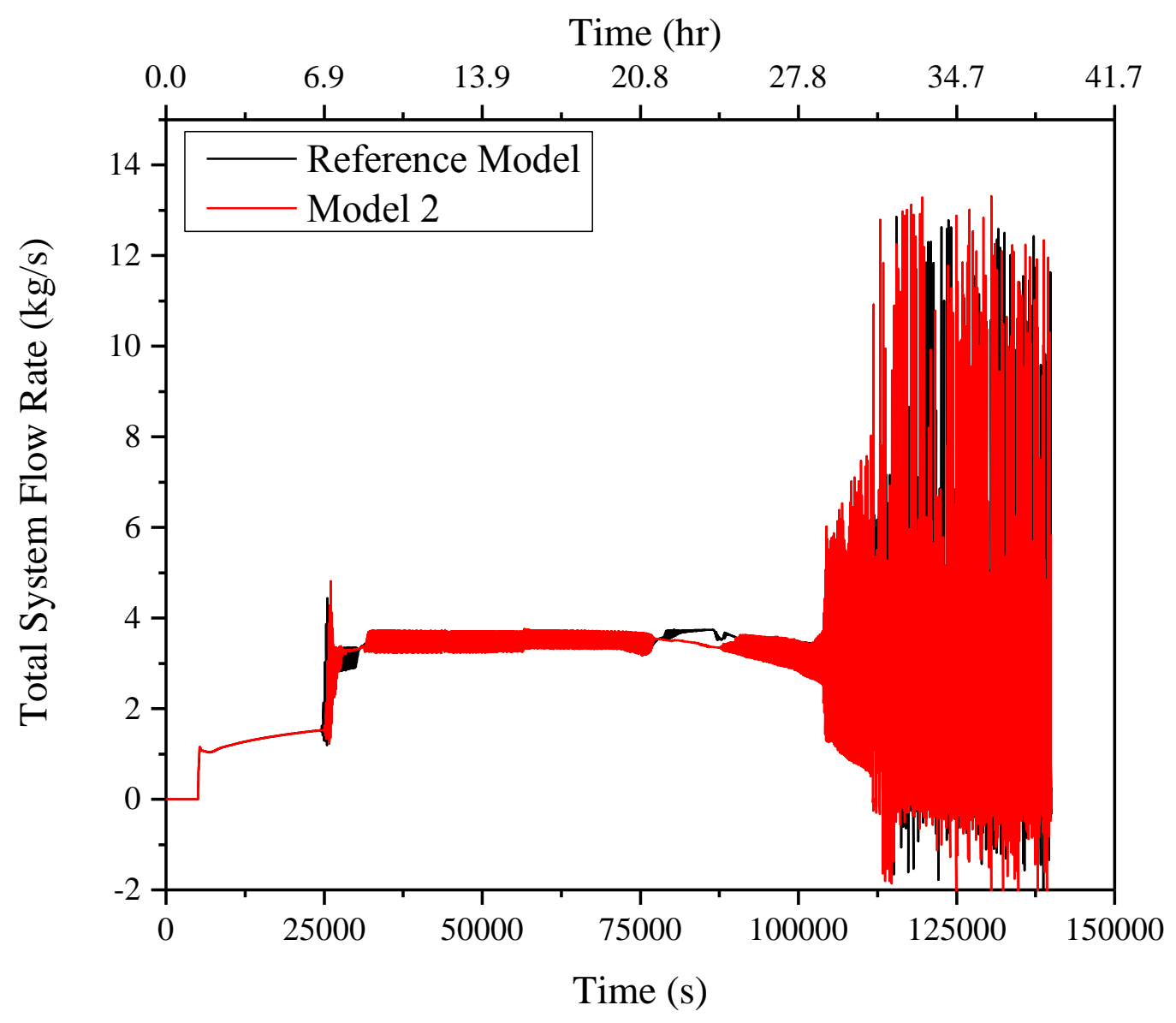

Figure 2-8: Comparison of system total mass flow between the reference model and Model 2

\subsection{Parametric Study of Varying Test Cases}

A general test matrix covering a variety of tests under variant operation conditions and with variant system configurations has been developed for the water-based NSTF [2-5]. To provide some insights on the system behaviors, as well as guidance on the operations of the water-based NSTF, RELAP5 simulations of the tests proposed in the test matrix were performed. In what follows, the simulations results will be discussed in details.

\subsubsection{Single-phase Baseline Testing}

In the test matrix, two single-phase baseline tests to be performed are defined.

1. Conduct a baseline experiment at: a) single phase conditions, b) flat power profile at 1.4 MWt scaled SC-HTGR power, c) mid-height tank inlet port, and d) 80\% initial storage tank inventory volume. Achieve steady-state conditions at a constant riser inlet temperature of $30^{\circ} \mathrm{C}$ by removing equal power by $H X G$ loop off storage tank.

2. Repeat single-phase baseline experiment but adjust inlet throttle valve to obtain $15^{\circ} \mathrm{C}$ temperature rise across riser tubes. 
To simulate the single-phase baseline tests, the reference model discussed earlier was modified as follows.

1. Two time dependent junctions were added, with J439 connected to the side of B969 while J429 connected to the top of B969, as shown in Figure 2-9. A constant mass flow of $1 \mathrm{~kg} / \mathrm{s}$ was specified at both J429 (inflow) and J439 (outflow) to simulate the flow going through the HXG loop. The conditions of the cooled water that returns to the tank were defined through the time dependent volume 997. A proportional-integral (PI) control was adopted to vary the water temperature provided from 997 to reach the desired temperature of $30^{\circ} \mathrm{C}$ at the riser tube inlet (actually at the outlet of P840).

2. A control valve was added before the riser tubes inlet header. A PI control was adopted to vary the opening of the control valve to achieve the desired temperature rise of $15^{\circ} \mathrm{C}$ across the riser tubes (actually from the inlet of the inlet header to the outlet of the outlet header).

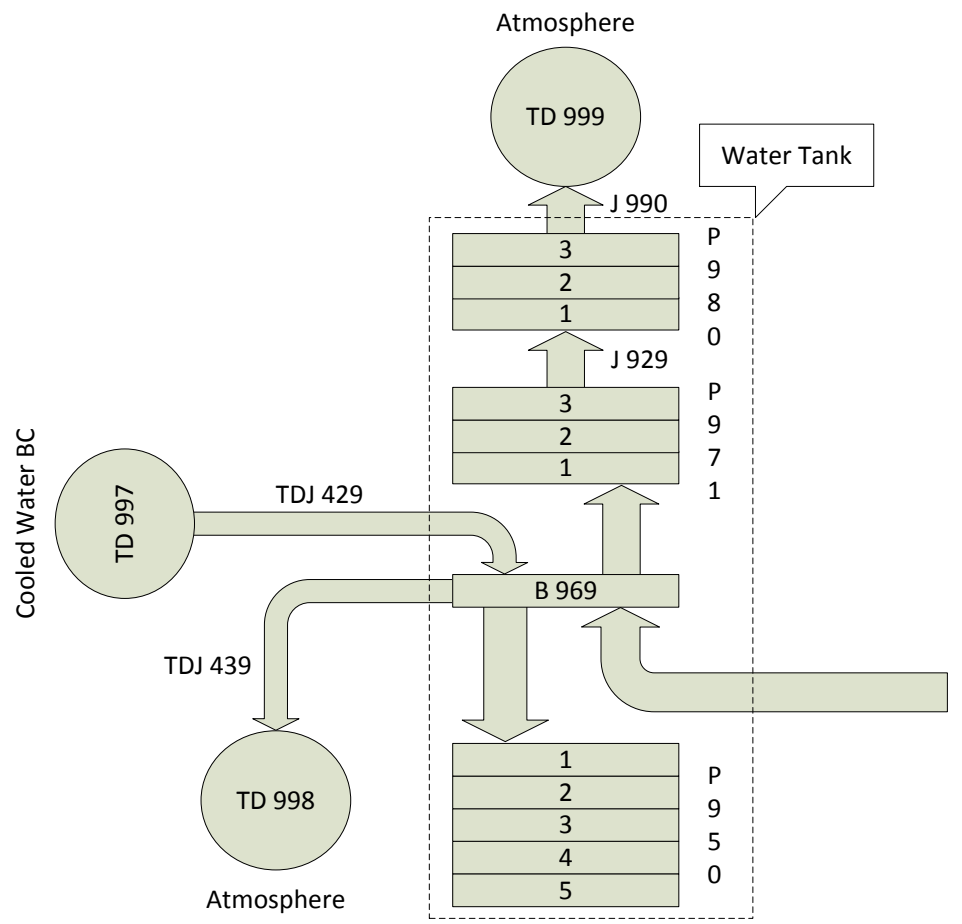

Figure 2-9: Simulation of tank cooling in RELAP5

The riser tube inlet temperature in baseline 1 test is shown in Figure 2-10, indicating that the desired riser tube inlet temperature of $30^{\circ} \mathrm{C}$ was achieved. The riser tube inlet and outlet temperatures in baseline 2 test are shown in Figure 2-11, and similarly both the desired riser tube inlet temperature and temperature rise were achieved. The system total mass flows in the two single-phase baseline tests are also illustrated in Figure 2-12. To achieve the desired temperature rise across the riser tubes, the control valve was partially closed (open area to total area $=0.105$ ), resulting in a smaller system flow in baseline test 2 . 


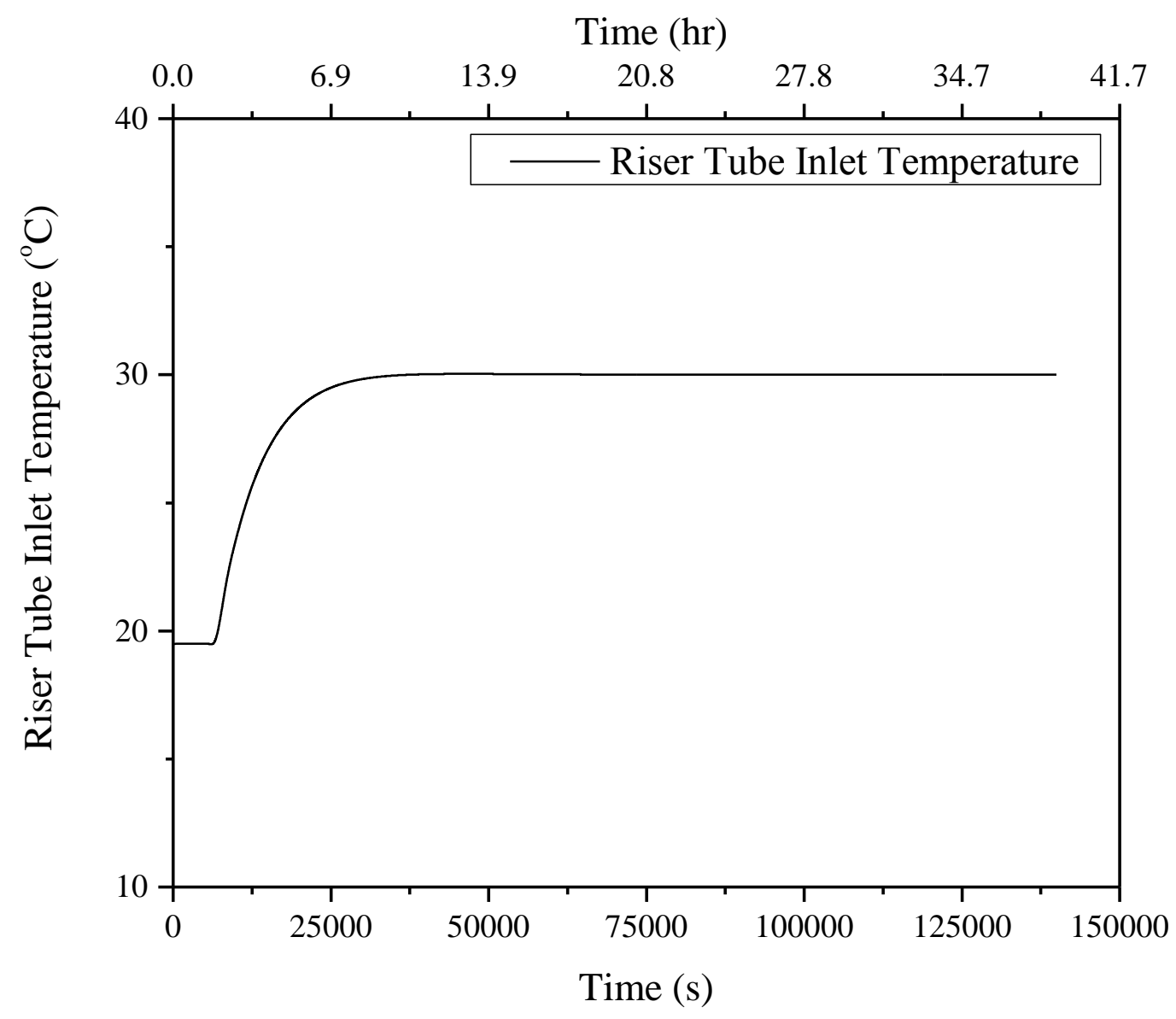

Figure 2-10: Riser tube inlet temperature in single-phase baseline test 1 


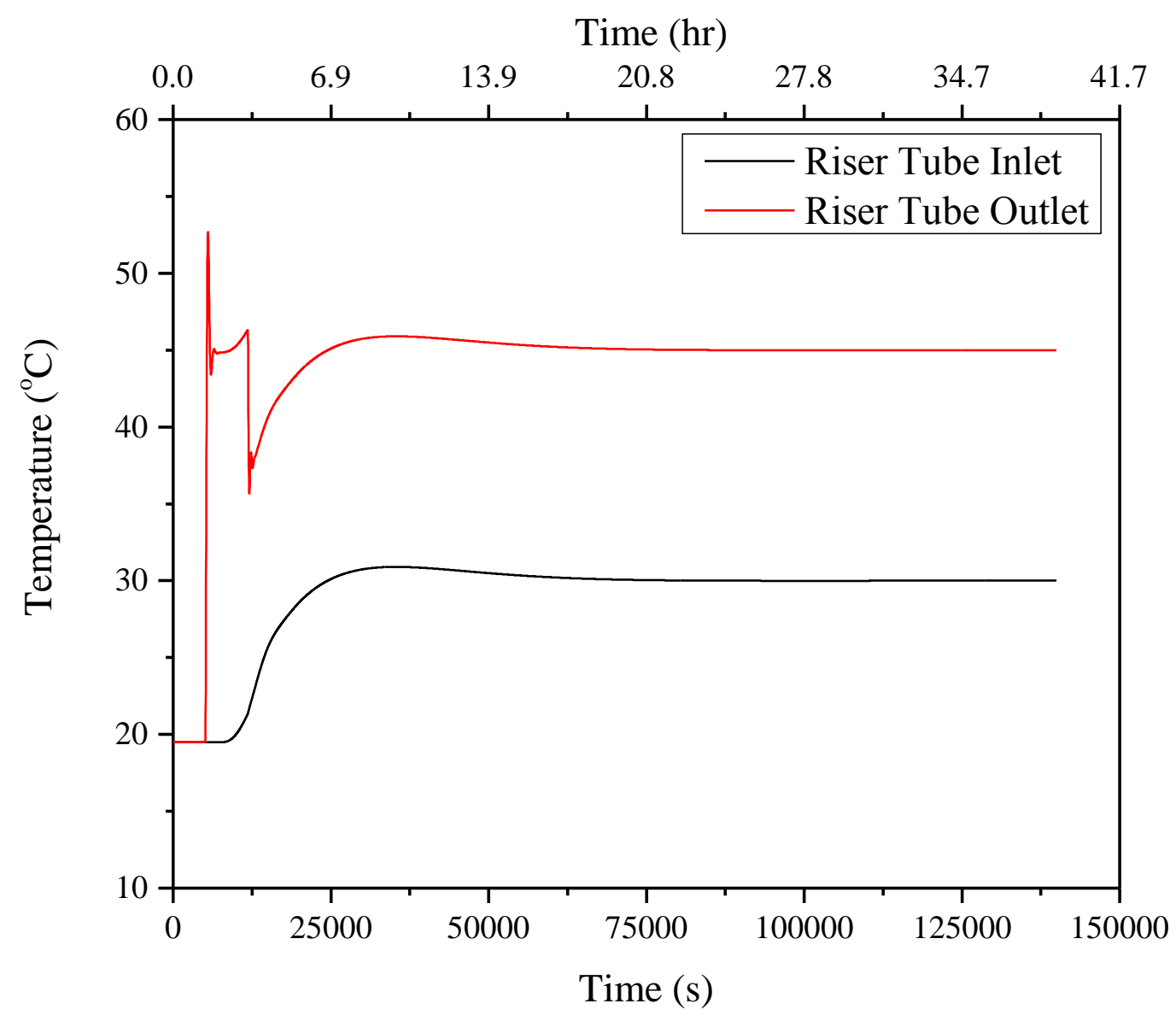

Figure 2-11: Riser tube inlet and outlet temperatures in single-phase baseline test 2 


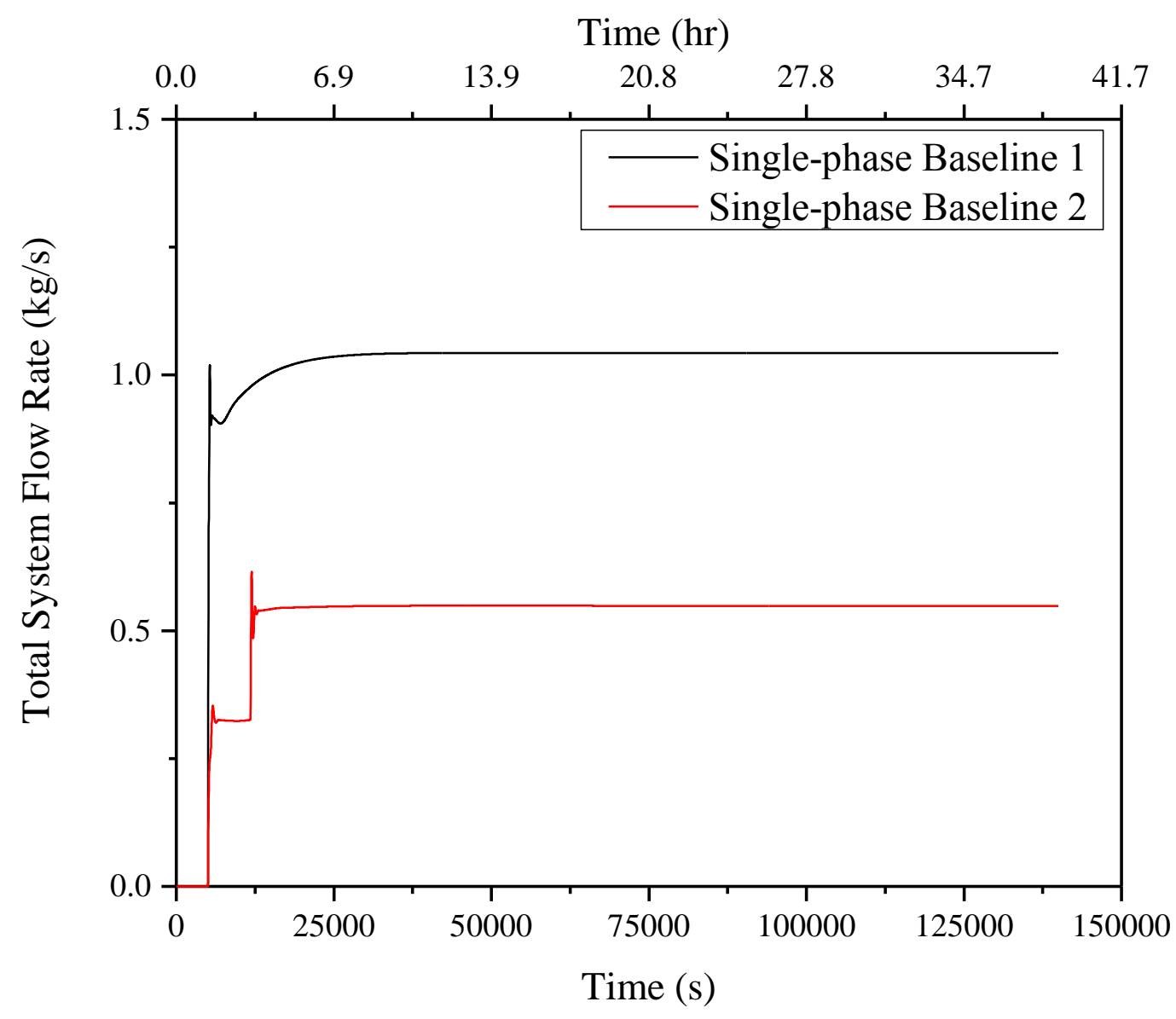

Figure 2-12: System total mass flow rates in the two single-phase baseline tests

\subsubsection{Two-phase Baseline Testing}

The two-phase baseline test is defined as [2-5]:

An experiment at: a) two phase conditions, b) flat power profile at 2.1 $\mathrm{MW}_{\mathrm{t}}$ scaled SC-HTGR power, c) mid-height tank inlet port, d) $80 \%$ initial storage tank inventory volume, and e) carbon fins with stainless risers. Allow system to reach saturation and subsequent boil-off for minimum 4 hours at this quasi-steady-state period.

The RELAP5 simulation results of the two-phase baseline test have been discussed previously in Section 2.2 and will not be repeated here.

\subsubsection{Integral Power Testing (Repeat Baseline with Varying Powers)}

For this testing, four different full scale power levels are defined: a) Reduced $-700 \mathrm{~kW}(17.2$ $\mathrm{kW}$ in NSTF), b) Normal - 1.4 $\mathrm{MW}_{\mathrm{t}}\left(34.4 \mathrm{~kW}\right.$ in NSTF), c) Accident $-2.1 \mathrm{MW}_{\mathrm{t}}(51.6 \mathrm{~kW}$ in NSTF), and d) Elevated $-2.8 \mathrm{MW}_{\mathrm{t}}(68.8 \mathrm{~kW}$ in NSTF). The power condition of c) corresponds to the two-phase baseline test discussed earlier. The system total mass flow rates with the four different power levels are shown in Figure 2-13. As can be seen, at lower power levels, all the phenomena are delayed, including the initiation of flashing and decrease of the system flow. For 
the case of Reduced power, Case A, decrease of system flow was not observed, indicating that the water level inside the tank never dropped to the elevation of the inlet nozzle over the simulated transient period. Also, as the power increases, both the single-phase and two-phase flows increase.

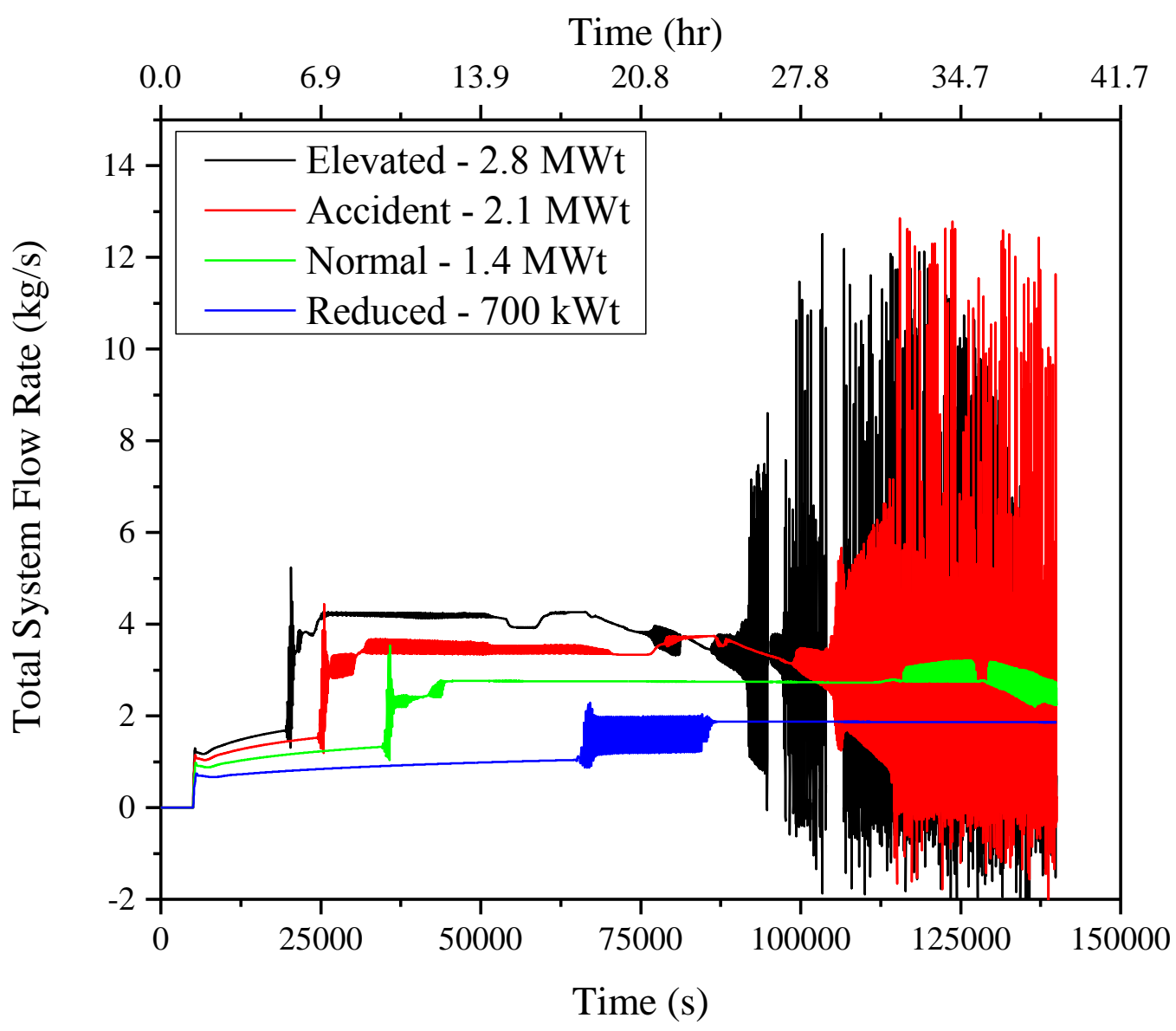

Figure 2-13: System total mass flow rates at varying power levels

\subsubsection{Storage Tank Inventory (Repeat Baseline with Varying Initial Inventories)}

Tests defined in this category include:

a. Varying initial tank volumes
i. $80 \%$ full
ii. $60 \%$ full
iii. $50 \%$ full

b. Accelerated tank inventory loss

c. Full tank depletion

The reference model corresponds to an initial water tank inventory of $80 \%$ full. The system total mass flow rates with the varying initial water tank inventories are shown in Figure 2-14. For the present water tank design, the upper inlet nozzle is located at the elevation of $50 \%$ tank inventory. Therefore, in the RELAP5 model for the case of a-iii (50\% full), B969 was not initially 
filled with water, and thus predicting an earlier initiation of flashing. Also, once flashing initiates in the case of a-iii, the water level inside the water tank immediately starts to drop below the elevation of the tank inlet nozzle, leading to a decrease in the system flow, as can be seen from Figure 2-14. For the cases of a-i ( $80 \%$ full) and a-ii (60\% full), despite of the different initial water tank inventories, because of the same height for B969 used in their RELAP5 models, identical initiation time of flashing was predicted. However, the higher initial water tank inventory will cause a delay in the system flow decrease, as seen from Figure 2-14. Lastly, the two-phase quasi-steady-state flow seams insensitive to the initial water tank inventory. The different initial water tank inventories will result in different hydrostatic heads and thus different system pressures, which however are insufficient to cause any appreciable difference in the twophase quasi-steady-state flows.

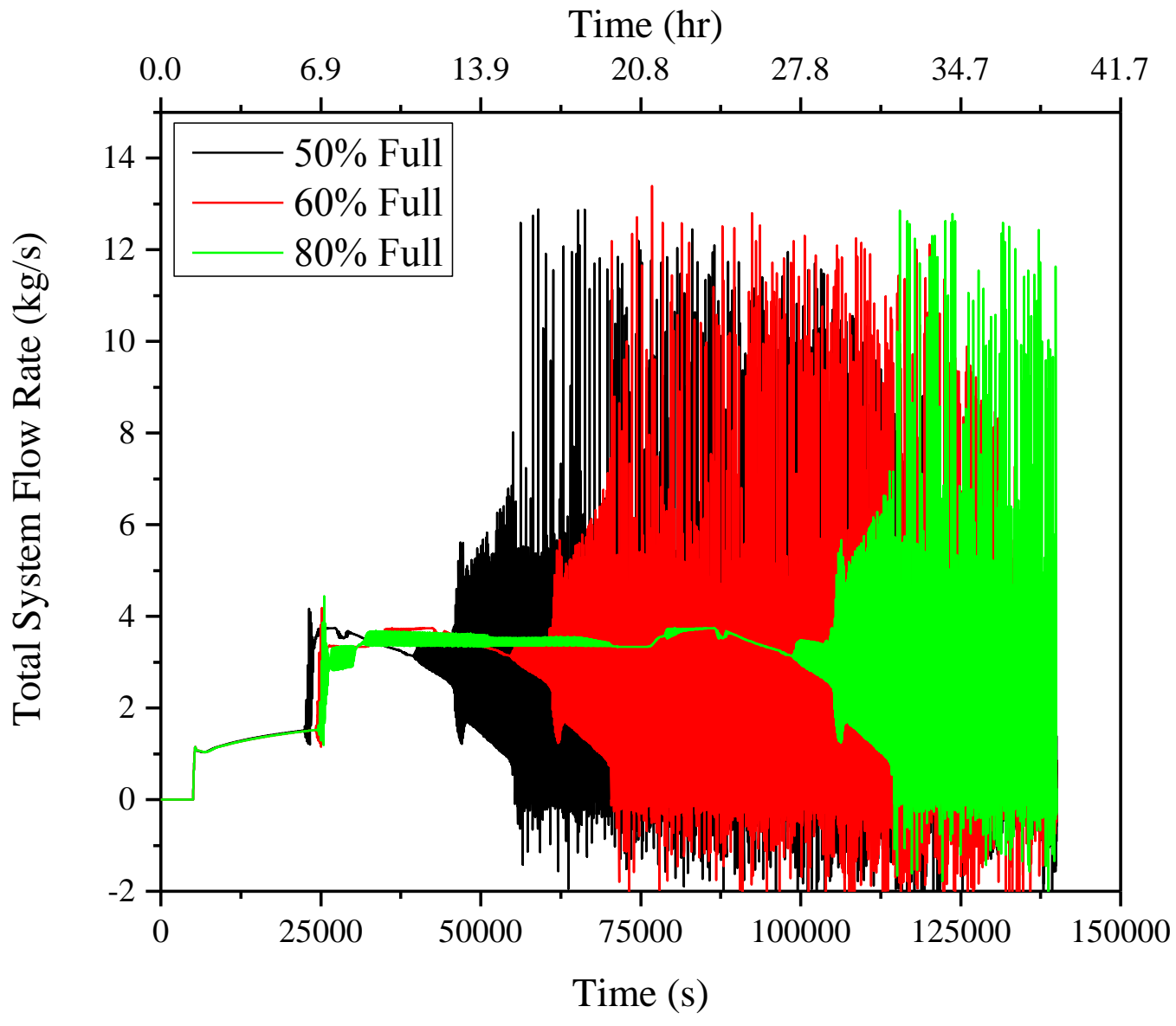

Figure 2-14: Total system mass flow rates with varying initial water tank inventories

To simulate the accelerated tank inventory loss test case, a time dependent junction was added to the bottom of pipe P860. The time dependent junction was connected to atmosphere, and by varying the specified flow rates at the junction, the tank inventory loss could be well controlled. After discussing with the experimental group, a tank inventory loss rate of $1 \mathrm{~kg} / \mathrm{min}$ was selected. The corresponding system total mass flow rate is shown in Figure 2-15. As can be seen, the tank inventory loss does not change the initiation of flashing compared to the baseline test, which is 
understandable since the thermal mixing region heights are identical in the two cases. Also, with accelerated tank inventory loss, the two-phase quasi-steady state is shortened and the system flow experiences an earlier decrease.

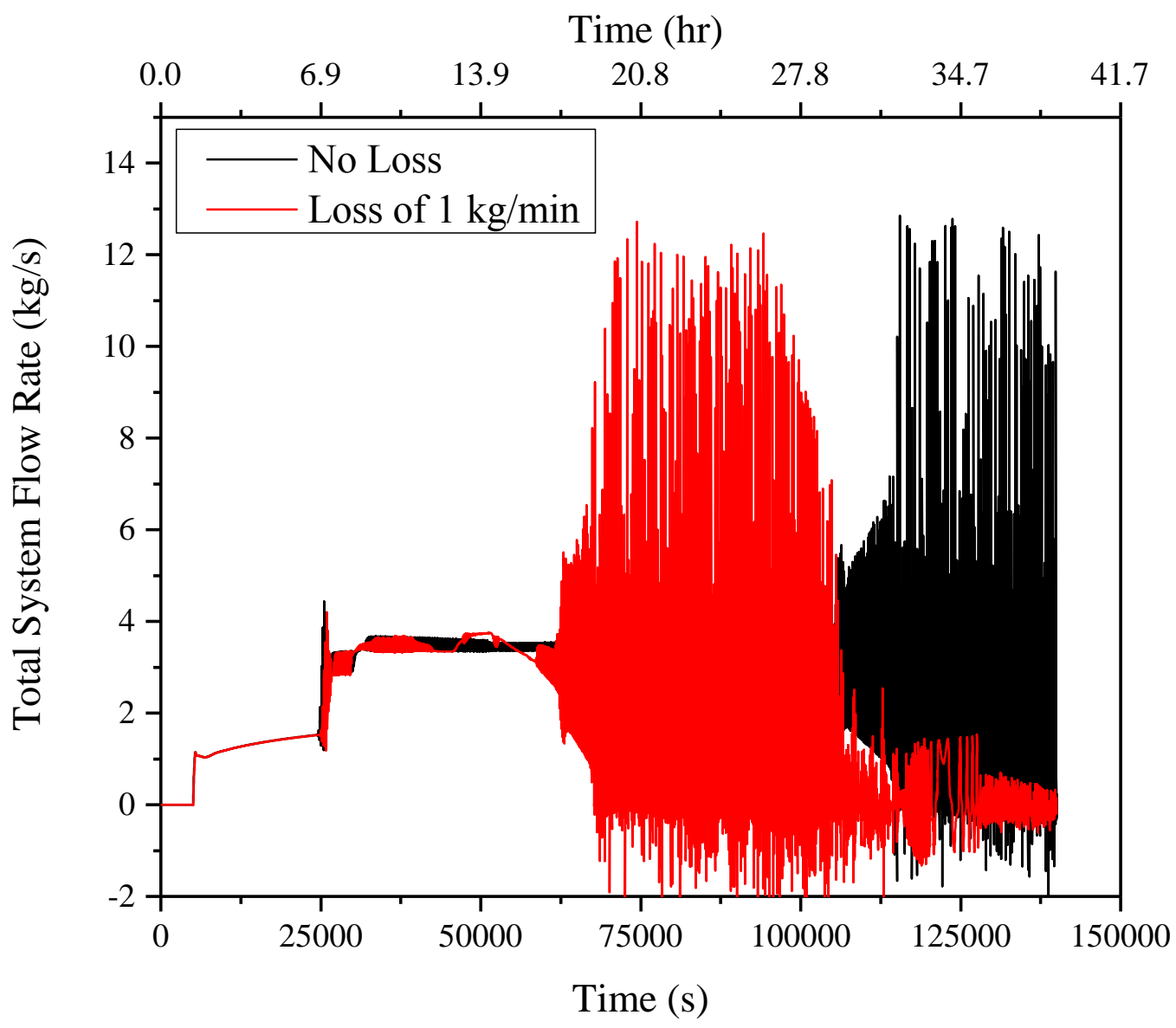

Figure 2-15: System total mass flow rate with tank inventory loss of $1 \mathrm{~kg} / \mathrm{min}$

To simulate the full tank depletion, the reference RELAP5 model was selected and executed over a long period of up to 2.0E5 seconds (55.6 hours). The system total mass flow rate of this extended run is shown in Figure 2-16. Over the first 1.4E5 seconds (38.9 hours), the system behavior is the same as discussed before. At 1.4E5 seconds (38.9 hours), the system has entered the geysering instability regime, and the system flow oscillates back and forth. As the transient continues, the flow fluctuations get suppressed due to the reduced system water inventory, and eventually the system flow approaches zero. The steam void fraction in the bottom half of the water tank (P950) is shown in Figure 2-17. As can be seen, at 1.9E5 seconds (52.8 hours), the steam void fraction in the lowest volume of P950 reaches $\sim 1$, indicating a complete depletion of the water tank. The outer surface temperature at the center of the riser tube heated section (P671) is also shown in Figure 2-18. When the system flow is approaching zero, the structure temperature rises significantly from $\sim 378.5 \mathrm{~K}$ to $\sim 1734.3 \mathrm{~K}$. 


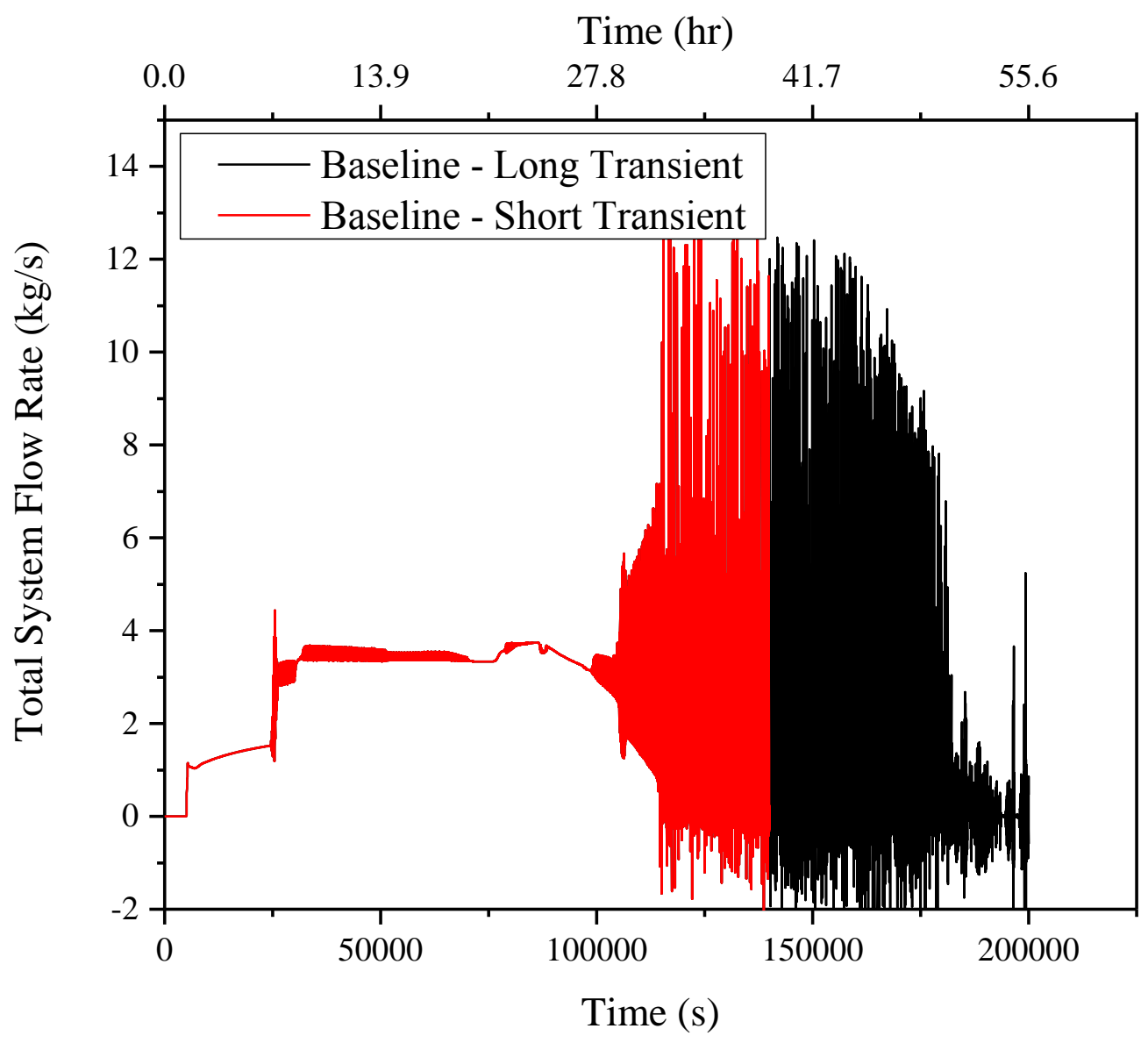

Figure 2-16: System total mass flow rate with full tank depletion 


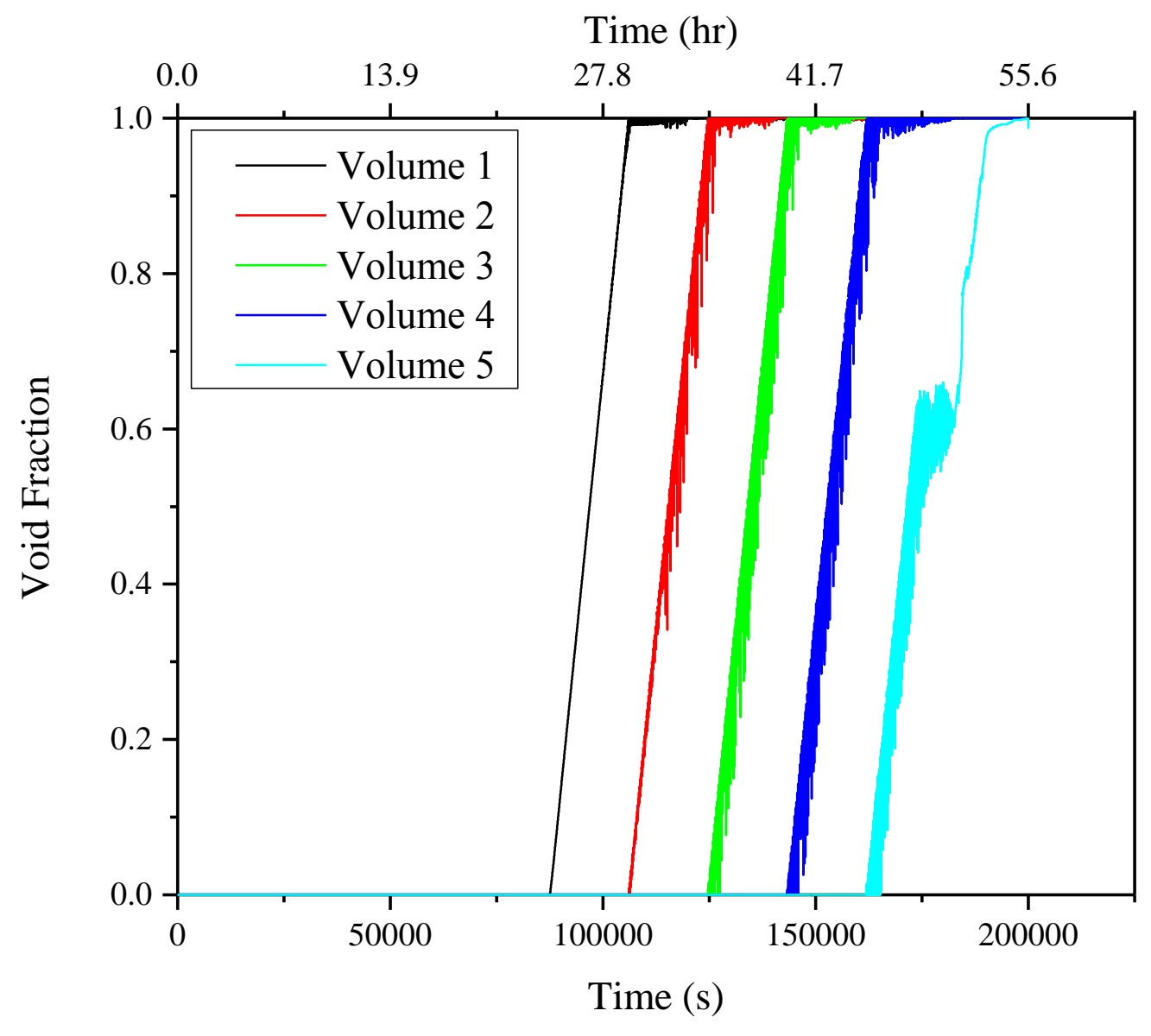

Figure 2-17: Steam void fraction in the bottom half of the water tank (P950) 


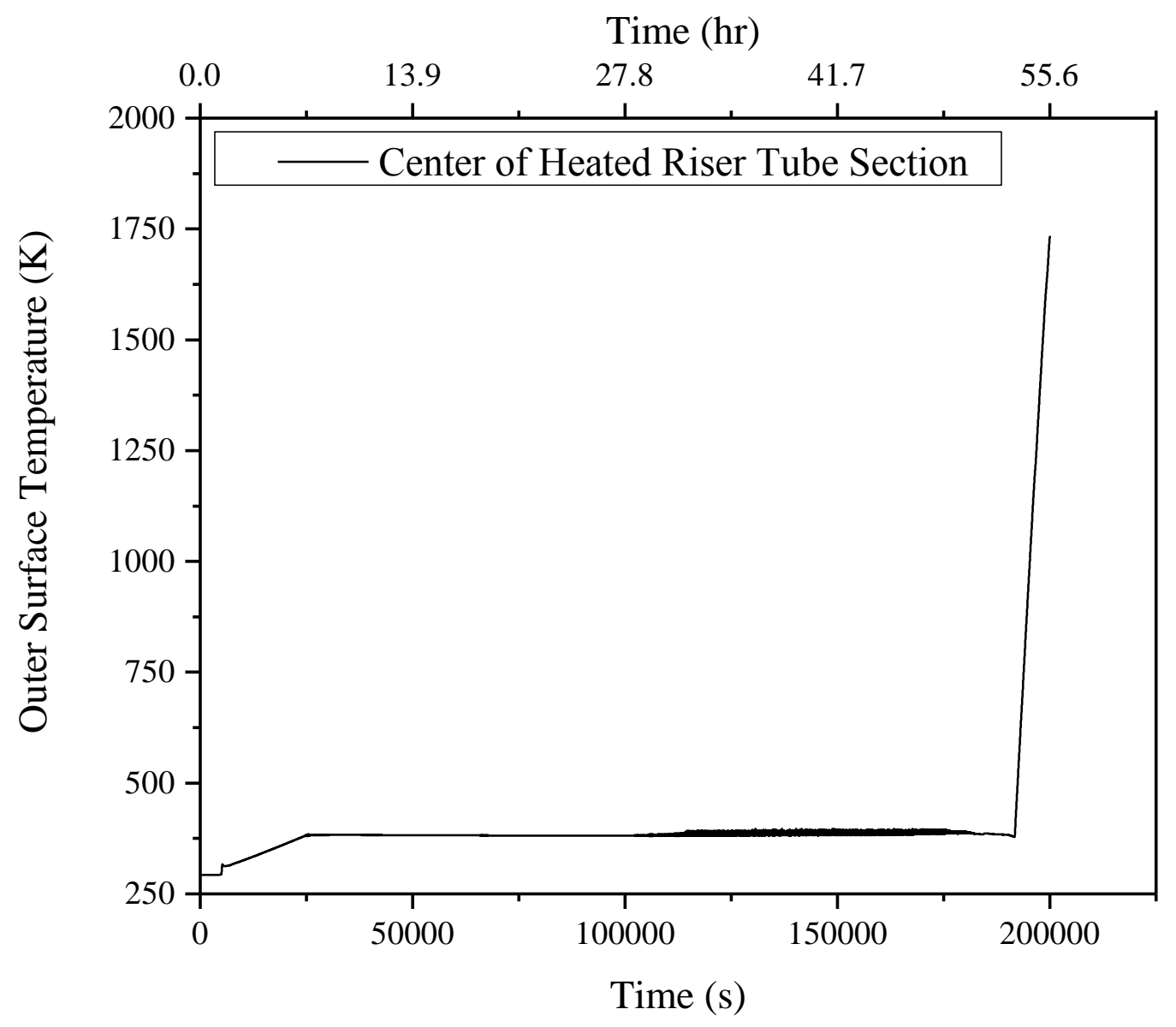

Figure 2-18: Outer surface temperature at the center of the riser tube heated section (P671)

\subsubsection{System Pressure (Repeat Baseline with Varying Pressures)}

To examine the effects of system pressure on the transient behaviors, tests at elevated system pressures of $1 \mathrm{bar}$ and 2 bar were proposed. The system total mass flow rates at the elevated pressures are compared with that of the baseline test, as shown in Figure 2-19. As can be seen, at higher system pressures, the transient behaviors including initiation of flashing and system flow decrease get delayed. This is due to the increased water saturation temperatures associated with the increased system pressures. The system pressure does not seem to affect the single-phase flow. However, the two-phase flow is seen to increase as the system pressure increases. 


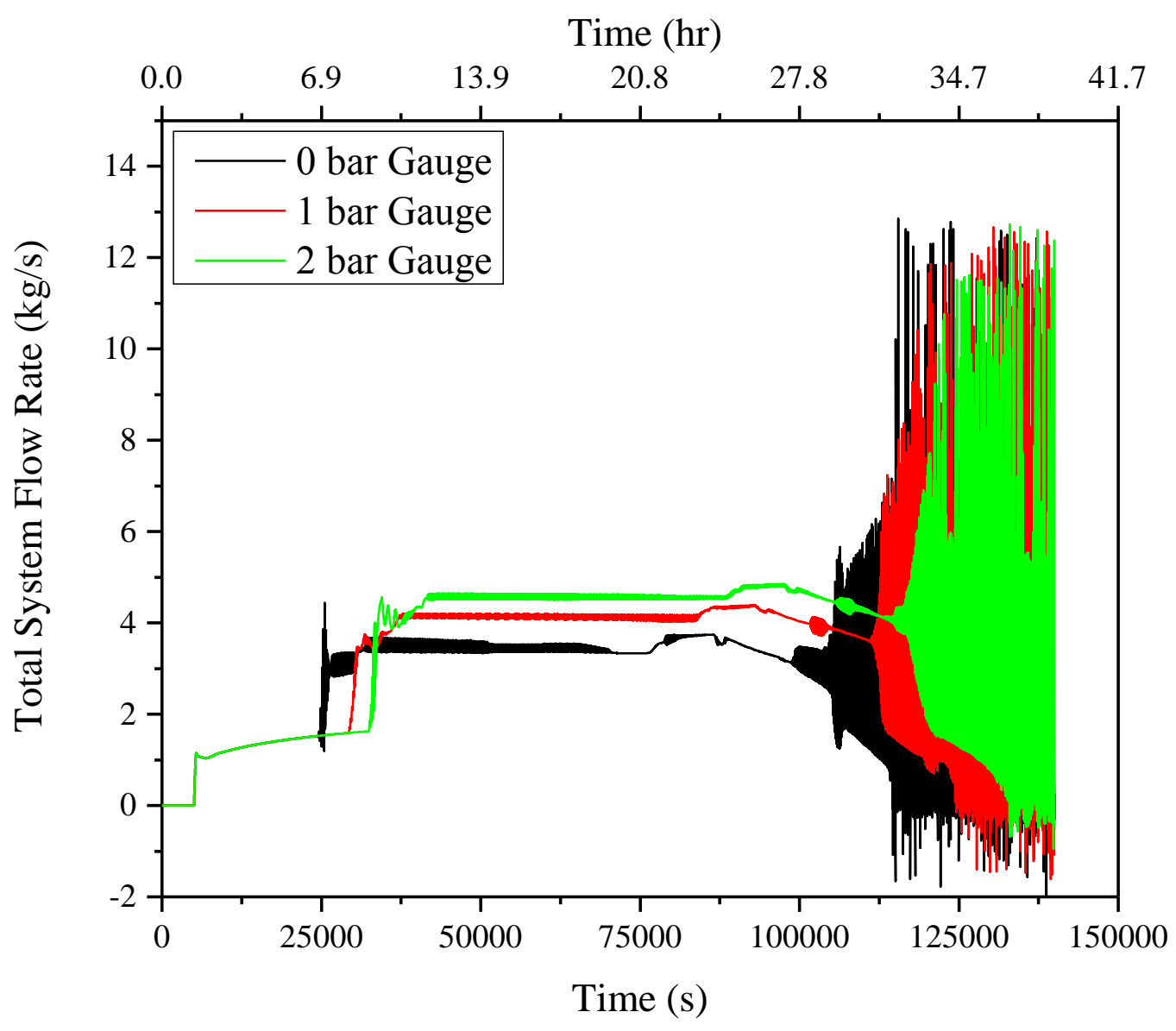

Figure 2-19: System total mass flow rates at varying system pressures

\subsubsection{Accident Scenario Testing}

This test was defined as a test incorporating full time history of design basis power profile, beginning from 'normal' single-phase steady-state at $1.4 \mathrm{MW}_{\mathrm{t}}$ until 'transient accident condition' with two-phase flow and boil-off at $2.1 \mathrm{MW}_{\mathrm{t}}$. To simulate this test in RELAP5, the previously discussed single-phase baseline test 2 was continued, but with the power increased to the 'Accident' level. The system total mass flow rate of the present case is shown in Figure 2-20. Compared to the two-phase baseline case which is a startup test from room temperature and zero initial flow, the accident scenario test has well-developed system flow and temperatures when the transient initiates. Therefore, initiation of flashing and decrease of system flow occur earlier in the accident scenario test. As also can be seen, the two-phase quasi-steady-state flows in the two tests are identical, indicating its insensitivity to the initial conditions of the system. 


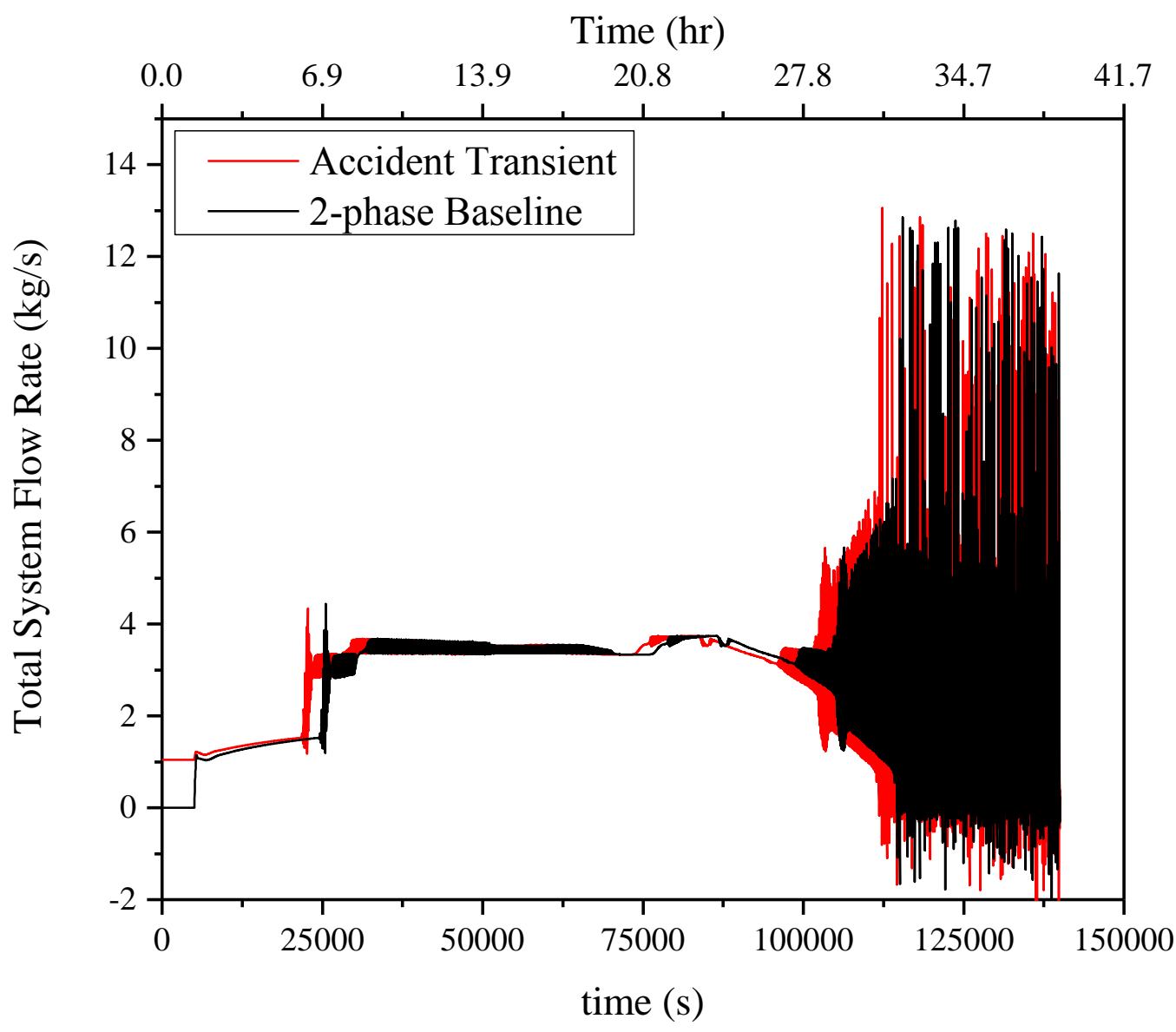

Figure 2-20: System total mass flow rate in the accident scenario test

\subsubsection{Geometric Variations (Repeat Baseline with Varying Geometry)}

Geometries to be examined in this testing include:

a. Lower tank inlet port

b. Varying riser tube blockages

c. Varying inlet throttling

d. Alternate chimney routing (u-shaped dip in upper chimney)

In the present water tank design, there are two inlet nozzles employed, the upper one located at the elevation of 50\% tank inventory while the lower one at the 5\% tank inventory [2-2]. The reference RELAP5 model, as well as the parametric tests discussed earlier assume the use of the upper nozzle. The system total mass flow rates with the upper and lower ports are both shown in Figure 2-21. With the lower inlet nozzle, the tank inventory that is heated up during the singlephase stage is smaller, thus resulting in an earlier initiation of flashing. For a natural circulation system, the system flow is dependent on the buoyancy that is further dependent on the loop height (more strictly, distance between the thermal centers of the heat source and heat sink) and coldhot-leg temperature difference. Although use of the lower inlet nozzle will result in a decrease in the loop height, the water inventory in the water tank that is involved in the circulation is also 
reduced, resulting in a higher cold-and-hot leg temperature difference and a net effect of increased buoyancy. Therefore, the single-phase natural circulation flow with the lower inlet nozzle is observed to be slightly larger than that with the upper inlet nozzle, as shown in Figure 2-22. Also, with the lower inlet nozzle, the utilizable water tank inventory is increased, resulting in a longer two-phase quasi-steady state. By the end of the simulation, the system flow with the lower inlet nozzle sees no significant drop, indicating that the water level inside the tank is still well above the elevation of the inlet nozzle. Lastly, as observed from Figure 2-21, with the lower inlet nozzle, the density wave instabilities are seen to be inhibited.

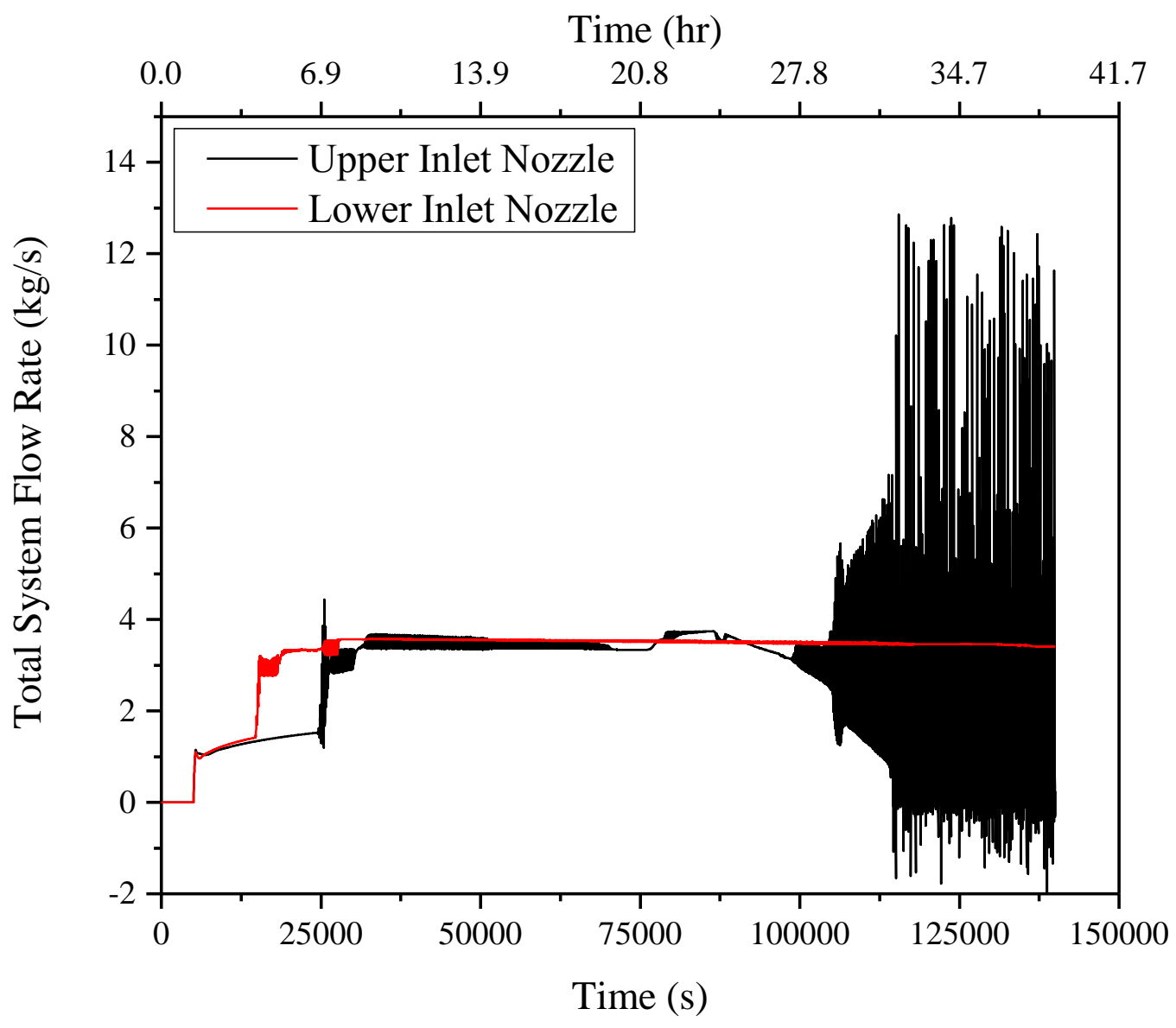

Figure 2-21: System total mass flow rates with varying water tank inlet ports 


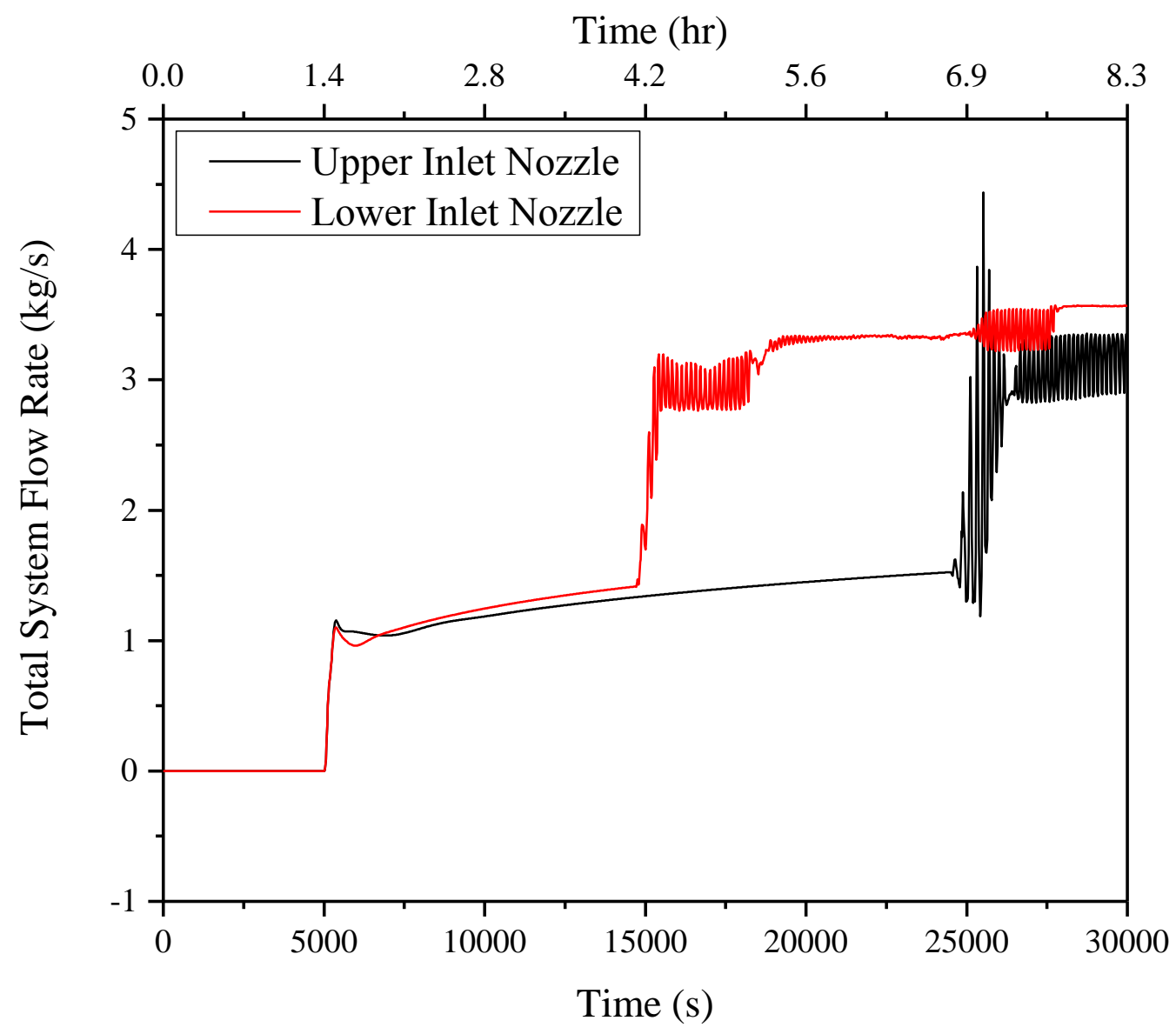

Figure 2-22: Comparison of the single-phase natural circulation flows between the lower and upper inlet nozzles

To model the effects of varying riser tube blockages, flow resistance (in terms of form loss coefficient) was added to the upstream unheated riser tubes (P691 - P698) in the RELAP5 model. Four form loss coefficients of $0,5,20$, and 80 were applied, with 0 representing the reference baseline case of no blockage. The system total flow rates with varying riser tube blockages are shown in Figure 2-23. As can be seen, the initiation of flashing and decrease of system flow in all four cases occur at similar times. This is because these two phenomena are mainly affected by the heat balance which is the same in all four cases. With higher riser tube blockage, both the singlephase and two-phase flows are reduced, which is understandable. Also, the higher riser tube blockage seems helpful to damp the fluctuations associated with wave density instability. For the case of largest riser tube blockage, due to the damping effect, the flashing, after initiated, is first suppressed for a while, and then re-initiates, as seen from Figure 2-23. 


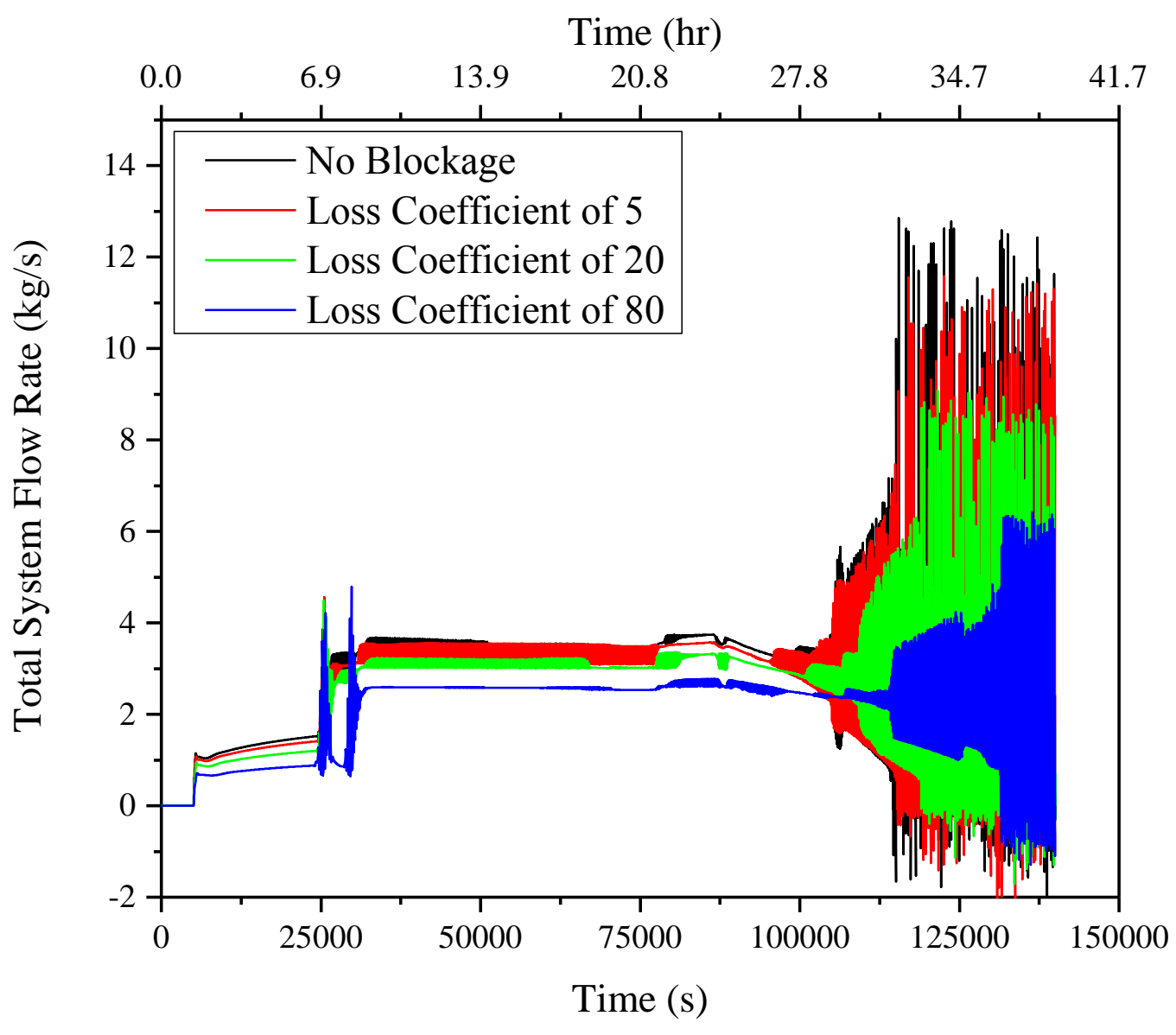

Figure 2-23: System total mass flow rates with varying riser tube blockages

To simulate the effects of varying inlet throttling, the form loss coefficient specified at the elbow (J849) upstream of the riser tube inlet header was varied in the RELAP5 model. Four different form loss coefficients of $0.39,5,20$, and 80 were used, with 0.39 representing the reference baseline case with no additional throttling. The system total mass flow rates with varying riser tube assembly inlet throttling are shown in Figure 2-24. The observations in the present case are similar to those in the previous case of varying riser tube blockages, and will be repeated here. 


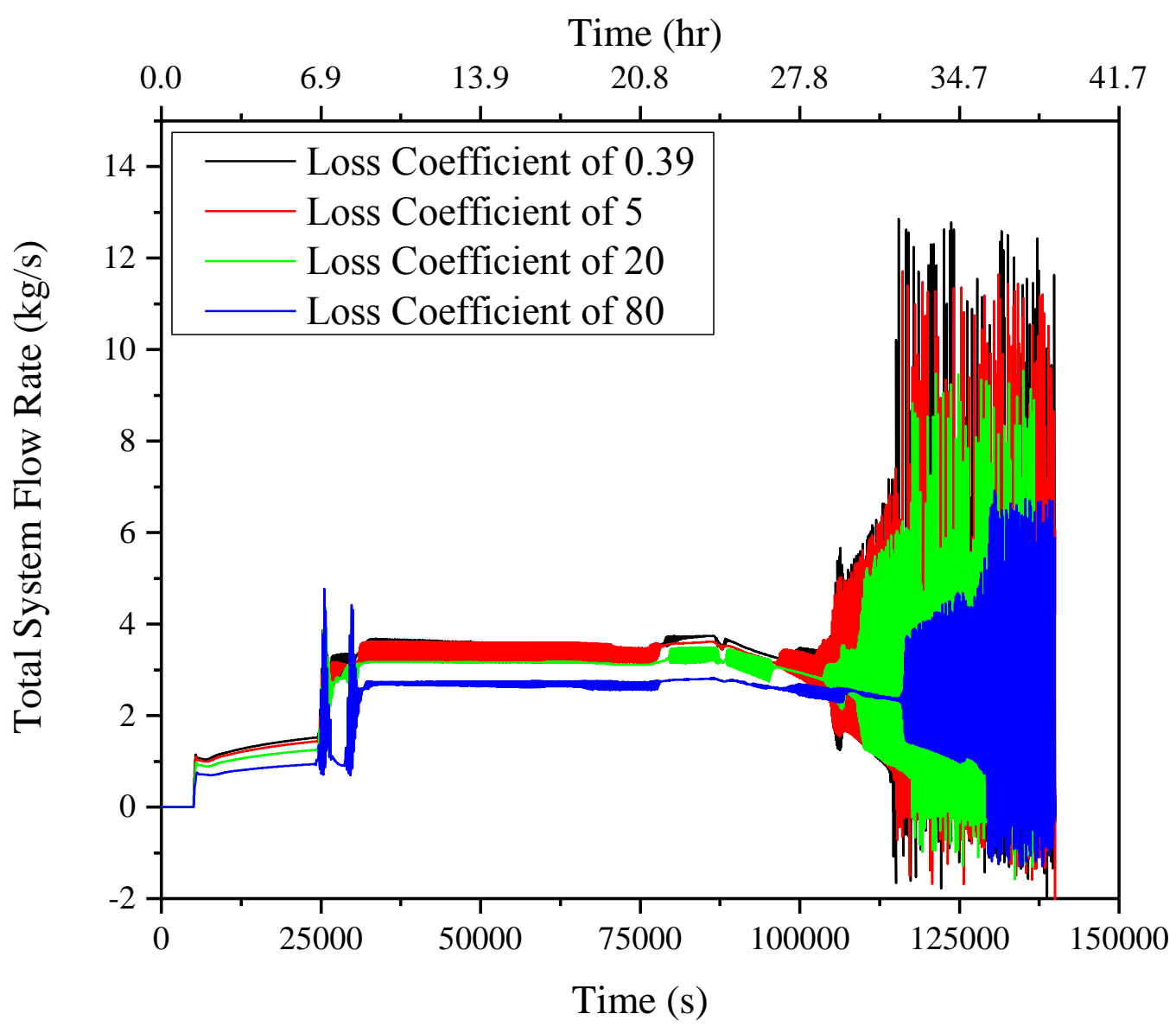

Figure 2-24: System total mass flow rates with varying riser tube assembly inlet throttling

For the last test in this category, the reference RELAP5 model was modified to include a Ushaped dip in the upper chimney, as shown in Figure 2-25. The dip is $0.5 \mathrm{~m}$ deep and $0.98 \mathrm{~m}$ wide. The system total mass flow rate with the added dip is shown in Figure 2-26. As can be seen, there is almost no effect on the system flow due to the additional u-shaped dip. A closer examination on the system flow, as shown in Figure 2-27 and Figure 2-28, both the single-phase and two-phase flows are reduced due to the additional flow resistance induced by the u-shaped dip. However, the effect is insignificant to be seen on Figure 2-26. 


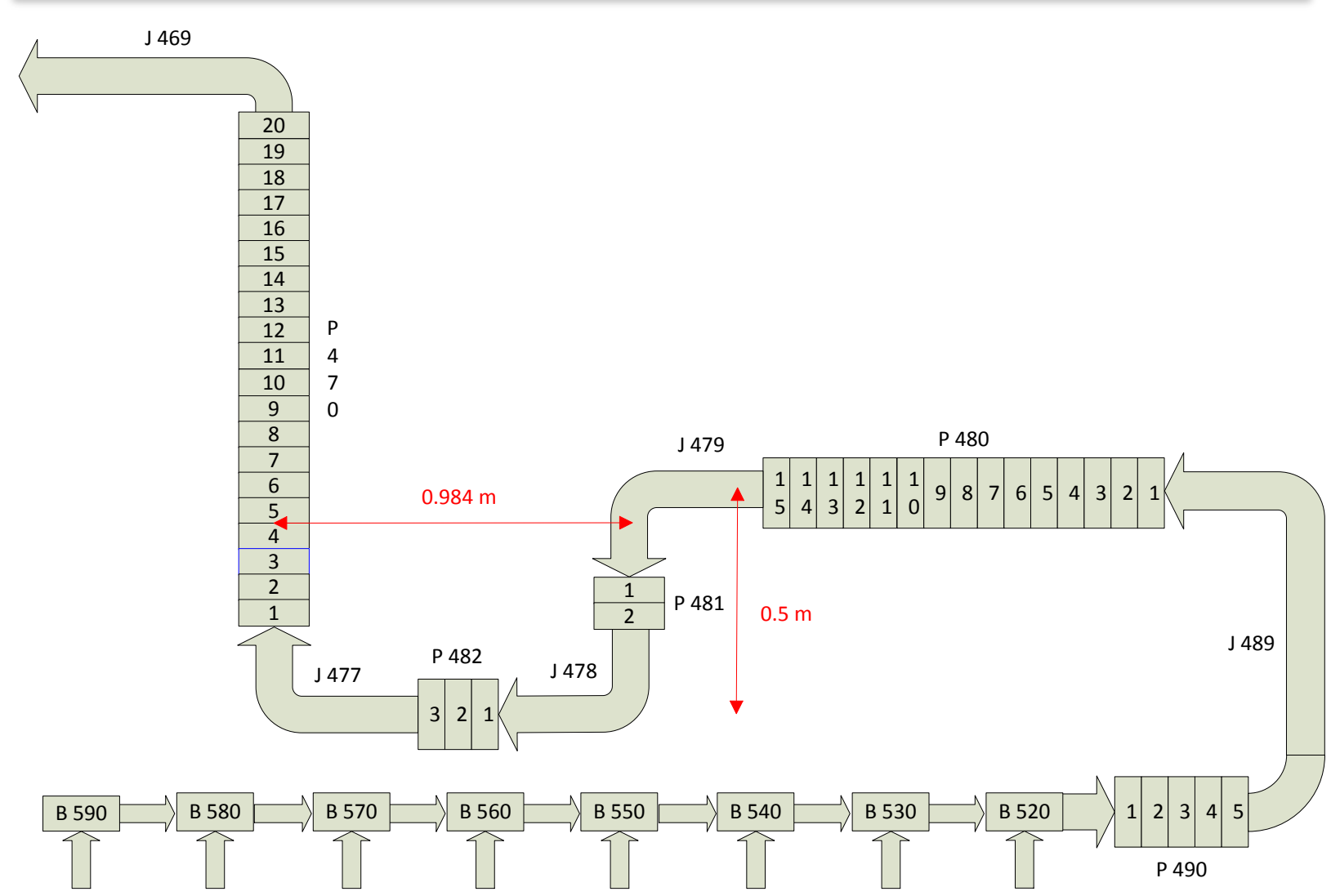

Figure 2-25: Modified RELAP5 model including a u-shaped dip in the upper chimney 


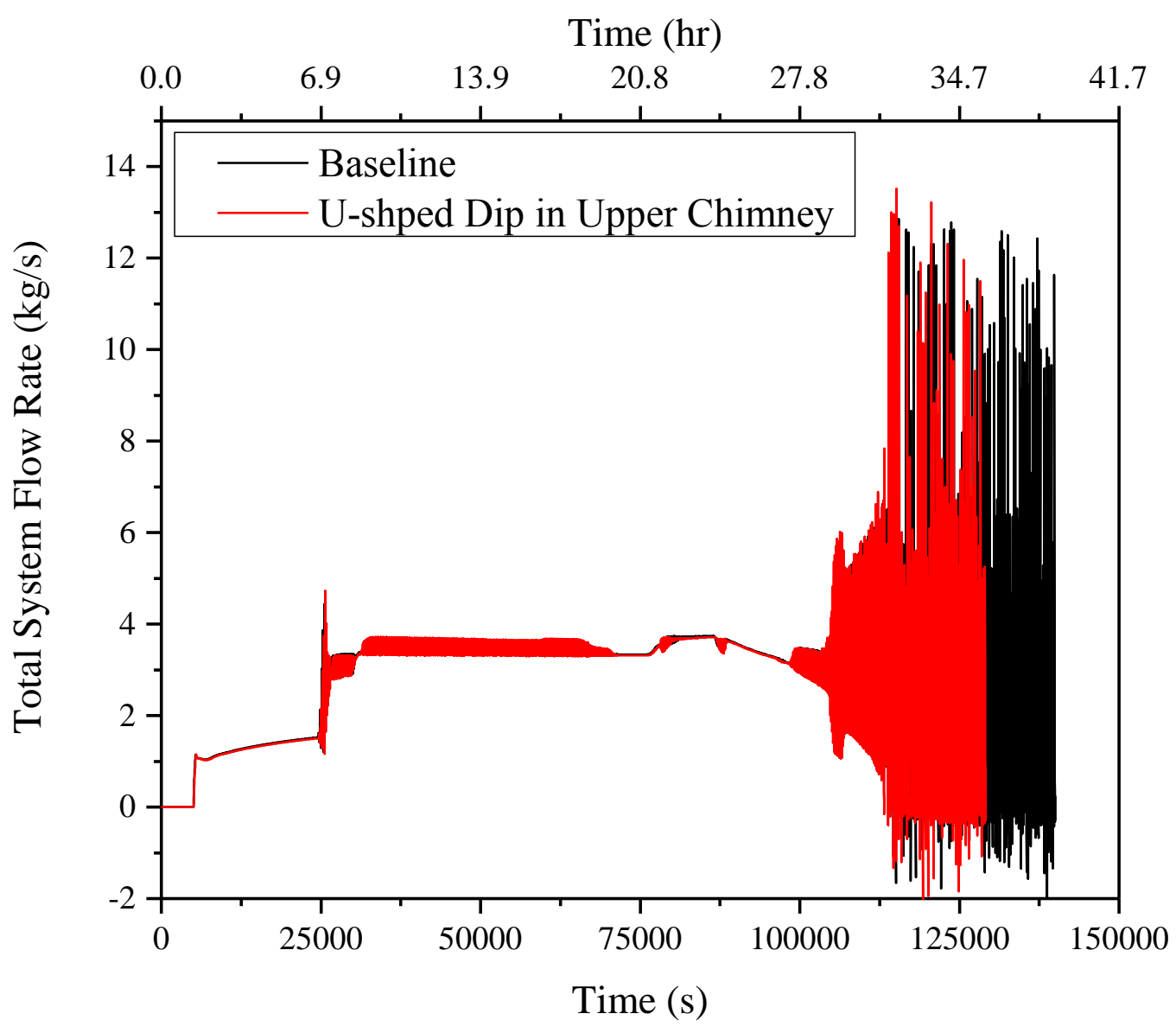

Figure 2-26: System total mass flow rate with u-shaped dip in the upper chimney 


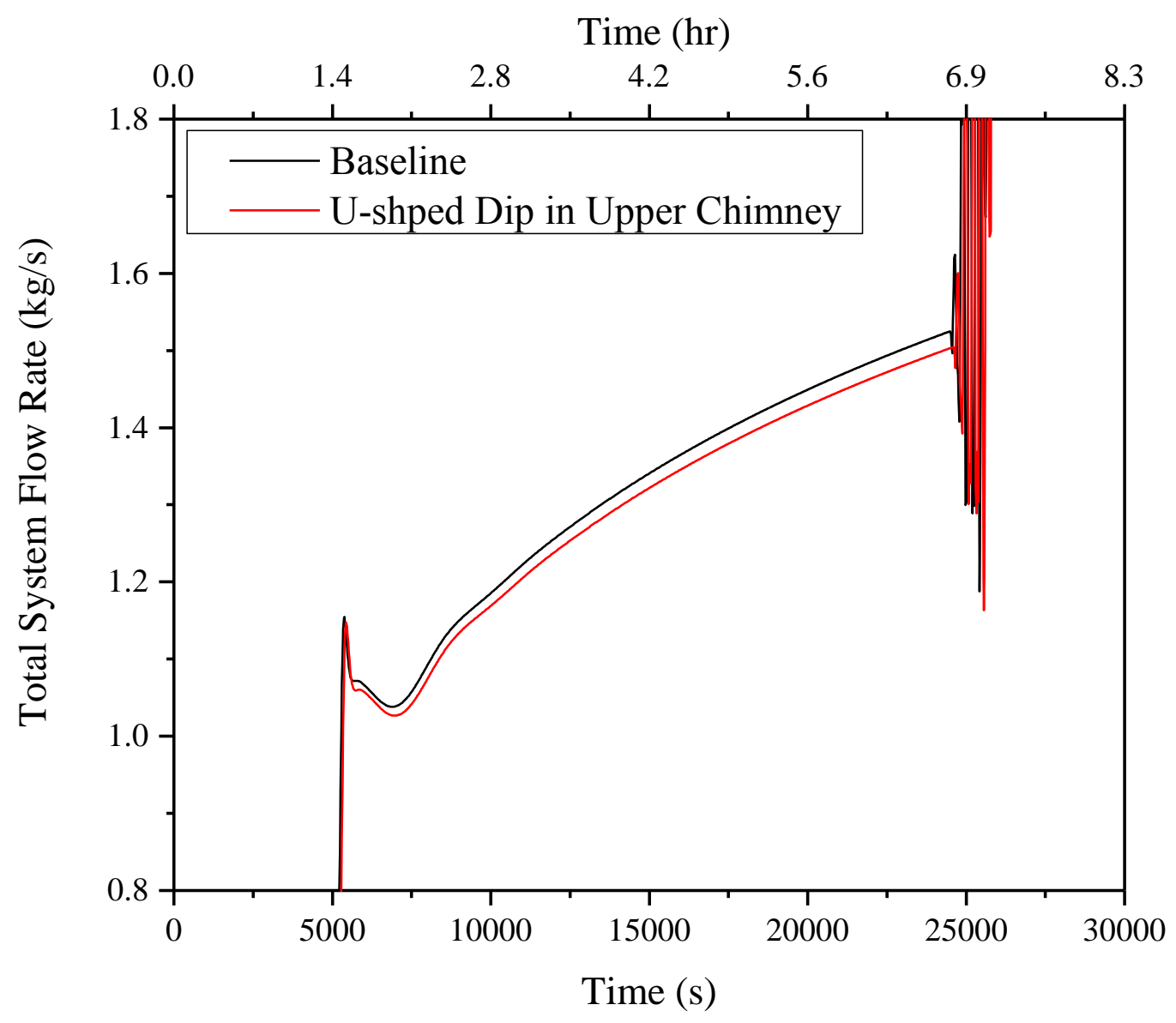

Figure 2-27: Single-phase flow with u-shaped dip in the upper chimney 


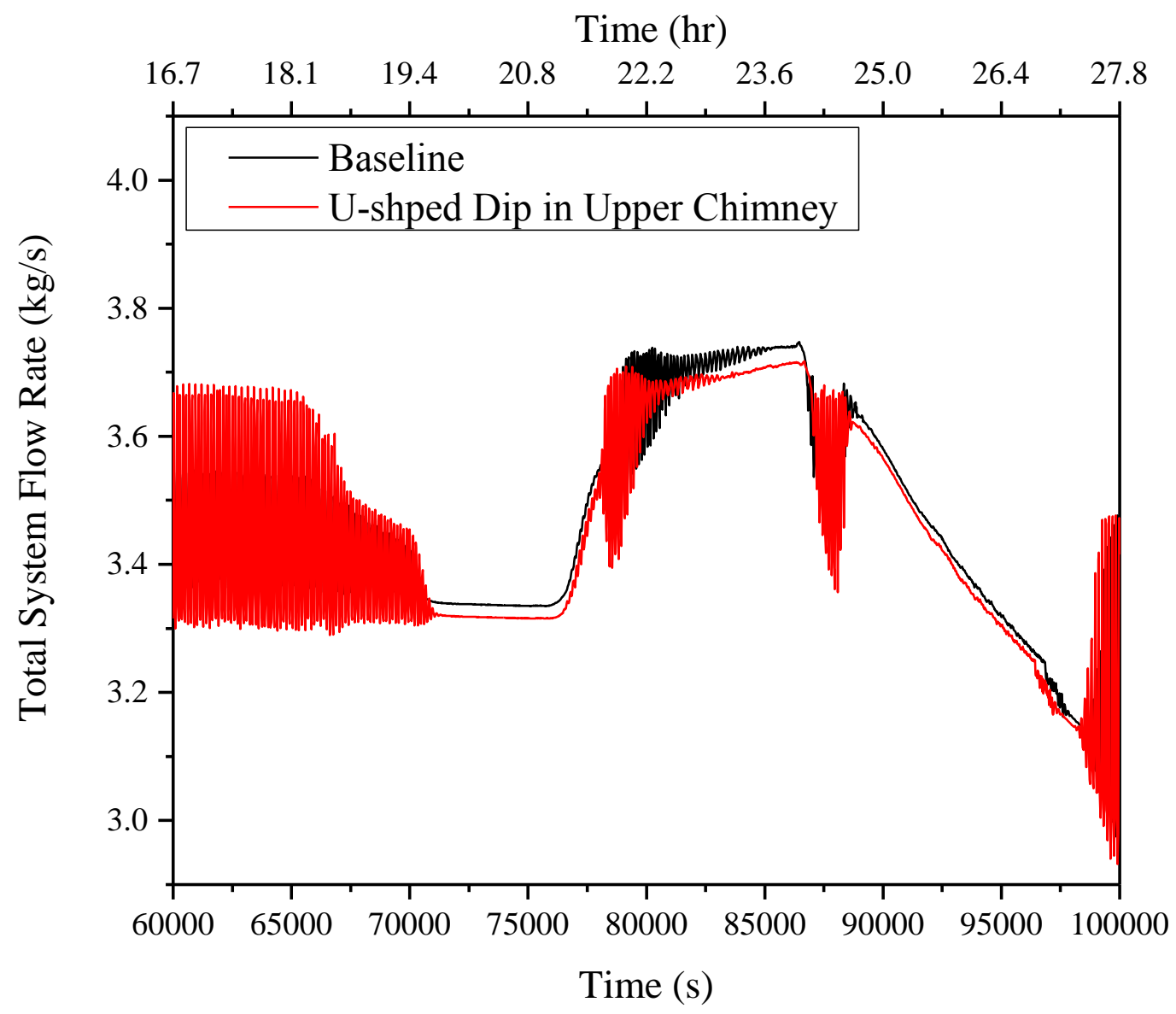

Figure 2-28: Two-phase flow with u-shaped dip in the upper chimney

\subsubsection{Test Section Material Selection}

In the reference RELAP5 model, the riser tubes and fins were modeled as a single unit without modeling the thermal conduction in between, and stainless steel was used for both the riser tubes and fins. However, it should be noted that, in the actual NSTF design, stainless steel riser tubes and carbon steel fins are employed [2-2]. To investigate the effect of the riser tube and fin material on the system behavior, a new model was developed in which carbon steel was used for the riser tubes and fins. The system total mass flow rates with the two different materials are compared as shown in Figure 2-29. Overall, the system flows with the two different materials are quite similar. Although carbon steel has better thermal conductivity, the transient in the present case is a slow process such that the overall heat transfer is more limited by the convection inside the riser tubes. Therefore, the difference in the material does not cause any significant difference in the total system flow. However, it should be noted that, using a material with higher thermal conductivity will help to reduce the structure temperature. Shown in Figure 2-30 is a comparison of the outer surface temperature at the center of the riser tube heated section between the two materials. As can be seen, carbon steel with better thermal conductivity results in a lower structure temperature. 


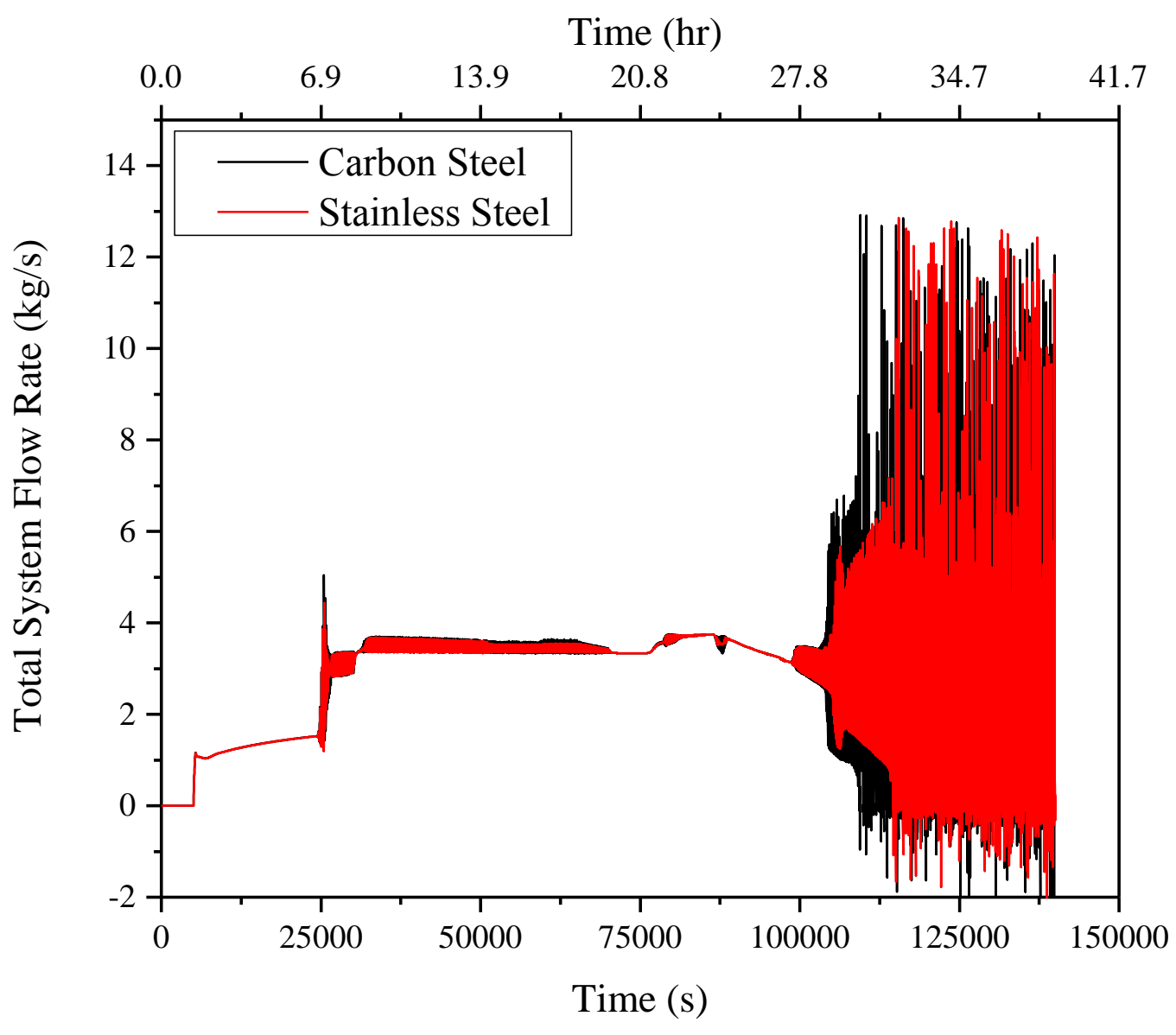

Figure 2-29: System total mass flow rates with different test section materials 


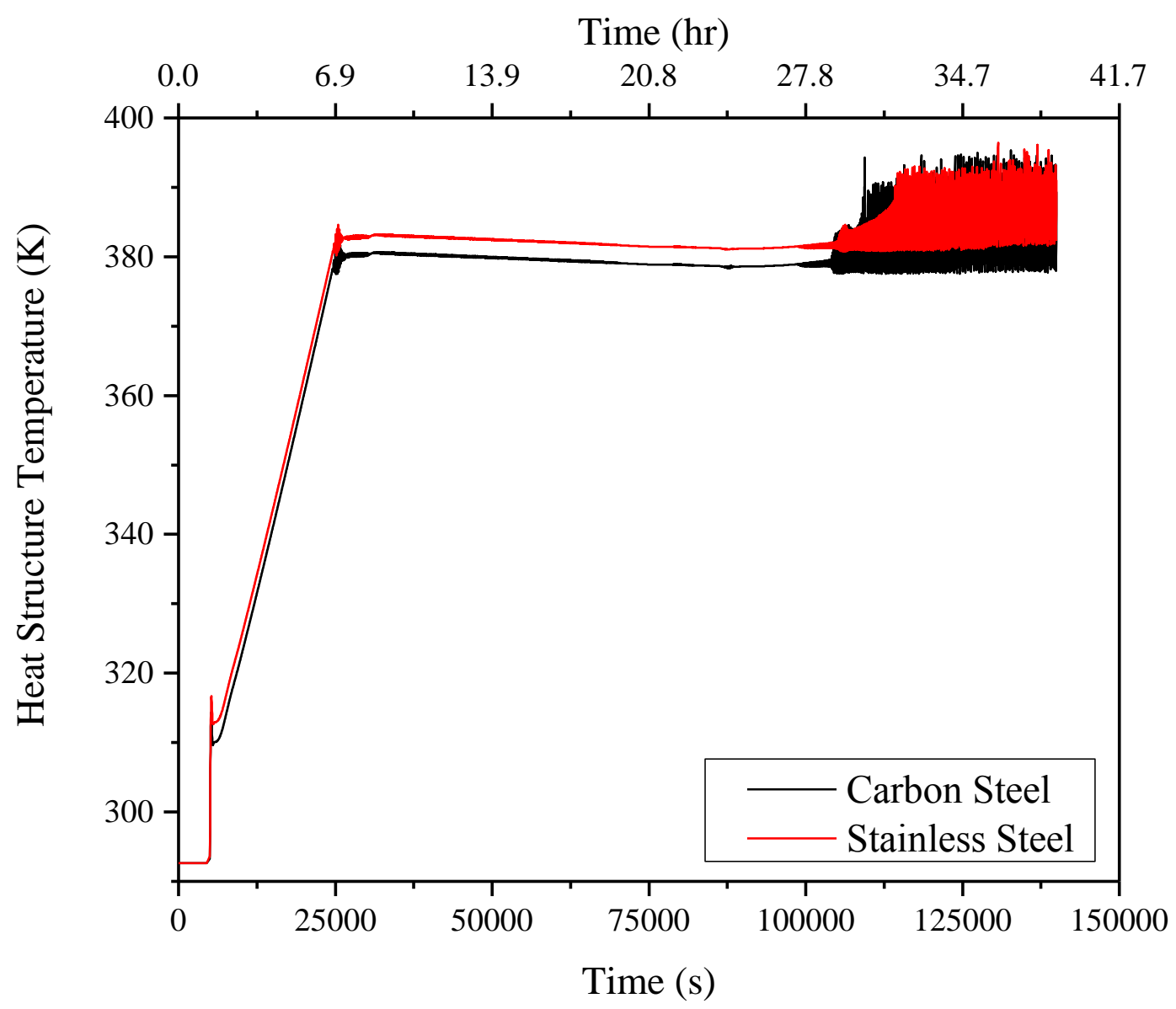

Figure 2-30: Outer surface temperature at the center of the riser tube heated section

\subsubsection{Water Tank Discharge}

The effect of the steam discharge resistance on the system behavior was also investigated. Three cases with different steam discharge resistance were examined. In the first case, a smooth transition from the inside of the water tank to the atmosphere with no form loss was assumed. In the second case, an 8 " nozzle with a user-specified form loss coefficient of 1.5 was assumed as the discharge port, while the last case employed a 0.25 " nozzle with a user-specified form loss coefficient of 1.5. The system total mass flow rates with varying water tank discharge resistance are shown in Figure 2-31. As can be seen, the single-phase flows in all three cases are quite similar. For the two-phase flow, only the case with the 0.25 " nozzle exhibits a significantly different behavior. During the single-phase stage, there is no drastic vapor generation, and therefore, the tank cover gas pressure or the system pressure are not significantly different in the three cases, as shown in Figure 2-32. Therefore, the single-phase flows as well as initiation of flashing in the three cases are similar. However, once flashing initiates, due to the large vapor generation, the 0.25 " nozzle with high flow resistance causes a significant elevated system pressure, as shown in Figure 2-32. The elevated system pressure first causes a suppression of the flashing and thus the system flow, but once the flashing re-initiates, the system flow starts to increase again. As can also been seen, the two-phase flow increases with the increase in the 
system pressure, which is consistent with the findings in previous parametric study on the effect of the system pressure.

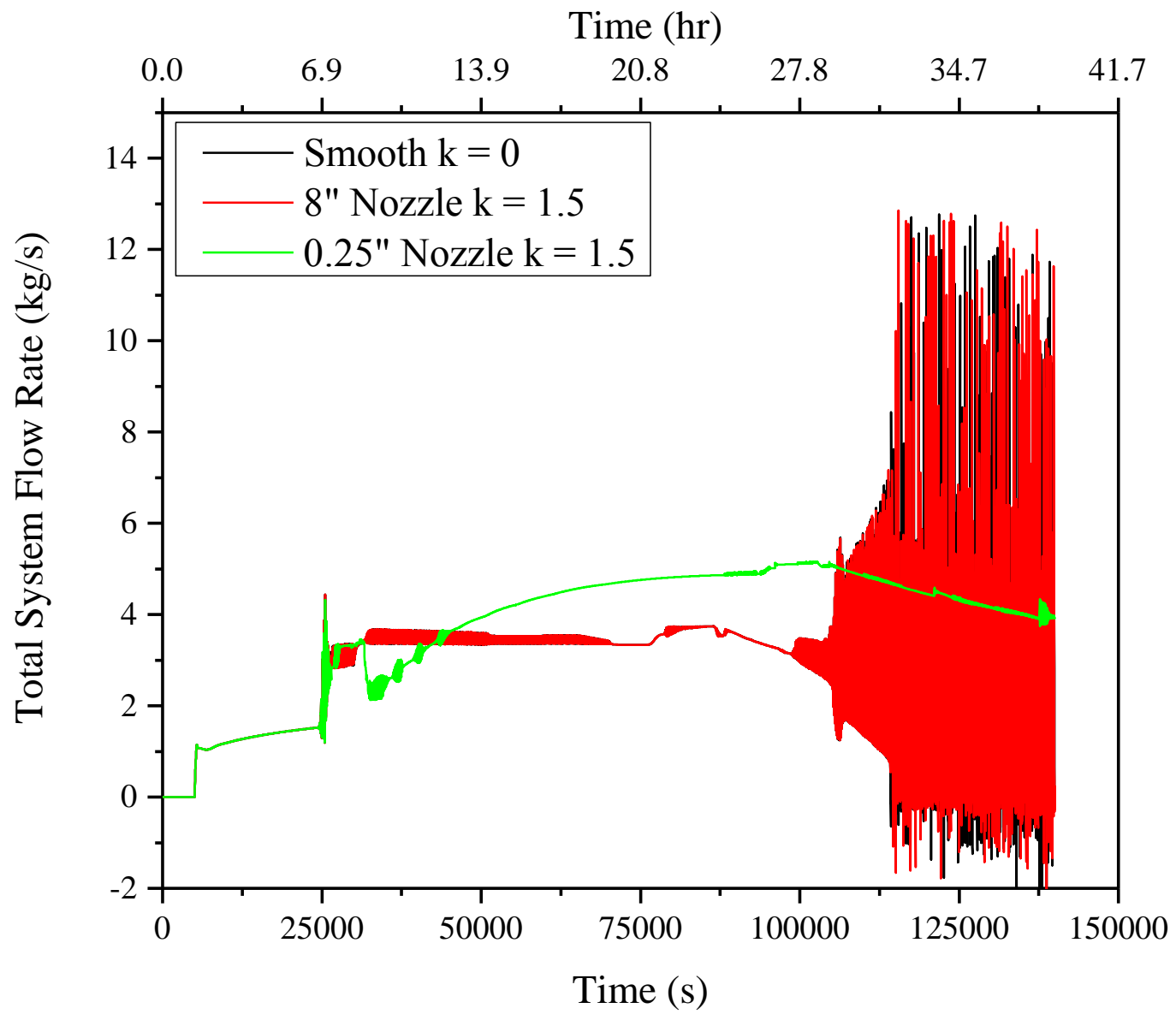

Figure 2-31: System total mass flow rates with varying water tank discharge resistance 


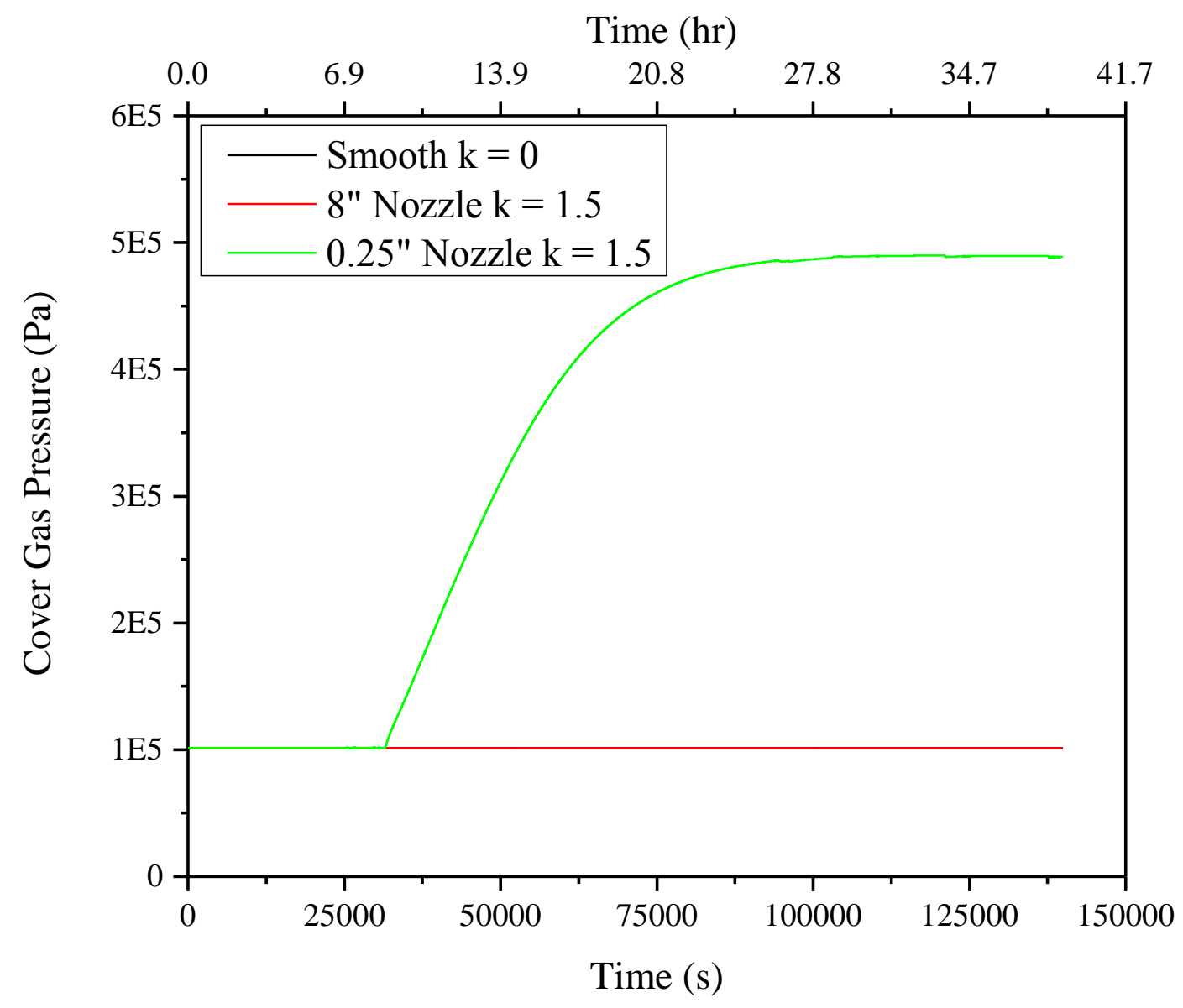

Figure 2-32: System pressure with varying water tank discharge resistance

\subsection{Scaling Check for the Water-based NSTF}

The Argonne water-based NSTF was intended to be a $1 / 2$ scale test facility based on the AREVA conceptual RCCS design [2-6]. The operation conditions used in the previous parametric study were determined based on the scaling ratio given in [2-2], which is also summarized in Table 2-1. Due to various constraints, the Argonne water-based NSTF was not strictly scaled according to the scaling ratio, and would cause some distortions. To examine the distortions, RELAP5 model of an ideal $1 / 2$ scale test facility rigorously scaled from the AREVA conceptual RCCS design was developed. The baseline two-phase test was then simulated for the ideal design, and the results were compared with those of the water-based NSTF to examine the distortions. It should be noted that, the AREVA conceptual RCCS design is not finalized, and detailed information on the design is limited. Reasonable assumptions were made wherever necessary. It should also be noted that, the scaling check presented here is not meant to be a detailed and thorough study, but a preliminary and quick check to provide some qualitative idea on the distortions. 
Table 2-1: Scaling ratio for NSTF compared to AREVA conceptual RCCS design

\begin{tabular}{lcc}
\hline & Relationship & Ratio \\
\hline Axial Length & $l_{R}$ & 0.5 \\
Radial Length & 1 & 1.0 \\
Power & $\sqrt{l_{R}}$ & 0.707 \\
Heat Flux & $l_{R}{ }^{-0.5}$ & 1.414 \\
Flow Rate & $\sqrt{l_{R}}$ & 0.707 \\
Temperature & 1 & 1.0 \\
Time & $\sqrt{l_{R}}$ & 0.707 \\
\hline
\end{tabular}

Based on the information available from [2-6] and reasonable engineering assumptions, a conceptual $1 / 2$ scale RCCS test facility design was developed, as shown in Figure 2-33. The sources of the dimensions shown in Figure 2-33are summarized in Table 2-2. For the prototypic tank design, there were no detailed information provided in [2-6], except for the distance from the inlet nozzle to the tank bottom. The distance from the tank inlet nozzle to the water surface inside tank $(4.75 \mathrm{~m})$ was determined based on the statement in [2-6] that "It is anticipated that the Downcomer will exit the tank through the bottom and that the Hot Leg horizontal run will enter the tank 0.5 meters above the tank bottom. This sizing includes an allowance for a residual volume of approximately $5 \%$ of the tank total volume remaining in the tank when natural circulation is interrupted by uncovering of the hot leg". The water tank inner diameter $(2.57 \mathrm{~m})$ was determined in two steps. First, based on the statement in [2-6] that "The preliminary sizing of the RCCS water storage tanks is based on providing 7 days of decay heat removal by the RCCS with only one of the two RCCS loops in operation and no heat removal from the tank by the RCCS Tank Cooling subsystem", the inner diameter of the prototypic water tank design was sized to be $9.74 \mathrm{~m}$. Second, the prototypic RCCS design contains a total of 230 riser tubes [2-6], which are too many to be modeled in RELAP5. Instead, only 8 riser tubes were modeled for the conceptual RCCS test facility, and the total power and the water tank inner diameter (i.e., water inventory) were scaled accordingly, resulting in an inner diameter of $2.57 \mathrm{~m}$ for the water tank. Lastly, the inner diameter of the piping system was not specified for the prototypic RCCS design in [2-6], and a 4" Sch 40 pipe was assumed, which would give a flow area similar to the total flow area of the 8 riser tubes. 


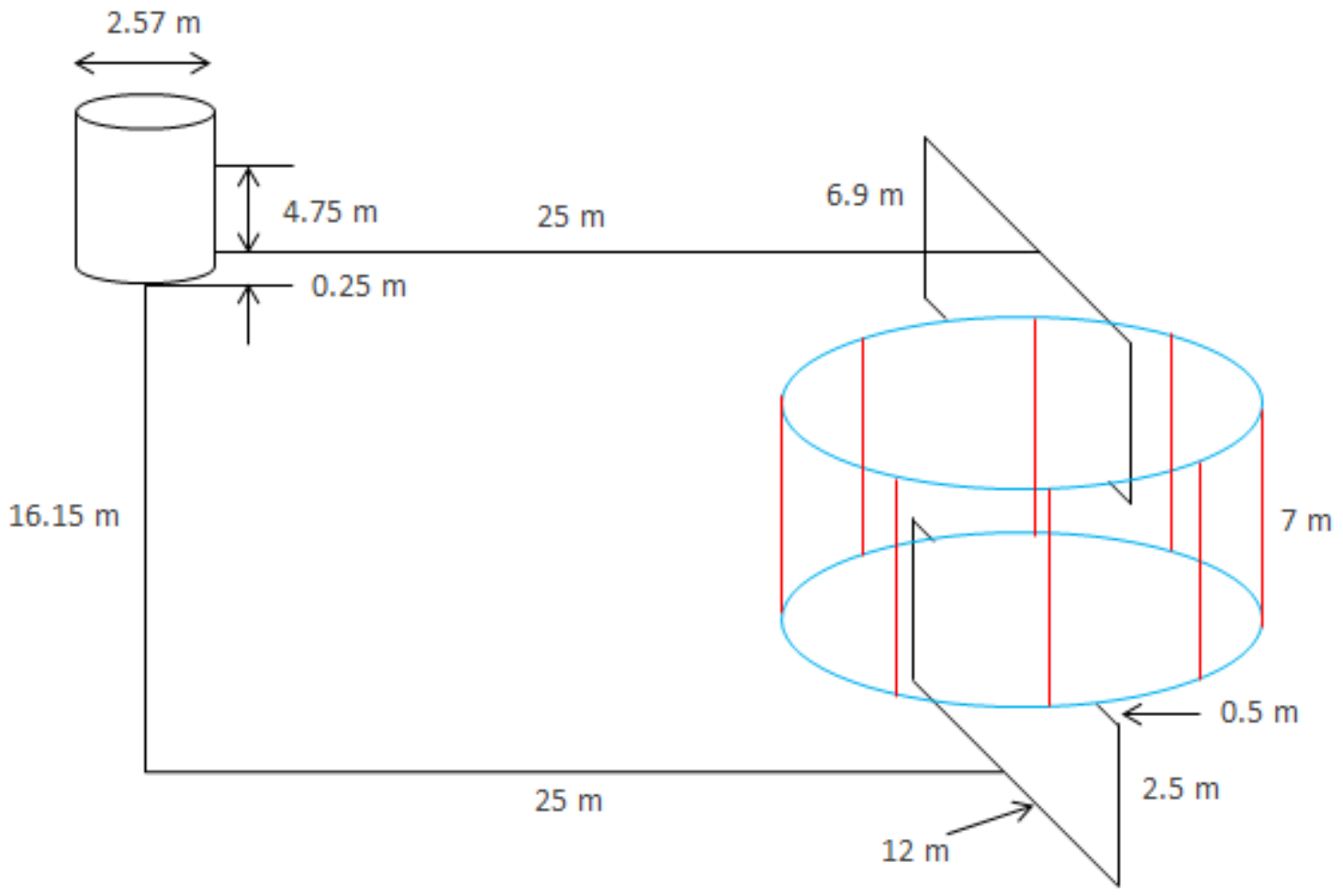

Figure 2-33: Schematic of the conceptual 1/2 scale RCCS test facility

Table 2-2: Dimensions of the conceptual 1/2 RCCS test facility

\begin{tabular}{lcc}
\hline & Value & Source \\
\hline Downcomer, m & 16.15 & {$[2-6]$} \\
Horizontal piping, m & 25 & {$[2-6]$} \\
Header horizontal piping 1, m & 12 & Assumption \\
Header vertical piping, m & 2.5 & {$[2-6]$} \\
Header horizontal piping 2, m & 0.5 & Assumption \\
Riser tube, m & 7 & {$[2-6]$} \\
Tank inlet to bottom, m & 0.25 & {$[2-6]$} \\
Tank inlet to water surface, m & 4.75 & {$[2-6] \&$ Assumption } \\
Tank inner diameter, m & 9.74 & {$[2-6] \&$ Assumption } \\
\hline
\end{tabular}

The system total mass flow rates of the baseline two-phase test for the conceptual RCCS test facility and the Argonne water-based NSTF are compared as shown in Figure 2-34. Despite the larger water inventory in the water tank of the conceptual RCCS test facility, due to the same height of thermal mixing region of the water tank adopted in the present RELAP5 models for the two test facilities, initiation of flashing was predicted to occur at similar times. However, the larger water tank inventory in the conceptual RCCS test facility does cause a delay in the development of the two-phase quasi-steady state, and a longer time scale for the two-phase transient. This is mainly due to the difference in tank scaling. The $1 / 2$ scale conceptual RCCS design employs a larger tank than that in the water-based NSTF design, which causes an extended two-phase transient for the former design. As can be seen from Figure 2-34, there are some 
distortions in the single-phase natural circulation flow, which are partially due to the distortions in the vertical height scaling, as summarized in [2-2]. A plot of the ratio of the single-phase flow (water-based NSTF to conceptual RCCS test facility) signifying the magnitude of distortions is shown in Figure 2-35. Except for the large fluctuations when the flow initiates, the ratio stays stable over the majority of the single-phase period. The average distortions in the single-phase and two-phase quasi-steady-state flows are summarized in Table 2-3, as seen to be less than $13 \%$.

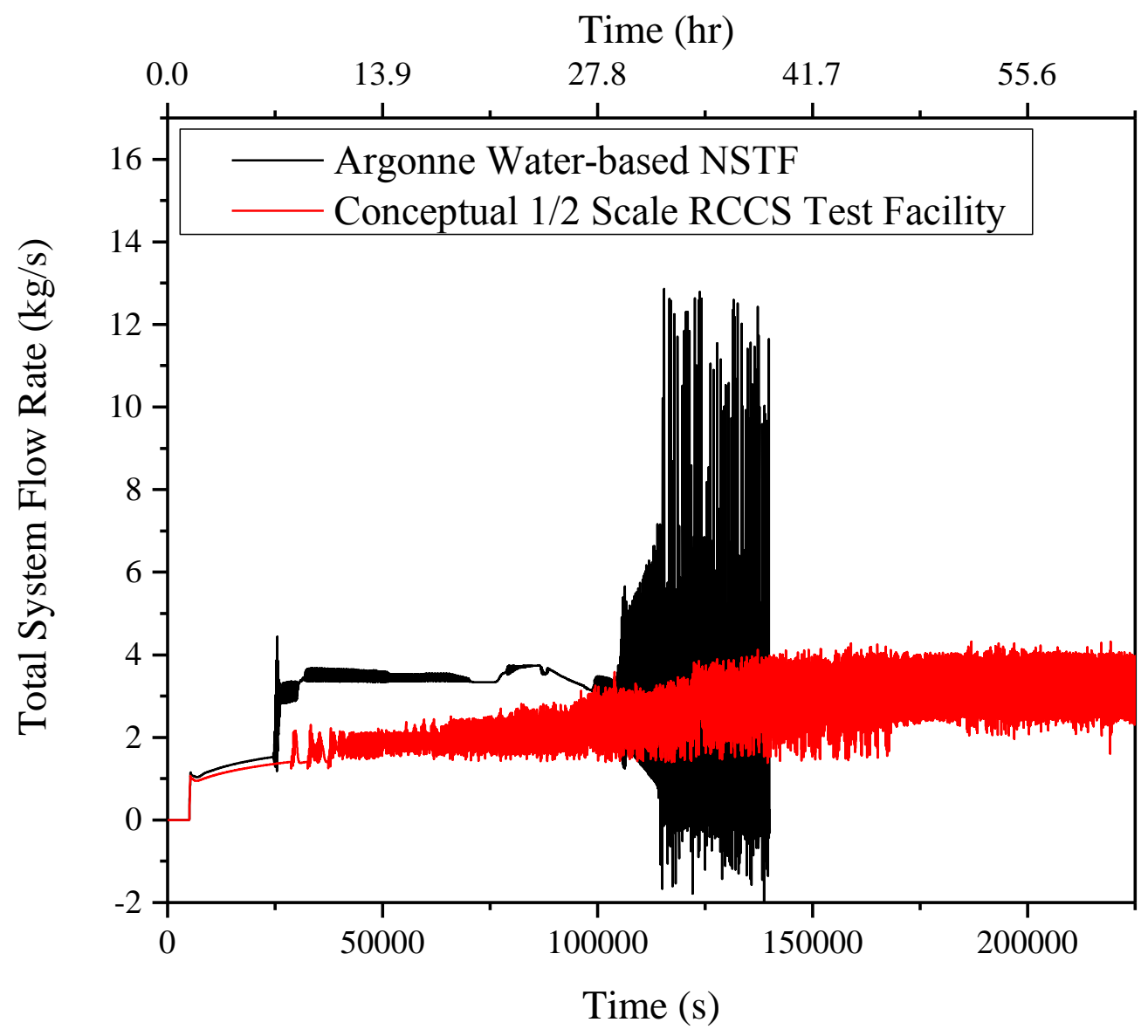

Figure 2-34: Total system mass flow rates of the baseline two-phase test for the conceptual RCCS test facility and the water-based NSTF 


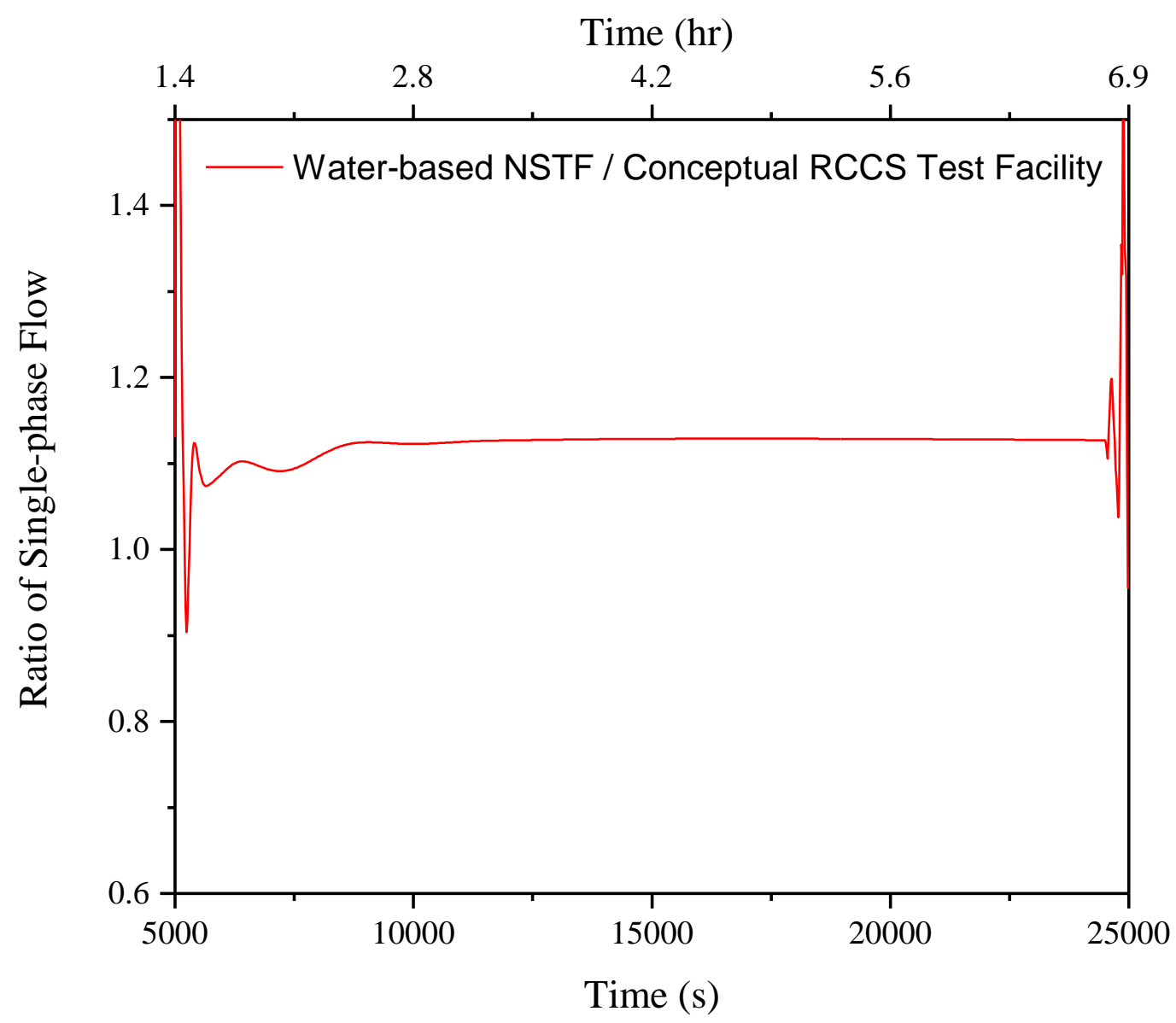

Figure 2-35: Distortions in single-phase natural circulation flow

Table 2-3: Distortions in the single-phase and two-phase flow rates

\begin{tabular}{lc}
\hline & Ratio (Water-based NSTF / Conceptual RCCS) \\
\hline Single-phase flow & 1.128 \\
Two-phase quasi-steady-state flow & 1.101 \\
\hline
\end{tabular}

\subsection{Summary}

In FY17, efforts were dedicated to developing a RELAP5 model for the Argonne water-based NSTF. A reference RELAP5 model was determined based on a tank modeling study, which investigated the thermal mixing inside the water tank, and the connection between the inlet nozzle and the water tank. Due to the fact that RELAP5 is not capable of modeling the three-dimensional phenomenon inside the water tank, an artificial thermal mixing region had to be developed to simulate the three-dimensional effect. The height of the thermal mixing region that affects the initiation of flashing will need to be benchmarked against the experimental data once available. In addition, because RELAP5 is not able to track the water level inside a volume, the connection of the tank inlet nozzle to the tank had to be made at the bottom of the thermal mixing region. This is important as the way the connection is made will affect when the system flow starts to 
decrease. With the reference RELAP5 model determined, a parametric study on the effects of varying operation conditions and system configurations on the system behaviors was performed. The study results will provide some insights on the system behaviors and guidance on the system operations before starting any real experiments. Lastly, a scaling check was performed on the water-based NSTF to examine any distortions. A conceptual 1/2 scale RCCS test facility was first developed based on available information from the AREVA design report [2-6] as well as some reasonable assumptions. A RELAP5 model was subsequently developed for the conceptual RCCS design. The baseline-two phase test was simulated for the conceptual RCCS test facility and the Argonne water-based NSTF, and the results were compared. It was found that the distortions in both the single-phase and two-phase flow rates are less than $13 \%$.

In FY18, the RELAP5 model for the water-based NSTF will first be updated to reflect the asbuilt dimensions of the test facility. A mesh sensitivity study will then be performed to determine the proper mesh size. Depending on the availability of data from any separate effect test, the RELAP5 model will be benchmarked against the data to determine the proper pressure drop and heat transfer models. In addition, a U tube problem will be investigated to determine the capability of RELAP5 in modeling bouncing flows.

\section{References}

[2-1] R. Hu, A. Kraus, M. Bucknor, Q. Lv, and D. Lisowski, "Final Project Report on Computational Modeling and Analysis of Air-Based NSTF," ANL-ART-46, Argonne National Laboratory, 2016.

[2-2] D. Lisowski et al., Argonne National Laboratory, unpublished information, 2015.

[2-3] J.A. Boure, J.E. Bergles, and L.S. Tong, "Review of Two-phase Flow Instability," Nuclear Engineering and Design, vol. 25, pp. 165-192, 1973.

[2-4] M. Furuya, F. Inada, and T.H.J.J. Van Der Hagen, "Flashing-induced Density Wave Oscillations in a Natural Circulation BWR - Mechanism of Instability and Stability Map," Nuclear Engineering and Design, vol. 235, pp. 1557-1569, 2005.

[2-5] D. Lisowski et al., Argonne National Laboratory, unpublished information, 2017.

[2-6] "RCCS Designer Input Report," Document No.: 12-9239789-000, AREVA, 2014. 


\section{Water-Cooled NSTF CFD Analyses}

\subsection{CFD Model Description}

CFD analyses of the water-cooled NSTF were performed using STAR-CCM+ v11.06 [3-1] with a focus on isolated areas of the system. A notable area of interest was the cavity region. This area is a good candidate for CFD analysis due to the multi-dimensional flow and heat transfer, which are not simulated directly by RELAP5. CFD simulations allow for the estimation of the boundary heat flux distribution along the riser tubes, which should better inform the temperature predictions in system-level RELAP5 analyses. The results could also provide additional data to help establish what level of modeling detail is necessary in the RELAP5 model. Also, the tube/fin temperatures can be more accurately calculated in CFD, particularly near the edges.

Analyses at this stage were focused on single-phase flow, with boundary conditions suggested by Table 9 of [3-2]. These runs are assumed to be quasi-steady-state, as temperature and flow conditions should only change very slowly over the course of the transient. The geometry layout of the CFD model is provided in Figure, and was based on the design drawings from [3-3]. Inside of the tubes is water, and the cavity contains air. The tubes and fins are of different materials and have different thermal properties. The tube/fin apparatus is not as wide as the heated cavity, and so there is insulation affixed to one side of the first and last fins in order to remove this gap. This effectively isolates the cavity into two regions: the heated side, and the "cold" side. Both of these are simulated in the model. For future flexibility, the entire width of the cavity was modeled, i.e. no symmetry condition was employed.
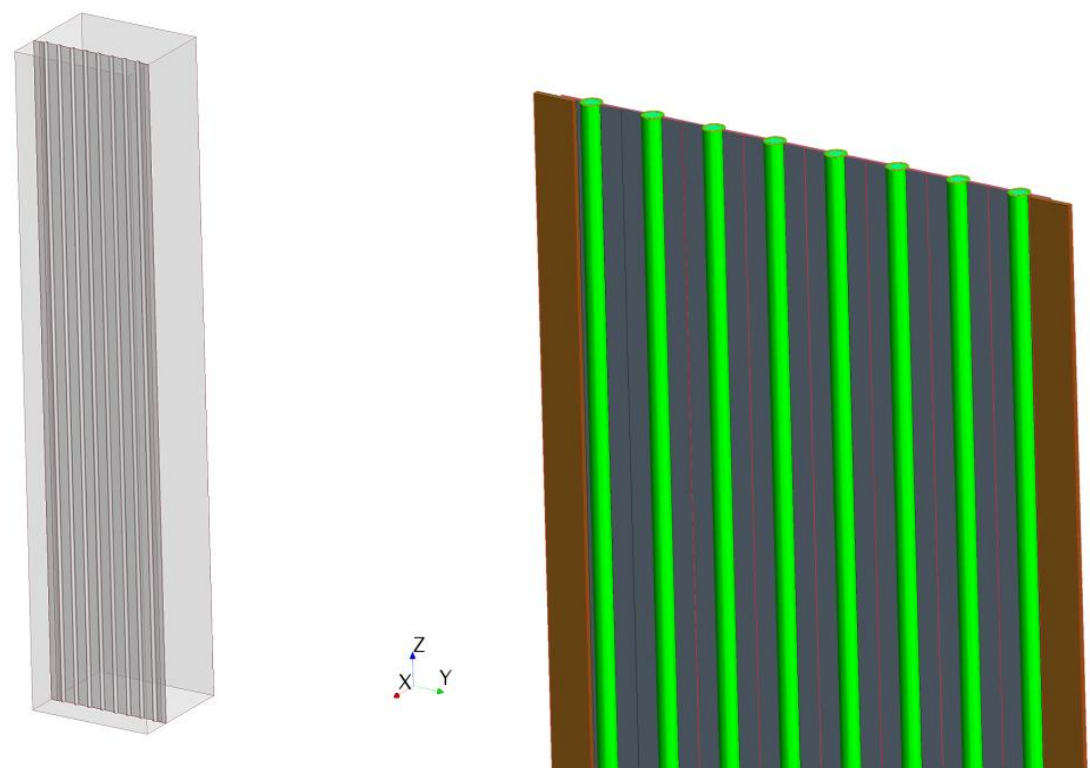

Figure 3-1: CFD domain geometry; Zoomed view on right shows tubes (green), fins (gray), and insulation (brown)

Given that the rest of the water-cooled NSTF is geometrically diverse and relatively more complicated than for the air-cooled case, and considering computation time, it was not considered 
of significant benefit to simulate the entire system at this early design stage. For this reason, the CFD domain only spans from the top to the bottom of the heated cavity. This was also deemed suitable given that the water flow was modeled with a fixed flow rate in these initial calculations.

Thermal properties for the various solid materials are provided in Table 3-1 [3-2]. The air properties were based on Sutherland's Law. A segregated solver approach was used. Radiation was solved in the cavity using a surface-to-surface, gray method. An ideal gas equation of state was used for the air, which provided a temperature-dependent density for evaluating buoyancy. Water properties were assumed constant given the small temperature change. Inlet temperature was fixed at $303.15 \mathrm{~K}$, and outlet temperature was set such that the system had a $15 \mathrm{~K}$ increase. Given these values and the specific heat, the inlet mass flow rate for each tube was set at 0.0675 $\mathrm{kg} / \mathrm{s}$, or $0.54 \mathrm{~kg} / \mathrm{s}$ through the whole apparatus, to achieve the required heat removal.

Table 3-1: Thermal properties for solid materials in the CFD model

\begin{tabular}{|c|c|c|c|c|}
\hline Component & Material & $\begin{array}{c}\text { Density } \\
\left(\mathrm{kg} / \mathrm{m}^{3}\right)\end{array}$ & $\begin{array}{c}\text { Specific Heat } \\
(\mathrm{J} / \mathrm{kg} / \mathrm{K})\end{array}$ & $\begin{array}{c}\text { Thermal Conductivity } \\
(\mathrm{W} / \mathrm{m} / \mathrm{K})\end{array}$ \\
\hline Fins & $\begin{array}{c}1018 \\
\text { carbon steel }\end{array}$ & 7832 & 434 & 51.9 \\
\hline Tubes & $316 \mathrm{~L}$ & 8000 & 502 & 16.0 \\
\hline Insulation & Cerablanket & 128.5 & 1000 & 0.1022 \\
\hline
\end{tabular}

Given the detailed welding of the fins and tubes [3-4], no contact resistance was employed in the model. The heated wall has a constant heat flux of $3839 \mathrm{~W} / \mathrm{m}^{2}$. All other cavity walls were treated as adiabatic. Conjugate heat transfer was simulated throughout the entire domain: air, tubes, fins, insulation, and water.

A Reynolds-Averaged Navier-Stokes (RANS) approach was used to handle turbulence. In the water, the Realizable Two-Layer k- $\varepsilon$ model was used with a high-y+ type mesh. Given the relatively simple flow through a circular tube this was deemed appropriate. For the cavity flow, it was established in prior work that the near-wall mesh resolution had more impact on the results than the particular turbulence model used [3-5]. For this reason, a fine wall mesh was used. Two turbulence models were tested: the Realizable Two-Layer k- $\varepsilon$ model and the v $2 \mathrm{f}$ model. A very fine overall mesh was used for the v2f model to test whether this had any impact.

The directed mesher was used to provide a high-quality mesh. An unstructured quad mesh was generated for all regions, then swept axially. This generates high-quality hexahedral cells while also reducing the mesh count compared to other entirely unstructured meshers. The mesh was conformal at all material interfaces. Pictures of the two meshes generated are provided in Figure 3-2. The base mesh had 6.8M cells, while the very fine mesh had $14.6 \mathrm{M}$ cells. Cell sizes were such that there were at minimum two cells through the thickness of each solid structure. 

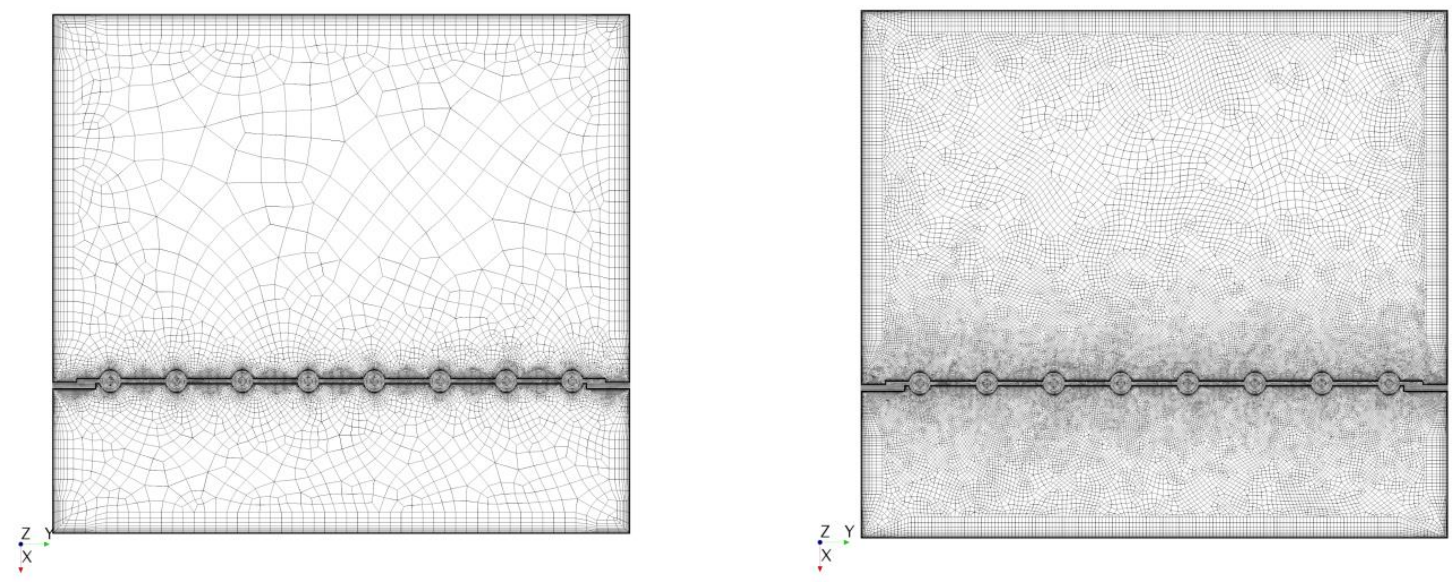

Figure 3-2: Views of the mesh at the axial midplane for the base case (top L), fine case (top R), and zoomed base case (bottom)

\subsection{Simulation Results}

Figure 3-3 shows the velocity magnitude at the axial midplane for the two turbulence models. Figure 3-4 also shows the velocity magnitude at the lateral midplane of the structure. There are only small differences in the profiles, and these are in relatively low-flow areas. The flow profiles are simpler than for the air-cooled case, as the walls are now all relatively flat. This results in relatively simple momentum and thermal boundary layers. For these reasons, the base mesh will be the focus in the results here, and will be used in future work. 

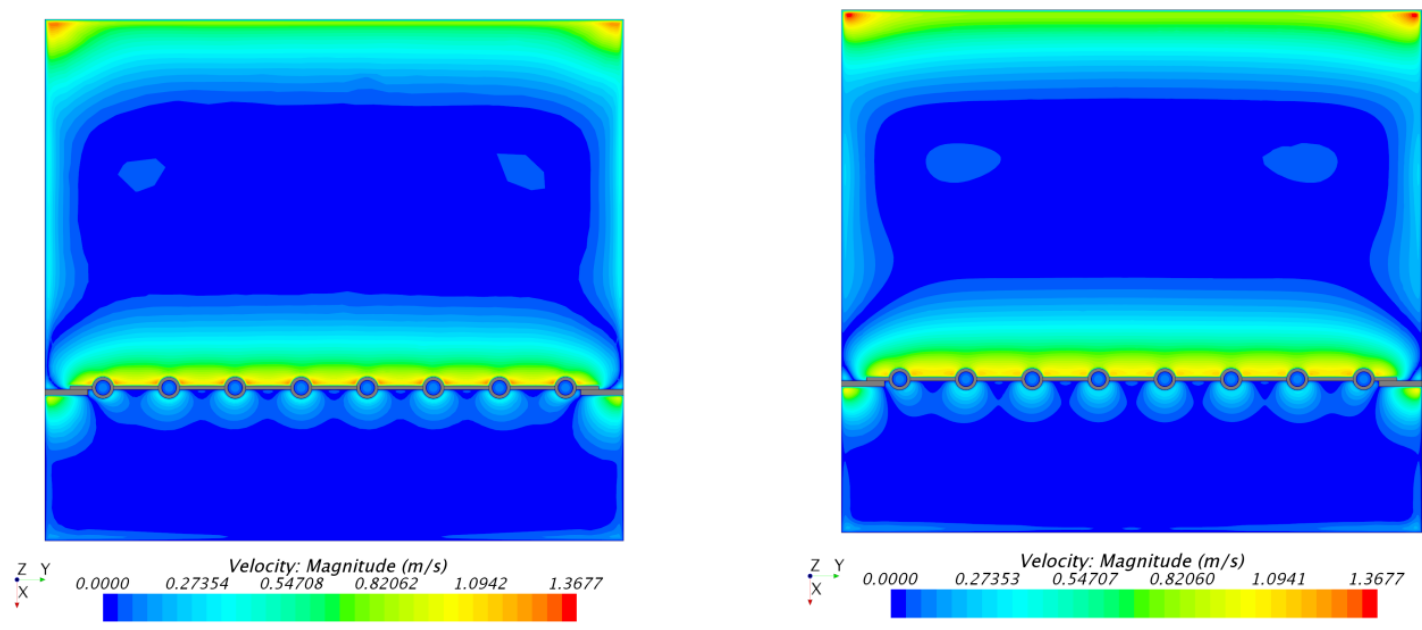

Figure 3-3: Velocity magnitude at the axial midplane for the base case $(\mathrm{L})$ and fine case $(\mathrm{R})$

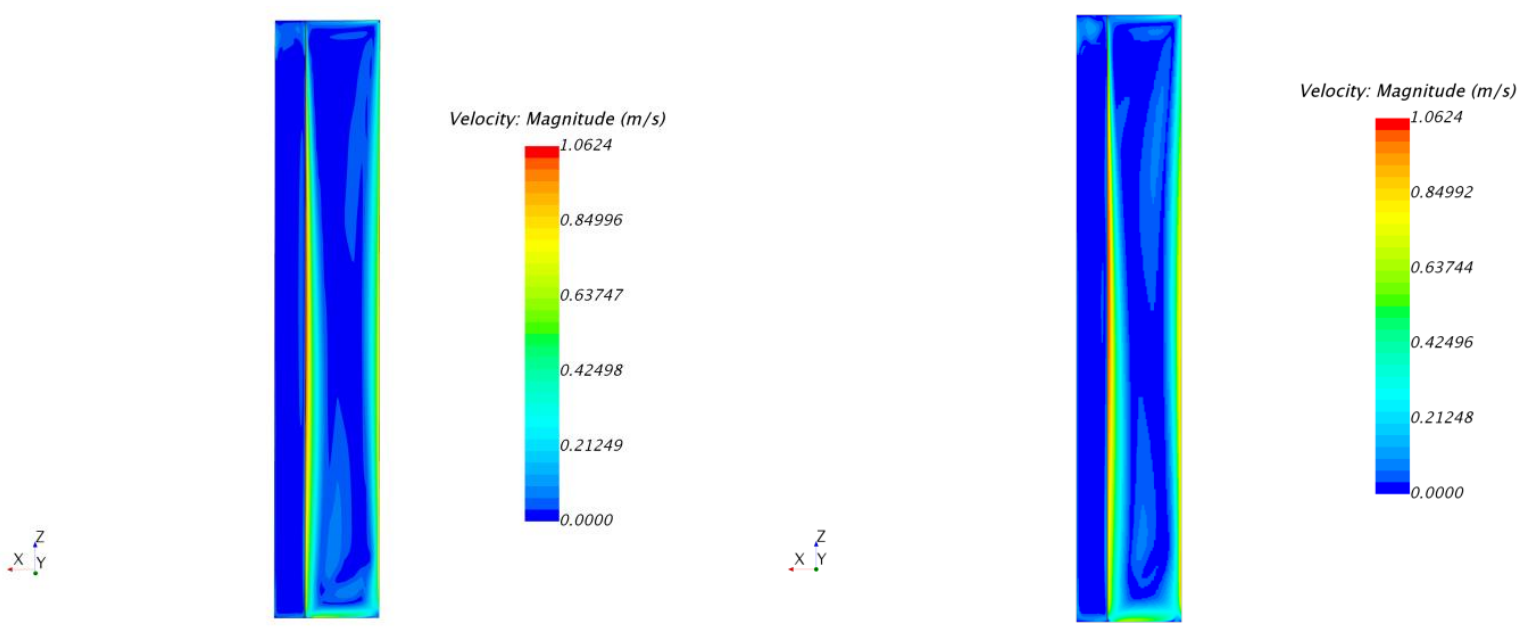

Figure 3-4: Velocity magnitude at the lateral midplane for the base case (L) and fine case (R)

Figure 3-5 shows the boundary heat flux through the tube/fin surfaces in the heated side of the cavity. The local heat flux noticeably increases axially, and is higher in the fins than in the tubes. These values were passed to given to the RELAP5 team to improve the detail of the models.

Figure 3-6 to Figure 3-8 show the temperature profiles at the axial midplane, along the hot side of the tubes, and also along the top surface where the peak temperatures are. There is a thin thermal boundary layer along each surface. Temperatures are higher in the fins than the tubes, but the maximum difference was only $22{ }^{\circ} \mathrm{C}$, and thus within design limits for thermal stresses [3-2]. Temperatures are higher in the edge fins in part due to additional radiation through the side of the fin and from the side cavity walls, but the peak temperatures are below $100^{\circ}$. While further work could be performed in this area for the peak conditions as predicted by RELAP5 (e.g. higher water inlet temperatures), these results provide some evidence that the temperatures and stresses in the test apparatus should be within acceptable limits during NSTF operation. 


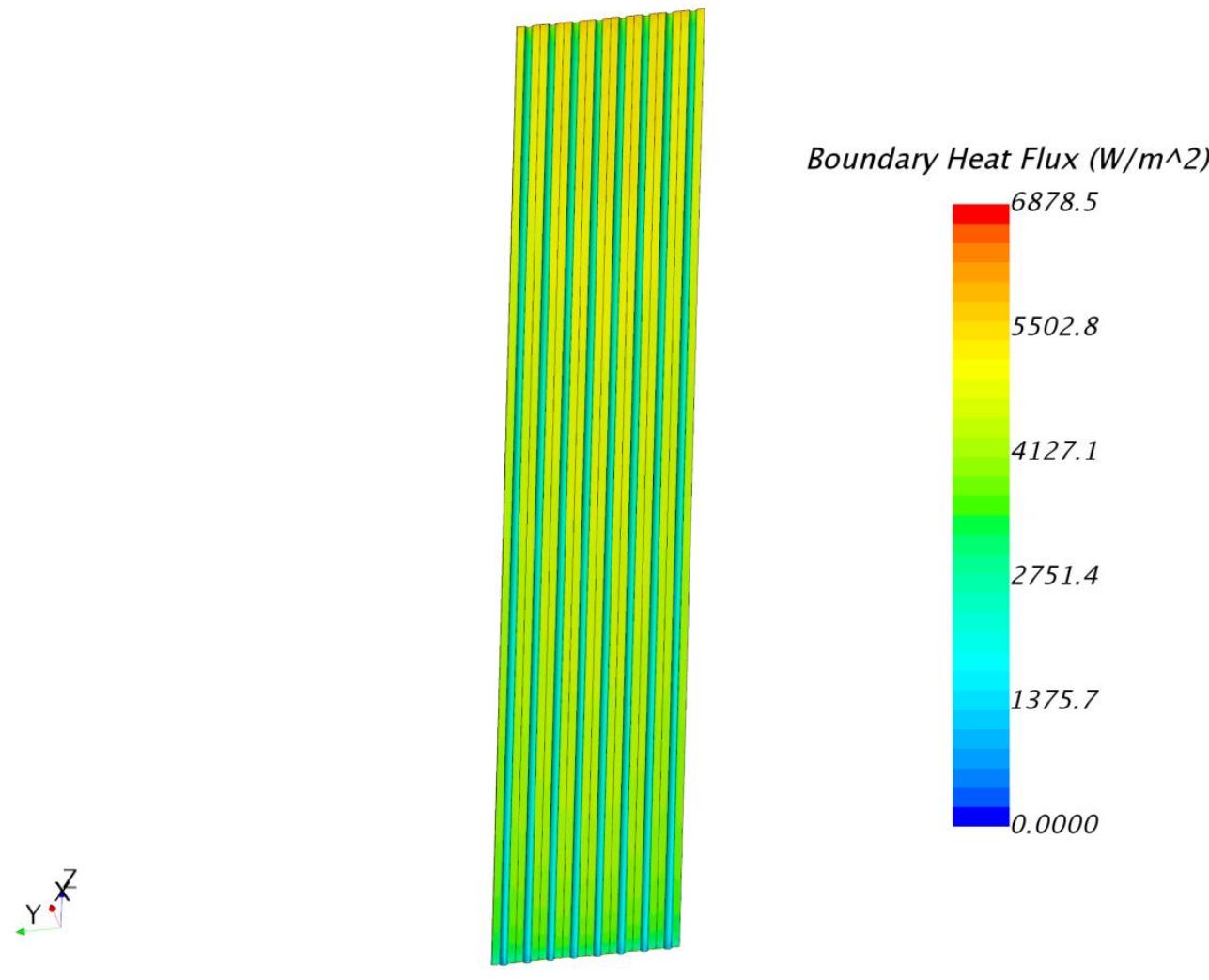

Figure 3-5: Boundary heat flux distribution on the hot side of the tubes

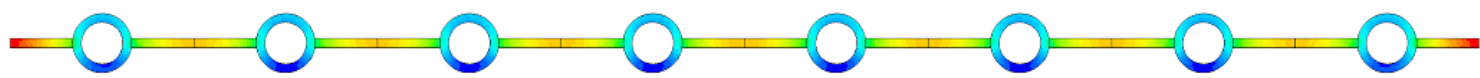

Temperature (C)

\begin{tabular}{llllll}
\multicolumn{7}{c}{ Temperature (C) } \\
48.470 & 57.322 & 66.175 & 75.028 & 83.880 & 92.733 \\
& & & &
\end{tabular}

$\underset{X}{Z} Y$

Figure 3-6: Temperature distribution along the top of the solid structure 


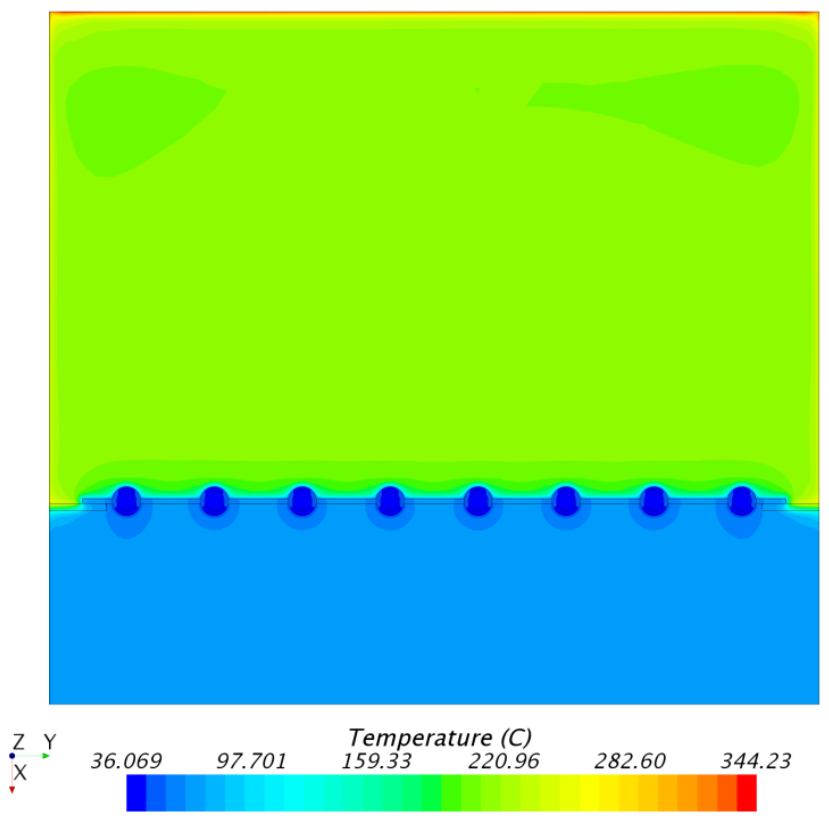

Figure 3-7: Temperature distribution along the axial midplane
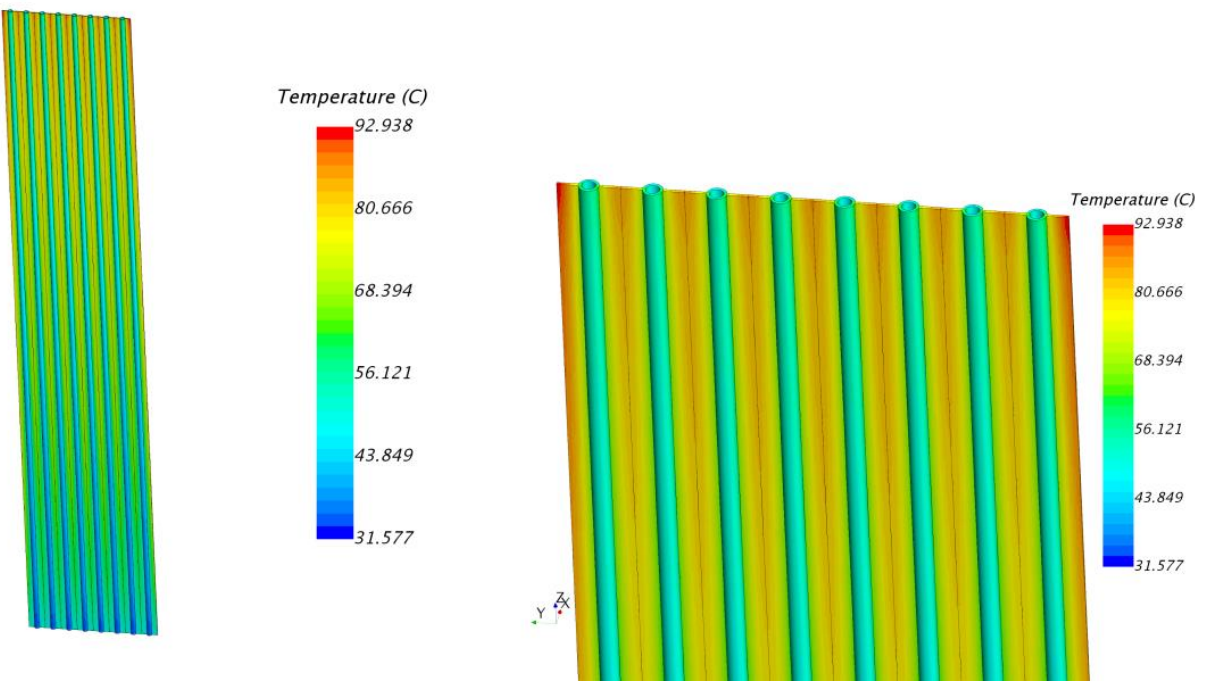

Figure 3-8: Temperature distribution of the tubes and fins (zoomed view $\mathbf{R})$

\subsection{Tank Modeling}

A preliminary investigation into the flow behavior in the water storage tank was undertaken. Using boundary conditions provided by RELAP5, transient CFD simulations were performed for the initial heat-up of the tank. The goal of these studies was to provide some insight into the basic flow phenomena with detailed 3-D analysis. The impacts of any thermal stratification could be assessed, which can be difficult to handle a priori with a 1-D system-level code. The CFD results could then be used to better inform the tank modeling in RELAP5. 
Detailed mesh convergence and turbulence studies were performed. These found nonnegligible differences in the thermal front propagation between the Realizable $\mathrm{k}-\varepsilon$ model and the Elliptic Blending Reynolds-Stress Model (EBRSM). On the basis of physical grounds and literature review, it was decided to prioritize the EBRSM results. The RELAP model nodalization was adjusted and showed good agreement with the CFD for this timeframe.

Investigation into the tank modeling is ongoing. Further simulations of the tank at different times with differing boundary conditions may be warranted to see if this behavior is still matched during those intervals. Preliminary simulations also showed that the mixing behavior may be quite different depending on which of the two inlet junctions is being used between the tank and the piping. These differences should be better quantified through further simulation work.

\subsection{Future Work}

There are a number of future CFD work topics that would be beneficial to the NSTF project. First, now that RELAP results have become mature, the CFD cavity and tank modeling can be extended using the anticipated boundary conditions at different times as predicted by RELAP. Extending the simulations to these conditions would help establish if different flow and thermal phenomena may be expected during the tests. For example, the impact of two-phase vs. singlephase flow on mixing and thermal stratification in the tank could produce different results. Additionally, the influence of skewed heat flux profiles, both axially and azimuthally, are of interested and will be studied with CFD. These results could in turn further inform the RELAP modeling in various areas. Further work should be done to conclude the studies of differing flow behavior for the two tank inlets as well.

One potential topic for future work is that of coupled simulations with RELAP. STAR-CCM+ has a native co-simulation framework for RELAP coupling. This should allow for the potential to treat areas with detailed, three-dimensional flow in CFD, and areas of largely 1-D or two-phase flow in RELAP. This could provide potential benefits in accuracy, while also significantly reducing the simulation time relative to simulating the entire NSTF with CFD.

\section{References}

[3-1] CD-Adapco, "STAR-CCM+ 11.06 Manual," Melville, NY, 2016.

[3-2] D. Lisowski, T. Lee, D. Kilsdonk, N. Bremer, C. Gerardi, S. Lomperski, and M. Farmer, Argonne National Laboratory, unpublished information, 2015.

[3-3] Design Drawing, Argonne National Laboratory, unpublished information, 2016.

[3-4] D. Lisowski, C. Gerardi, D. Kilsdonk, et al., Argonne National Laboratory, unpublished information, September 2016.

[3-5] R. Hu, A. Kraus, M. Bucknor, Q. Lv, and D. Lisowski, "Final Project Report on Computational Modeling and Analysis of Air-Based NSTF," ANL-ART-46, Argonne National Laboratory Report, 2016. 


\section{Acknowledgements}

This work is funded by U.S. Department of Energy Office of Nuclear Energy's Advanced Reactor Technology (ART) program. We gratefully acknowledge use of the Blues cluster in the Laboratory Computing Resource Center and the Eddy cluster in the Nuclear Engineering Division at Argonne National Laboratory. 


\section{Argonne}

Nuclear Engineering Division

Argonne National Laboratory

9700 South Cass Avenue, Bldg. 208

Argonne, IL 60439

www.anl.gov 